Hydrological drought and wildfire in the humid tropics

Muh Taufik 


\section{Thesis committee}

\section{Promotor}

Prof. Dr Remko Uijlenhoet

Professor of Hydrology and Quantitative Water Management

Wageningen University \& Research

\section{Co-promotor}

Dr Henny A.J. van Lanen

Associate professor, Hydrology and Quantitative Water Management Group

Wageningen University \& Research

\section{Other members}

Prof. Dr Meine van Noordwijk, Wageningen University \& Research

Prof. Dr Fulco Ludwig, Wageningen University \& Research

Dr Cathelijne R. Stoof, Wageningen University \& Research

Prof. Dr Guido R. van der Werf, VU Amsterdam

This research was conducted under the auspices of the Graduate School for Socio-

Economic and Natural Sciences of the Environment (SENSE) 


\title{
Hydrological drought and wildfire in the humid tropics
}

\author{
Muh Taufik
}

Thesis

submitted in fulfilment of the requirements for the degree of doctor at Wageningen University

by the authority of the Rector Magnificus,

Prof. Dr A.P.J. Mol,

in the presence of the

Thesis Committee appointed by the Academic Board

to be defended in public

on Tuesday 31 October 2017

at 11 a.m. in the Aula. 
Muh Taufik

Hydrological drought and wildfire in the humid tropics,

102 pages.

PhD thesis, Wageningen University, Wageningen, the Netherlands (2017)

With references, with summary in English

ISBN: 978-94-6343-635-9

DOI: $10.18174 / 419772$ 
I dedicate this thesis to my mom and dad

With love to

my wife, Hermi Putriati

my daughter, Raihana Salsabila Taufik 



\section{Contents}

1 Introduction 1

2 Drought severity in tropical peatland $\quad 13$

3 A modified fire drought index $\quad 21$

4 Fire hazard in human-modified wetlands 39

5 Hydrological drought understanding for wildfire area burnt prediction $\quad 51$

6 Synthesis $\quad 57$

$\begin{array}{ll}\text { Annexes } & 68\end{array}$

Bibliography $\quad 81$

Statement of authorship contribution $\quad 92$

Statement of code and data availability 93

$\begin{array}{ll}\text { Summary } & 94\end{array}$

$\begin{array}{ll}\text { Acknowledgement } & 96\end{array}$

About the author $\quad 98$

List of publications $\quad 99$ 



\section{Chapter 1}

\section{Introduction}

\subsection{Global importance of the humid tropics}

The humid tropics are globally important biodiversity hotspots and carbon pools (C pools). Despite covering less than 7\% of the Earth's land area (Junk et al. 2012), they are host to approximately 18,000 endemic plants (Kier et al. 2005), and to the highest proportion of country-endemic species (Sodhi et al. 2010). The region currently covers around $30 \%$ of the tropical biome (Underwood et al. 2014) and contains an estimated $268 \mathrm{Gt} C$ (Scharlemann et al. 2014). Of this, the peat swamp forests (only covering 0.4 million $\mathrm{km}^{2}$ ) store significant belowground C pools, that is 80-90 Gt C, with 69 Gt C in Southeast Asia forests (Page et al. 2011). In addition, the humid tropics are globally important for the hydrologic cycle through maintaining considerable flows of heat and moisture (Van der Molen et al. 2006). For instance, any large-scale disturbance (e.g. deforestation) in the region will influence precipitation amounts in the tropics and subtropics (Neale and Slingo 2003; Van der Molen et al. 2006). Currently, forests, including peat swamp forests, are deteriorating at an alarming level due to the high deforestation rate. This rate has consistently been the highest in the tropics since the 1990s (Sodhi et al. 2010). A recent estimate revealed that annually 47,600 ha of forests was lost in Indonesia, primarily in lowland forest ecosystems in Kalimantan and Sumatra (Margono et al. 2014). The deforestation potentially alters the belowground $C$ pools and carbon balance of the atmosphere. Hence it influences global climate, declines the ecological benefits of the peat swamp forests, and influences global water transport. In general, humid tropical forests are ecologically and economically crucial for climate and biodiversity, and any change to them will have substantial impacts.

Although rainfall regimes vary across the peat swamp forests in Southeast Asia (Aldrian and Susanto 2003), the forests face common threats of deforestation for crop and fibre export-oriented expansion, drought, forest fires, and a changing climate. These threats lead to forest degradation, which makes them more fire-prone during the dry season. Among the threats, forest fires have the highest socio-economic and ecological cost. Wildfires have attracted society's awareness and generated concern, but also scientific interest in the drought-wildfire generating mechanism over the recent decades. The concern about peat forest fires and related disasters in Indonesia has led international donors to fund over US\$30 million during 1980-2000s (Tacconi et al. 2006), and likely the funding rose in the recent decade. 
The growing public awareness on harmful impacts of fires on biodiversity and society (Forsyth 2014) revealed that there still remains a serious lack of scientific understanding about the fundamental role of drought in fire-generating processes, as well as an insufficient appreciation of the drought-fire relation to anthropogenic global environmental change. Clear identification of this role through understanding the drought-fire mechanism can help suppressing drought-fire impact to society. Most works suggest that climate controls wildfire in the humid tropics (Van der Werf et al. 2008a; Jolly et al. 2015; Williams and Abatzoglou 2016), but recent studies suggest that hydrology is of importance to suppress fire and associated carbon emission (Wösten et al. 2008; Jaenicke et al. 2010). However, the climate-centred approach, which is reflected in the currently used droughtfire related indices (Groot et al. 2006; Petros et al. 2011; Field et al. 2015; Di Giuseppe et al. 2016) overlooks soil and hydrological processes beneath the surface of the humid tropics. There is also uncertainty about the relative roles of climate variability and human activities in influencing the nature and distribution of drought related wildfires.

\subsection{Drought as a natural hazard}

Drought is a recurrent hazard (EEA 2010), which has happened throughout human history (Garnier 2017). Unlike flood hazard, however, drought received less attention from society, both in the news and in the scientific literature. Several factors can be identified why drought did not receive as much attention as many other hydroclimatological hazards (Wilhite et al. 2014), including: (i) drought is a relatively slow-onset natural hazard; (ii) drought is difficult to determine, when the onset and the end of this hazard are; (iii) there is no universally accepted definition; and (iv) the impact of drought is difficult to quantify, specifically when it occurs over a great spatial area (WWAP 2016; Van Lanen et al. 2017). Nevertheless, once drought happens over greater spatial and temporal scales, drought has more noticeable consequences on human life than floods. Drought events, which cover extensive areas and could last for months to years, can cause dramatic changes in society, such as migration (Rowell 1936; Gray and Mueller 2012), hunger (Loewenberg 2014), and even war (Kelley et al. 2015).

Drought occurs in all climate regimes from humid to dry and from hot to cold. It is characterized as a relative phenomenon, that is, drier than normal. Drought is triggered by below-normal rainfall usually associated with high temperature during summer (Diffenbaugh et al. 2015; Galván et al. 2015). In snow-dominated climates, winter drought sometimes happens when snowfall comes earlier or when snow melts later than normal (Van Loon and Van Lanen 2012). Even in cold desert environments, drought is apparent during summer (Schwinning et al. 2005). Drought events are also common in monsoonal climates, which are mostly driven by ocean dynamics (Wang et al. 2013; Alamgir et al. 2015). In the humid and hot tropics, short-term dryness in response to the absence of fortnightly precipitation is often the reason for drought events. In most cases, drought in the humid tropics can be characterized as a classical rainfall deficit drought (Van Loon and Van Lanen 2012), which occurs due to repositioning of the inter-tropical convergence zone-ITCZ (Russell and Johnson 2007; Stager et al. 2011), affecting rainfall variability. Further, atmosphere-ocean teleconnection in the Pacific and Atlantic Oceans (Shanahan et al. 2009; Marengo et al. 2011) concomitantly plays a key role in influencing climate variability in the tropics. In all humid tropical regions, likely atmosphere-ocean teleconnections (e.g. El Niño) plays a key role in increasing the frequency and severity of water-related disasters (Gallery 2014). 
Recent studies show that there is a drying trend across the humid tropics driven by below-normal rainfall, although globally this is not the case (Sheffield et al. 2012). For instance, strong negative rainfall anomalies in response to increased sea surface temperature have caused drying trends in the Amazon (Fu et al. 2013; Gloor et al. 2013). Rainfall analysis using data from the Climate Research Unit (CRU) and the Tropical Rainfall Measuring Mission (TRMM) revealed seasonal and annual climatic water deficits across Central and West Africa (Asefi-Najafabady and Saatchi 2013). Other studies employed the Global Precipitation Climatology Centre (GPCC) dataset and report a similar drying trend over humid Africa (Zhou et al. 2014). In Southeast Asia, there is a tendency that annual and seasonal maximum daily rainfall have been decreasing over the maritime continent (including Indonesia) since 1957 (Villafuerte and Matsumoto 2015). One study has revealed an increase of the drought severity and frequency since the 1960s in northeastern Borneo (Walsh 1996).

Future climate in the Southeast Asia remains uncertain because of internal climate variability (Lintner et al. 2012). Rainfall variability over the maritime continent, including Indonesia is anticipated to remain mainly controlled by the ITCZ and dynamics in sea surface temperature over the Pacific (Hendon 2003). Future projected warmer sea temperatures in the Pacific (Cai et al. 2014) will reduce rainfall leading to lengthening of the dry season over Indonesia. Climate projections over Southeast Asia show consistency in increasing temperatures (Lobell et al. 2008; Diffenbaugh and Charland 2016), but inconsistency in decreasing rainfall between seasons (Lobell et al. 2008) and emission scenarios (Chadwick et al. 2015). However, it has been recorded that maximum daily rainfall already shows a drying trend (Villafuerte and Matsumoto 2015).

The future drought hazard varies among regions and seasons. Droughts are projected to intensify in the $21^{\text {st }}$ century in some regions, for example in Southern Europe (Seneviratne et al. 2012), as result of climate change. Areas in other Mediterranean climate zones, such as California, shows a similar tendency of increased drought due to anthropogenic warming (Diffenbaugh et al. 2015). In the humid tropics, there is medium confidence that some regions (south-eastern Amazon) are anticipated to face amplifying drought hazard in the future (Seneviratne et al. 2012), whereas for other regions future drought remains uncertain. The outlined emission scenarios are one of the reasons for the differences in future drought hazard. Other studies revealed that climate and catchment characteristics also play a significant role when assessing future drought hazards (Wanders and Van Lanen 2015), in particular for hydrological drought (that is, drought in groundwater and streamflow). Globally, a likely increase in the severity of hydrological drought is projected for multiple regions by either a simple approach (Wanders and Van Lanen 2015) or a more comprehensive, multi-model approach (Prudhomme et al. 2014). Wanders \& Van Lanen (2015) used a synthetic global hydrological model (GHM) to quantify the impact of a changing climate on drought characteristics across the globe. They found that hydrological drought frequency is expected to decrease on a global scale because of pooling of events, hence their severity and duration are expected to intensify. Drought occurrence over the $21^{\text {st }}$ century is projected to increase almost everywhere, except in northern Canada, North East Russia, the Horn of Africa and parts of Southeast Asia (Prudhomme et al. 2014). Likely, future drought over southeast Asia is linked to rising temperatures (Dai 2013; Diffenbaugh and Charland 2016) and projected El Niño Southern Oscillation-ENSO (Cai et al. 2014). This thesis discusses hydrological drought in the humid tropics with focusing on Southeast Asia region (red circle, in Figure 1.1). 


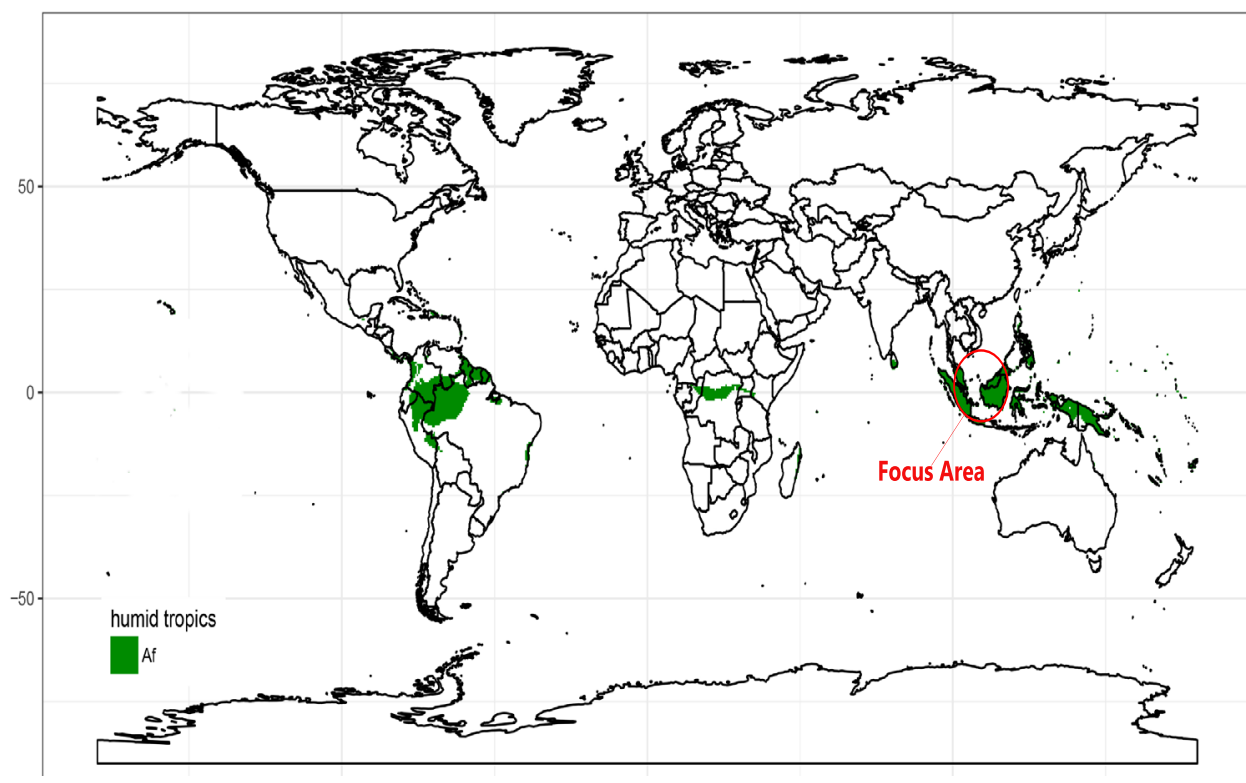

Figure 1.1. Distribution of the humid tropics in the world based on Köppen-Geiger climate classification (Kottek et al. 2006). Region is defined as humid tropics if the minimum precipitation is above $60 \mathrm{~mm} /$ month (climate type Af).

\subsection{Impacts}

\subsubsection{Drought related impacts}

Drought is often viewed through its impact on environment and society (Wilhite et al. 2007; Stahl et al. 2016). The nature of impacts differs remarkably from region to region. During drought, many economic sectors are affected (Tallaksen and Van Lanen 2004). In Europe, drought impacts are manifold, e.g. effects on crop yield, water-borne transport, aquatic ecosystems, water supply, energy production (Van Lanen et al. 2016). In snowdominated climates, winter drought influences society through limitations on inland water navigation (Pfister et al. 2006), energy production (Van Lanen et al. 2016), sometimes on rural displacement (Sternberg 2010), and on reduced inflow in reservoirs. In Syria, intense drought has increased the human conflict (Kelley et al. 2015). Drought markedly influences society through relocating wet and dry-environmental regions (Stager et al. 2011) driving forced human migration (Gray and Mueller 2012) in Africa. Drought also threatens food security by a lowered agricultural production worldwide (Qin et al. 2014; Nath et al. 2017; Páscoa et al. 2017). For instance, in the monsoonal climate of India, drought affected 300 million people in 2002 (Gupta et al. 2011).

In the tropics, drought impacts occur everywhere. Drought in tropical Africa had immense impacts on human welfare (Gray and Mueller 2012). In recent years, drought-related ecology received attention as well, as revealed by Zhou et al. (2014), who found a decline in the greenness of humid tropical forests in Africa, despite potential adaptability of tropical forests to severe short-term drought (Asefi-Najafabady and Saatchi 2013). In the Amazon, drought has been more related to ecology than to the human dimension, as reported for Africa. Drought leading to vegetation drying weakens the tropical forest carbon sink (Phillips et al. 2009; Lewis et al. 2011; Corlett 2016). The intense and longer dry season in 2010, leading to very low river water levels in the Amazon (Marengo et al. 
2011), substantially declined the carbon sink through extensive tree mortality (Lewis et al. 2011). In the humid Southeast Asia, drought had immense impacts on socio-economic activities and environment, in particular when the event coincided with strong El Niño events, such as in 1997/1998 and 2009 (Glover and Jessup 1999; Varma 2003; Marlier et al. 2013). In Indonesia, drought associated with El Niño has been linked to low rice production (Naylor et al. 2001; Surmaini et al. 2015).

Public awareness on drought has risen due to its impacts on society and environment. Economic activities that are impacted and the societal vulnerability to periods of water shortage (Sivakumar et al. 2014) determine how the public responds to drought events. There is growing recognition that a greater understanding of the role of drought in society is needed, and can be gained through the study of the human influence on frequency and impact of past drought events (Van Loon et al. 2016). Nowadays, an increased awareness to publicize drought related disasters is institutionally recognized, for instance, through the European Drought Centre ${ }^{1}$, the US Drought Monitor ${ }^{2}$, and the Global Drought Monitor ${ }^{3}$. In 2013, World Meteorological Organization (WMO) together with the Food and Agriculture Organization (FAO) and the United Nations Convention to Combat Desertification (UNCCD) held the High-level Meeting on National Drought Policy in Geneva to provide practical guidance and science-based actions to address key drought issues and various strategies to cope with drought (Sivakumar et al. 2014). These are now being implemented in the WMO regions, e.g. in Central and Eastern Europe (http://www.droughtmanagement.info/idmp-activities/idmp_cee/).

\subsubsection{Drought-related wildfire impacts}

Direct and indirect impacts of drought are difficult to separate (Tallaksen and Van Lanen 2004). Although drought does not directly cause wildfire, it provides favourable conditions for wildfire ignition and spread. When drought coincided with El Niño in the humid tropics, e.g. Southeast Asia, the impacts escalated through forest fires causing disturbance of the global carbon cycle, incl. reduction of the carbon stock (Page et al. 2002; Hooijer et al. 2010; Huijnen et al. 2016; Page and Hooijer 2016) and intensifying haze hazard (Lee et al. 2016). In addition, the amplified air pollution (Novelli et al. 2003; Reddington et al. 2014) caused an increased health risk (Marlier et al. 2013; Crippa et al. 2016). Health impact was reported far away from the location where fire occurred. Drought coinciding with strong El Niño in 1997/1998 and 2015 have caused mega-wildfires and led to severe socio-economic impacts in Southeast Asia (Glover and Jessup 1999; Varma 2003; World Bank 2016), including disrupting airport and flight operations. The 1997/98 ENSO-driven forest fires resulted in economic costs of approximately US\$8.8.billion (Glover and Jessup 1999). The 2015 fire event caused almost 70 million people to be exposed to unhealthy air in the autumn season alone (Crippa et al. 2016). Fires meant for land clearance for oil palm plantations over extensive areas have proven to change biodiversity by reducing the number of species (Yule 2008; Koh et al. 2011).

\subsection{Drought-fire mechanism}

Interactions between atmosphere and biosphere play a key role in the generation of forest fire in a region. Atmospheric drivers of fire, such as climate/weather variables are relatively well known, that is, significantly regulating fuel drying. Climate/weather is one of the collective drivers of fire, together with ignition and vegetation characteristics,

\footnotetext{
${ }^{1}$ http://europeandroughtcentre.com/

2 http://droughtmonitor.unl.edu/

${ }^{3}$ https://gis.ncdc.noaa.gov/maps/ncei/drought/global
} 
the 'fire-triangle' (Moritz et al. 2005; Falk et al. 2007; Harris et al. 2016). Daily weather conditions determine fire spread and intensity (Di Giuseppe et al. 2016). Low precipitation, low humidity, high temperature and strong wind favour generation of a fire event, but it will differ across vegetation types. Forest fire may naturally occur with lightning as source of ignition, specifically in the sub-tropics (Stephens et al. 2014), yet this lightning is rarely reported as ignition factor in tropical forests (Cattau et al. 2016).

The fire-triangle differs across temporal and spatial scales. At short-time scales (seconds to a day) and local scale (from leaf to site scale), heat, oxygen and fuel availability together determine fire. At local scale, the fire event develops depending on how much fuel is available, and on dryness of the weather. Topography sometimes becomes a physical barrier (Harris et al. 2016) for fire spread (such as water, gullies, fire corridors, and surface roughness). At the landscape scale, climate and vegetation types determine fire regimes. Forest and savannah have different atmospheric and vegetation feedbacks, which determine flammability (Bowman et al. 2015). Climate has been observed as fire driver at regional scale, both in tropics (Page et al. 2002; Van der Werf et al. 2008b), and subtropics (Meyn et al. 2007; Van der Werf et al. 2008a; Stephens et al. 2014). Atmospheric and oceanic teleconnections, such as El Niño Southern Oscillation (ENSO), play a key role beyond the regional scale through regulating the climate (Hendon 2003) and may drive long lasting dry periods in the tropics.

In the tropics, canopy layers cause moisture levels to be high in soils and between forest trees. Studies of tropical ecosystems showed that these are relatively fire-free, although biomass-fuel is highly available (Krawchuk et al. 2009). When a short-term dry spell occurs in this ecosystem, the drying process starts. This meteorological drought (Figure 1.2) triggers a soil water deficit, hence, increasing plant water stress, and then causing desiccation of forest canopy at local scale. When a combination of low precipitation and high temperature lasts longer, the drought propagates into the subsurface (that is, soil moisture drought, Figure 1.2), which usually happens at a larger scale, both spatially and temporally. The drying process is then amplified causing extensive tree mortality in tropical forests (Lewis et al. 2011; Bonal et al. 2016). The drought-induced tropical tree mortality is more severe when drought coincides with a warm ENSO event, like in 1997/1998. In humid tropical forests, climate is claimed as the superordinate control on large infrequent wildfires (Meyn et al. 2007), as climate governs the distribution and quantity of flammable vegetation to burn. However, this claim seems to overlook hydrological processes beneath the surface influencing soil moisture. Recent studies also indicate that the position of the groundwater table will affect the fire hazard in the humid tropics (Wösten et al. 2008; Turetsky et al. 2015).

\subsection{Drought and fire-drought indices}

Different approaches in classifying drought addressing different purposes (e.g. different impacts) led to various drought indices. Generally three groups of drought indices can be distinguished following the three types (Figure 1.2): meteorological drought, soil moisture drought, and hydrological drought. More than 100 drought indices have been developed to study drought and its impacts on society (Niemeyer 2008; Zargar et al. 2011). For operational use, only a limited number has been applied worldwide, for instance the Standardize Precipitation Index-SPI (McKee et al. 1993), the Palmer Drought Severity Index-PDSI (Alley 1984), and the Standardized Precipitation and Evapotranspiration IndexSPEI (Vicente-Serrano et al. 2010). Drought indices are used as a numerical standard for assessing a measure of drought for intercomparison among different regions and climate regimes. Both observed and modelled data are used to derive drought indices. The World 
Meteorological Organization (WMO) has compiled a dynamic online list with indices used to describe drought conditions (World Meteorological Organization and Global Water Partnership 2016) that cover precipitation, streamflow, groundwater and reservoir levels, soil moisture and snowpack.

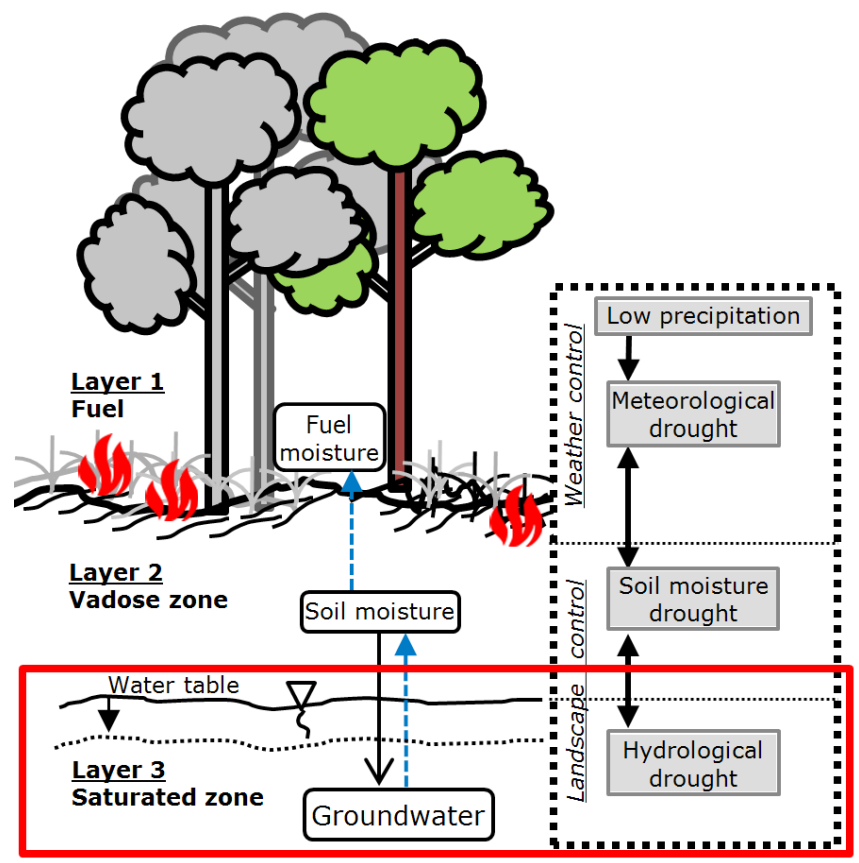

Figure 1.2. Drought-fire mechanism is driven by climate-vegetation feedbacks within a forest. Current knowledge assumes that meteorological drought and soil moisture drought determine drying forest (that is, fuel layer, layer 1, which contributes to fuel availability. Hydrological drought, i.e. drought in groundwater (layer 3), has not explicitly been considered as fire driver (in red box), so far. The classical drought types, which are also relevant for the fire hazard, can be described as follows. The meteorological drought is defined here as a rainfall deficiency that occurs over an extensive region for a longer period of time. It is assumed that low temperatures do not play a role in drought development in the humid tropics (Van Loon and Van Lanen 2012), except for some mountainous areas. Soil moisture drought is related to inadequate supply of soil water to plants because of below-normal rainfall. This drought type is an intermediate between meteorological drought and hydrological drought, which is controlled by weather conditions, plant physiology, and soil properties. Soil moisture drought may intensify fire hazard by providing additional fuel from canopy desiccation. Hydrological drought refers to below-normal conditions of water in surface or subsurface water bodies (Tallaksen and Van Lanen 2004; Mishra and Singh 2010). Lower levels of groundwater than normal reflect a particular hydrological drought. Hardly any research has been done to explicitly identify the link between hydrological drought and fire hazard.

To study meteorological drought, people use by definition precipitation (rainfall and snow) either observed or modelled, to characterize drought in a region. To deal with the high temporal variation in precipitation in a region (usually many zeros in daily records) and in the spread among regions, monthly values or moving-averaged values are often used when calculating precipitation-based indices to allow intercomparison (Wanders et al. 2010). In addition to the SPI, the cumulative precipitation anomaly, and number of consecutive dry days has been used (Deni and Jemain 2009; Van Huijgevoort et al. 2012). In addition to precipitation, some meteorological indices include evapotranspiration, 
such as the SPEI (Vicente-Serrano et al. 2010). SPEI considers cumulated anomalies of precipitation and potential evapo-transpiration. WMO has suggested that, to study drought in a region, at least the SPI should be used, as precipitation data are mostly available worldwide (World Meteorological Organization and Global Water Partnership 2016), although they state that no single indicator fits all purposes and climate regions.

Soil moisture drought indices focus on anomalies in soil moisture. As not many observed soil moisture data are available, most studies used water balance models to derive soil moisture indices. The Palmer Drought Severity Index is one of the most well-known indices to characterise drought globally (Sheffield et al. 2012; Trenberth et al. 2013). Other indices are the soil moisture deficit index (Narasimhan and Srinivasan 2005), crop moisture index (Palmer 1968), and the soil moisture anomaly (Orlowsky and Seneviratne 2013).

Hydrological drought indices cover the saturated zone (groundwater) and streamflow, and are observed or modelled. These indices have already been proposed, similar to the others, a long time ago, for example the Palmer Hydrological Drought Index (Palmer 1965). However, hydrological drought did not receive attention until in recent decades (Tallaksen and Van Lanen 2004; Tallaksen et al. 2009; Van Loon et al. 2016). Other hydrological drought indices can be identified, such as the groundwater resources index and surface water supply index (Shafer and Dezman 1982).

Most of the above-mentioned indices are determined by applying so-called standardised approaches. Drought can also be derived directly from time series of observed or simulated hydrometeorological variables by using the threshold approach (Yevjevich 1967; Tallaksen and Van Lanen 2004). When the variable is below a predefined level, drought occurs and its characteristics are calculated (duration, severity, deficit volume, and frequency). This approach is called 'threshold level method'. The big advantage of the threshold approach is the deficit volume that can be derived, whereas this is impossible when using the standardised approach. Two different procedures to apply the threshold approach can be identified, namely the fixed and variable threshold (Van Loon and Van Lanen 2012; Heudorfer and Stahl 2016). A fixed threshold means the use of a static value for the whole period of drought assessment, whereas the variable threshold reflects a seasonal pattern in the data.

Several criteria have been introduced to select indices for intercomparison, including simplicity, easiness to calculate, and a physical meaning. Wanders et al. (2010) added additional criteria, i.e. the indices should be climate-independent and have high temporal resolution. Actually, drought impact should also be considered to select drought indices (Stahl et al. 2016). Application of various drought indices to a specific region frequently results in different drought properties. Differences in concept and calculation method are the reason for the dissimilar properties. The SPI is an interesting drought index because of its simplicity, and it is widely used, however the SPI is less suited for calculating water deficits. Further, Wanders et al. (2010) suggested that the variable threshold approach may fit for intercomparion of drought indices globally.

The above-mentioned, more conventional drought indices are not specifically meant for drought and associated forest fires. A lot of effort has been put into connecting forest fire regimes (area burnt, occurrence, frequency) with more targeted drought indices. Most works use statistical approaches to link drought indices and fire regime, in particular for monitoring, prediction and forecasting purposes. The most widely used are the KeetchByram Drought Index-KBDI (Petros et al. 2011) and the Fire Weather system Index-FWI 
(Amiro et al. 2005). The KBDI involves a rather simple calculation with input of two weather variables (rainfall and temperature). The calculation aims to estimate moisture deficiency in the upper soil and litter layer within a forest. The KBDI was initially developed for forest fire control in the south-eastern US, and is now widely used, including in the Mediterranean (Petros et al. 2011) and in Australia (Caccamo et al. 2012). The FWI was initially developed for fire prediction in Canada. The FWI calculation is rather complex, that is, prediction of the six components of the FWI (namely, the fine fuel moisture code, duff moisture code, drought code, initial spread index, build-up index, and fire weather index). The six components of the FWI consider, among others, fuel moisture and wind on fire behaviour. Although highly demanding in terms of weather variables (rainfall, temperature, relative humidity and wind) and rather complex in calculation, the FWI is used worldwide (e.g. Di Giuseppe et al. 2016), including in the humid tropics of Southeast Asia (Groot et al. 2006). Nowadays, high resolution global climate data are used to calculate the FWI (Field et al. 2015) and maps are disseminated online (https://data.giss. nasa.gov/impacts/gfwed/).

Concerns about both the KBDI (e.g. Snyder et al. 2006) and the FWI (e.g. Waddington et al. 2012; Yang et al. 2015) have been risen, in particular when the indices are applied to different climate and soil-hydrological regimes than for which the indices were developed. The concerns are obvious when the indices are used for predicting area burnt. For instance, the application of the FWI in the Mediterranean (Dimitrakopoulos et al. 2011; Amatulli et al. 2013; Urbieta et al. 2015), in Canada (Flannigan et al. 2005), and in America (Urbieta et al. 2015), and in Hawaii (Dolling et al. 2005) for the KBDI. The performance appeared to increase when the indices are used at a coarser temporal resolution, such as the seasonal scale (Bedia et al. 2015) or annual scale (Williams et al. 2015). Studies that used 'conventional' drought indices as alternative for the KBDI and the FWI, such as SPI (Riley et al. 2013; Alencar et al. 2015) and PDSI (Riley et al. 2013) obtained similar performance in predicting area burnt. Therefore, it remains challenging how to integrate subsurface processes, that is, soil and hydrology, into the existing drought indices for better prediction of the fire regime, specifically in the humid tropics.

\subsection{Human influence on drought, specifically in the humid tropics}

In the Anthropocene, human activities play a significant role in controlling the water cycle. Global warming in the Southeast Asia region is expected as a result of the projected temperature rise (Lobell et al. 2008; Diffenbaugh and Charland 2016). The higher temperature may increase severity of the future drought hazard in the region (Section 1.2). Deforestation also occurred during the last three decades, which has influenced the hydrological cycle across the humid tropics (Asefi-Najafabady and Saatchi 2013; Gloor et al. 2013; Villafuerte and Matsumoto 2015; Khanna et al. 2017), see also Section 1.1. Deforestation leads to changes in the surface energy and water balance through an increased surface albedo, reduced surface roughness and turbulent transport, reduced water transpiration to the atmosphere, increased sensible heat flux, and reduced latent heat flux (Bonan 2008). In Southeast Asia, the deforestation rate has consistently been the highest in the tropics since the 1990s (Sodhi et al. 2010). The influence of deforestation on drought, in particular hydrological drought, remains uncertain, although some studies indicate a decline in precipitation (Lee et al. 2011; Lawrence and Vandecar 2014).

Other human activities, such as overexploitation of groundwater (Zeng et al. 2017) have affected groundwater drought. In Jakarta, a decreasing trend in groundwater levels is reported in most groundwater monitoring wells due to water over-abstraction (Delinom et al. 2009). In the wetlands of Southeast Asia, lowering of groundwater levels is linked to 
canal drainage (Wösten et al. 2008; Hooijer et al. 2010; Ishii et al. 2016). Canals are built to get access to wetland forest to transfer the forest into plantations (Wösten et al. 2006; Hooijer et al. 2010; Jaenicke et al. 2010; Page and Hooijer 2016). Studies showed that canalization results in very low groundwater tables in the peatland. Yet, quantification of extensive canal drainage on drought development remains a research challenge.

Drought research that defines three drought types (see Figure 1.2) has focused for a long time on so-called climate-induced drought, that is, due to climate variability. Due to human development, overexploitation of natural resources, as mentioned above, has caused a remarkable change in water availability leading to water deficits, and associated drought. Therefore, the established approach to define drought as a response to climate variability needed to be revisited to accommodate human processes driving and modifying the hydrological cycle (Van Loon et al. 2016). The modified drought concept can be classified into three categories (Van Loon et al. 2016): (i) climate-induced drought, (ii) human-induced drought, and (iii) human-modified drought. As described-above, in our study area (Figure 1.1), there are several drivers of human activities that change drought characteristics, namely canalization, and land-use change, that lead to humanmodified drought and even human-induced drought. The impact of these drivers on (hydrological) drought is not yet well understood.

\subsection{Research objective and questions}

The general objective of this $\mathrm{PhD}$ research is to examine how characterization of hydrological drought under natural and human-modified conditions can improve understanding of wildfires in the humid tropics. More specifically, I address the following questions:

- To what extent does hydrology add to a better prediction of the fire hazard in the humid tropics?

- How do the existing drought-related indices perform in predicting fire hazard, and can these indices be made more reliable by including hydrology?

- What are the characteristics of hydrological drought in the humid tropics, that is, for climate-induced, human-modified and possibly human-induced drought conditions?

- How can water management mitigate hydrological drought and associated fire hazard?

The research questions are elaborated in the following four chapters (Chapter 2 to 5 ) and subsequently discussed and synthesized in Chapter 6. Since Chapters 2 to 5 have been published in, or have been submitted to, peer reviewed journals, they are stand-alone papers that can be read independently. Consequently, some repetition may occur in the introduction and methods sections of these chapters.

Chapter 2 starts with addressing hydrological drought characteristics under natural forest in the humid tropics. Next, the chapter discusses human influences on drought development through canalization and land use change. Changes of drought characteristics that may occur under climate change scenarios are explored as well.

Chapters 3 and 4 address development of an improved drought index for assessing fire hazard in the humid tropics. First, Chapter 3 elaborates modification of a widely-used drought index by including hydrological variables at the local scale. Then, Chapter 4 tests the modified drought index (Chapter 3) by assessing historical fire hazard in the humid tropics. Water management options to reduce the fire hazard are also addressed in Chapter 4. 
Chapter 5 considers the use of global climate data to study the spatial distribution of hydrological drought characteristics in the humid tropics. The chapter also investigates the use of hydrological drought characteristics as complementary predictors for the assessment of fire area burnt at the regional scale.

Finally, Chapter 6 presents a synthesis of the research findings outlining the improved knowledge on hydrological drought under natural and human-modified conditions for the assessment of wildfires in the humid tropics. 


\section{Chapter 2 \\ Drought severity in tropical wetland}

Peatland in Southeast Asia is deteriorating at an alarming rate. Drought is the important reason for the declining peatland. Because humans have affected tropical peatland, it is unclear whether the region's forest ecosystem is more impacted by natural climate variability (climate-induced drought) or by human interference (human-modified drought). Using a comprehensive hydrological model, we quantify the severity of these droughts under different land-use and water management options for peatland regions in Southeast Asia. Analyzing simulated historical groundwater levels from the region, we found that human interference has amplified drought severity. The drought severity due to human interference was at least three times higher than for the native (i.e. unchanged) forest. We report that canal drainage has a greater impact on drought severity than projected climate change. Our findings suggest that even if the Paris Agreement target is met, drought risk of peatlands remains high unless sustainable water management practices become a high priority in the region.

This chapter is based on: Taufik, M., J. Van Dam, B.I. Setiawan, H. Wösten, P.D. Jones, and H.A.J. Van Lanen. 2017. Human contribution to increased drought severity in Southeast Asian peatland. Science of the Total Environment, in review. 


\subsection{Introduction}

Over the past decades, the Southeast Asian region has suffered from a series of large drought-related wildfires, such as those that occurred in 1982/83, 1997/98, 2009, and most recently the 2015 drought. The droughts have had immense adverse ecological and societal consequences, including smoke/haze pollution, which led to economic losses reaching billions of dollars (Varma 2003; World Bank 2016). Natural processes driven by climate variability determine drought severity (climate-induced), but humans can amplify droughts (human-modified drought), for example, through water abstraction or dams (Van Loon et al. 2016), or extensive land drainage (Van Lanen et al. 2004). By 2010, a total of 2.3 million ha (roughly equivalent to two-thirds of the Netherlands) of peat swamps have been clear felled, with half of these from lowland forest ecosystems in Kalimantan and Sumatra (Koh et al. 2011). It is crucial to examine whether the severity of droughts has increased or not over recent decades.

The Southeast Asian region has globally important biodiversity hotspots and carbon pools. Despite covering less than $1 \%$ of the Earth's land area, the region hosts approximately 10,000 endemic plants (Kier et al. 2005) and the highest proportion of country-endemic species (Sodhi et al. 2010). Studies revealed that the carbon store in Southeast Asia's peatland is the highest in the tropics (Page et al. 2011). However, the forests are deteriorating at alarming rates due to land-use change, mostly to produce fibre and export-oriented products. Land-use change usually happens together with canalization, which has been a major human interference (Hooijer et al. 2010; Konecny et al. 2016) in the peatland that has likely affected drought and the associated impacts.

Although human influences on droughts are clearly important, with numerous impacts in tropical peatland, understanding the mechanisms is challenging. For instance, have climate-induced droughts been amplified in this region by humans (human-modified drought) over the last decades or has this even initiated droughts (human-induced drought) (Van Loon et al. 2016), and to what extent will climate change drive further changes in these droughts? Analyzing observed data from several sites in Indonesia using a comprehensive hydrological model and scenario analysis allowed us to make predictions about drought characteristics (such as severity) for natural and humaninduced conditions, and to make recommendations on how to manage peatlands to reduce human-modified drought.

\subsection{Materials and methods}

Droughts can be characterized in different ways, using different approaches and indices. Here we focus on drought in groundwater, i.e. deviation of groundwater levels (GWLs) from normal at the plot and landscape scales in the most fragile and vulnerable peatland ecosystems in Southeast Asia. Four peatland regions were identified, including the Kampar Peninsula and the Air Hitam in Sumatra, and the Upper Sebangau and Upper Kapuas in Kalimantan (Annex A: Figure A.1). Historical records of GWLs in remote tropical peatland are sparse, and hence, we used the Soil Water Atmosphere Plant (SWAP) model after calibration to simulate groundwater levels over the last 3 decades (1980-2015). Such a long time series is required to adequately analyse drought (World Meteorological Organization 2012).

The hydrological model SWAP is a one-dimensional, vertically directed model to simulate, among other variables, transport of water in the vadose zone in interaction with vegetation development, subsurface hydrology and surface water levels (Kroes et 
al. 2008; Van Dam et al. 2008). SWAP can be run at different levels of complexity, making it fit to understanding of system dynamics in more data-poor environments. The SWAP model was forced with observed rainfall and potential evapotranspiration (ETP) as the top boundary condition. As a lower boundary condition, a drainage condition was identified that can accommodate variable surface water levels (e.g. controlled canal levels). For a detailed explanation about the SWAP model, readers may refer to Kroes et al. (2008). Below, we briefly describe the major features and data input.

\subsubsection{Climate and hydrology data}

Long time series of climate data from peatland regions are scarce. However, we managed to collate daily meteorological data from a nearby station for each of the four selected peatland regions. Each station needed to have a complete set of meteorological variables to be used for a potential evapotranspiration calculation based on Penman-Monteith (Allen et al. 1998), and be relatively close to the GWL monitoring site in the remote peatlands. We identified four climate stations (source: http://dataonline.bmkg.go.id/ home), two in Sumatra (i.e. WMO ID stations 96109 in Pekanbaru, and 96195 in Jambi), and two in Kalimantan (i.e. WMO ID station 96655 in Palangkaraya, and 96565 in Putussibau).

We used 12 datasets of observed GWL in this study, especially for calibration of the SWAP model. Most datasets were collated from the literature and have different observation lengths (Annex A: Table A.1), which were combined with our observed GWLs for the Bika catchment, Upper Kapuas. From the 12 selected GWL sites, we identified five existing land-use (LU) types, namely intact forest (IF, 2 sites), restored forest (RF, 2 sites), drained forest (DF, 2 sites), logged forest (LF, 3 sites), and drained acacia (DA, 3 sites). Soilhydrological characteristics for peatlands were collated from an unpublished consultancy report (Annex A: Figure A.2a). From the observed soil-hydrological characteristics, we developed generic characteristics of water retention relevant for all selected peatlands (Annex A: Figure A.2b).

At each site, we calibrated parameters of the SWAP model to minimize the deviation between simulated and observed GWLs. For human-modified land-use types, the calibration was performed for the situation of a controlled canal, where canal blocking exists as part of water management. Canal blocking is a common practice to rewet peatland. In forest estate, canal blocking is also used to regulate water levels to support operational activities (such as navigation). Two key input datasets had to be identified, namely canal water levels (CWLs) and drainage resistance (DR). DR reflects the subsurface resistance that controls how easy groundwater can flow to surface water (e.g. natural streams or canals in peatlands). We used local expert knowledge to make a first assessment of the CWL regime for each LU type. Hardly any information on the drainage resistance is available for different LU types in tropical peatlands. We used a trial and error approach to fine-tune the CWL regime and the DR. We assessed the model performance by visual inspection and by five-quantitative goodness of fit (GOF) criteria, including percent bias (pbias), index of agreement (Id), coefficient of correlation ( $r$ ), coefficient of determination $\left(r^{2}\right)$, and Kling Gupta Efficiency $(k g e)$. For detailed information about these five GOF criteria, readers are referred to Moriasi et al. (2007) and Bennett et al. (2013). In general, the SWAP model performed well in simulating GWLs across sites (Annex A: Figure A.3), as indicated by low pbias, high $r$, and high Id (Annex A: Table A.1). Next, for each LU type we selected the parameters from the site having the highest kge (Annex A: Table A.1). Table 2.1 presents the two key input datasets for the five LU types, which resulted from the calibration process. 
Table 2.1. Surface water level regime (CWL) and drainage resistance (DR) for the five selected land-used types. In human-modified land-uses, the calibration was performed under controlled canal levels, where canal blocking exists as part of water management.

\begin{tabular}{|l|c|c|c|c|c|}
\hline Parameters & $\begin{array}{c}\text { Intact forest } \\
\text { (IF) }\end{array}$ & $\begin{array}{c}\text { Restored } \\
\text { forest (RF) }\end{array}$ & $\begin{array}{c}\text { Drained } \\
\text { forest (DF) }\end{array}$ & $\begin{array}{c}\text { Logged } \\
\text { forest (LF) }\end{array}$ & $\begin{array}{c}\text { Drained } \\
\text { acacia (DA) }\end{array}$ \\
\hline Canal water levels (CWL, in cm below soil surface) \\
\hline Wet season & -50 & -50 & -50 & -50 & -70 \\
\hline Intermediate season & -60 & -80 & -80 & -100 & -100 \\
\hline Dry season & -100 & -110 & -120 & -120 & -130 \\
\hline Drainage resistance (DR, in days) & 500 & 400 & 300 & 200 & 200 \\
\hline
\end{tabular}

\subsubsection{Scenario analysis}

We used the SWAP model to focus principally on reporting the impacts of human interference, namely land-use change (LUC) and canalization, on drought severity. Although canalization often is part of land-use change, we have simulated it separately, because the effect of extensive canal drainage extends into the pristine forest. We simulated GWLs for the five LU types (Table 2.1) in each peatland region (Annex A: Figure A.1) with daily climate data back to 1980 from a nearby weather station. Land use of Intact Forest (IF) represents pristine conditions in which drought is driven by only climate (climate-induced drought), whereas other LU types are representative of a certain level of human interference (human-modified drought). The SWAP parameters were assumed to be the same as those resulting from calibration. We combined these with the CWL and DR regimes listed in Table 2.1 for each of the respective LU types. In the scenario analysis, we assumed that for a certain LU type the land use did not change over time (1980-2015), which enabled us to explore the effect of climate variability. The effect of land-use change was assessed through the intercomparison of the different LU types.

\subsubsection{Drought identification}

In each peat region, drought events were derived from the time series of simulated daily GWLs using the monthly variable threshold level approach, where the threshold is taken to be the $80^{\text {th }}$ percentile of the cumulative GWL duration curve (Van Loon and Van Lanen 2012). Drought occurs when the groundwater level is continuously below this threshold value for at least two months in a row. We applied different thresholds for each region, corresponding to the $80^{\text {th }}$ percentiles, to accommodate precipitation differences across the regions. Drought severity is defined as the mean annual deviation of GWL, which is the cumulative daily deviation in groundwater levels from the threshold during drought events divided by number of years (36 years).

We selected GWLs from intact forest (IF) in each region as a baseline to identify change in drought severity with other LU types. For each respective land-use type, we compared the results against the baseline (i.e. IF) to determine the drought amplification as a consequence of human interference. For each water management option, we quantified the $\%$ of change in amplification. Furthermore, we simulated the sensitivity of a drained acacia ecosystem to drought under a changing climate. We used projected precipitation changes in the range of $-10 \%$ to $+5 \%$ for Southeast Asia (Lobell et al. 2008; Chadwick et al. 2015). We combined projected precipitation with increased warming within $2^{\circ} \mathrm{C}$ above the pre-industrial levels. 


\subsection{Results}

\subsubsection{Climate-induced drought}

We uncovered an existing, yet overlooked drought, that is, in groundwater. Groundwater drought has long been - and continues to be - an important feature of the tropical peatland. We combined observations and simulation modelling to examine drought severity under baseline conditions (climate-induced drought) in the four selected peatland regions of Southeast Asia, including Kampar, Air Hitam, Upper Kapuas, and Upper Sebangau. Our simulation showed that droughts under pristine conditions (i.e. intact forest) occurred infrequently in all regions throughout 1980-2015. Events were hardly detected in the southern regions, with only four events in 36 years, whereas twice as many events were found for the northern regions (Table 2.2). Although few in numbers and relatively low in annual deviation, droughts in the southern region typically lasted longer than 5 months.

Table 2.2. Drought in groundwater levels in four peatland regions, Southeast Asia. The simulation is for natural conditions, 1980-2015.

\begin{tabular}{|l|c|c|c|c|}
\hline \multirow{2}{*}{ Location } & \multirow{2}{*}{ Region } & \multicolumn{3}{|c|}{ Drought characteristics } \\
\cline { 3 - 5 } & & $\begin{array}{c}\text { Total Number } \\
\text { of events }\end{array}$ & $\begin{array}{c}\text { Mean duration } \\
\text { (days) }\end{array}$ & $\begin{array}{c}\text { Severity } \\
\text { (mean annual deviation in cm) }\end{array}$ \\
\hline Kampar & northern & 10 & 149 & 1,047 \\
\hline Air Hitam & southern & 4 & 206 & 701 \\
\hline Upper Kapuas & northern & 7 & 137 & 1,045 \\
\hline Upper Sebangau & southern & 4 & 154 & 576 \\
\hline
\end{tabular}

\subsubsection{Human impact on drought - canalization}

The results change markedly, however, when we analyzed drought severity (change of mean annual GWL deviation, i.e. amplification) due to canalization (Figure 2.1, DF). The amplification is a measure for how many times the human-modified drought is greater than the climate-induced drought. The amplification is around a factor two, and is particularly prominent for the southern regions, where drained peatland in Air Hitam and Upper Sebangau exhibit a severity that is more than 2 times greater than under pristine conditions (Table 2.2). Drought amplification in the southern regions can be reduced by at least 59\% through restoring peatland (Figure 2.1, compare DF and RF). Impact of peatland restoration in the northern regions is smaller; reduction of drought amplification is only $36 \%$. The results show how human intervention in pristine forests (through canalization) amplifies drought severity over the region.

\subsubsection{Human impact on drought - land-use change and canalization}

All four peatland regions show an extreme amplification of drought severity (humanmodified drought) when we simulated canalization combined with land use change (LUC) relative to intact forest (climate-induced drought). Our analysis illustrates that the drought severity exhibits substantial amplification in the southern regions by more than 3.6 times (Upper Sebangau) and 4.8 times (Air Hitam) for logged forest (Figure 2.1, LF). An even more extreme amplification by 4.2 and 6.8 times occurs (Sebangau and Air Hitam, respectively), when intact peatland is transformed into acacia plantation (DA). For the northern region, amplification of drought severity is not as extreme as in the south. When intact forest is converted into logged forest, the drought severity is 2.4-2.9 times larger, or 3.0-3.7 times (acacia plantation). These findings clearly prove that human activities 
(land-use change, including canalization) amplify drought severity. Human-modified drought is substantially larger than climate-induced drought.
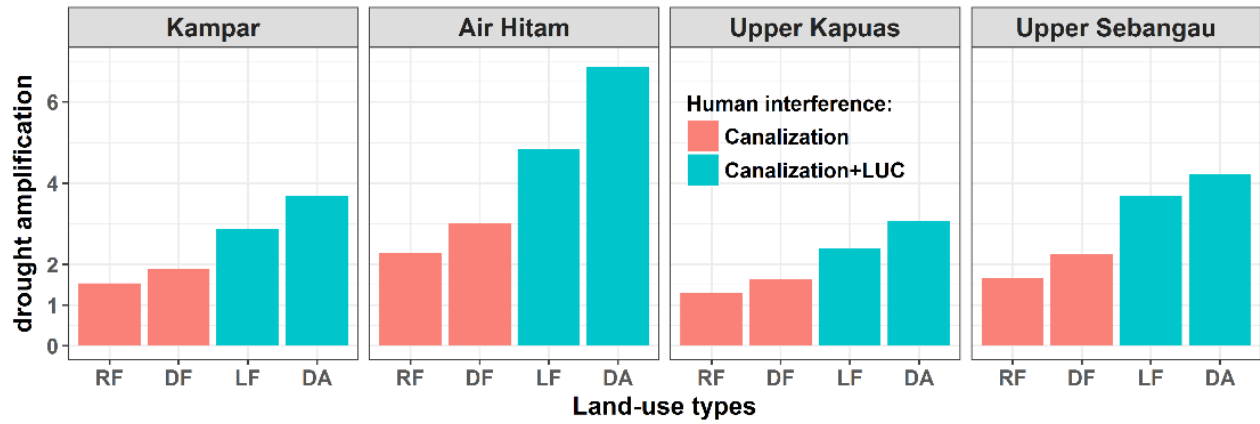

Figure 2.1. Impact of human interference (land-use change and canalization) on amplification of drought severity (change of mean annual deviation in GWL). The amplification is calculated relative to the baseline (Intact Forest) in each region. Four land uses are identified: RF-restored forest; $D F$ - drained forest; $L F$ - logged forest; and DA - drained acacia.

\subsection{Discussions and conclusions}

We used observation-based simulation modelling to understand the effects of human activities on drought in tropical peatlands. We found that humans contribute to the amplification of drought severity, as shown for the disturbed peatlands due to either drainage or land-use change. This finding is consistent with other land-use change studies, which have found evidence for drying trends in the humid tropics (Zhou et al. 2014; Khanna et al. 2017). Far fewer studies have evaluated impacts of canalization on drought severity. Previous studies reported declined groundwater levels in drained peatlands in Southeast Asia (Hooijer et al. 2010; Hirano et al. 2012), and this drawdown generally causes an increased fire susceptibility (Konecny et al. 2016). Nowadays, rising global demands for food and fibre have challenged tropical peatlands, including transformation of the pristine landscape into acacia plantations. However, the magnitude of this transformation has remained largely unquantified until now, in particular the impact of water management on drought severity. Human-modified droughts are found to be several times larger than climate-induced droughts, which occur under natural conditions.

\subsubsection{Assessment of human impact on drought}

We quantified the \% change in drought amplification as a response to several water management options. We changed the dry season canal water level of drained acacia from -110 to $-150 \mathrm{~cm}$ with steps of $10 \mathrm{~cm}(-15 \%$ to $15 \%$ change relative to the dry season CWL of DA, Table 2.1). A dry season CWL of $-150 \mathrm{~cm}$ here refers to uncontrolled drainage. The results exhibited that the drought amplification changes from $-49 \%$ to $46 \%$, with the southern region exhibiting a higher sensitivity (Figure 2.2a). The Upper Sebangau region appears to be the most sensitive region, as shown by the lowering of the dry season canal water level with $10 \mathrm{~cm}(+8 \%,-140 \mathrm{~cm})$, which led to a marked increase of the drought severity ( $23 \%$ change). For the other regions the severity changed less than $14 \%$ in response to a $10 \mathrm{~cm}$ lowering of the dry season CWL. Clearly, water management options (through changing CWL) have a big impact on drought severity. Drought severity shows a major increase under uncontrolled drainage (deeper CWLs). This finding reveals the notable influence of canalization and canal level management on drought. 


\subsubsection{Impact of climate change on drought}

Land-use change and canalization have amplified drought severity. The impact of climate change on hydrological drought in Southeast Asia is yet unclear, but future climate change will likely alter drought amplification over the Southeast Asia region. The region has been assessed to be one of the most vulnerable to an increase of extreme temperatures associated with large carbon emissions (Diffenbaugh and Charland 2016). By increasing the historic temperature from 0.5 to $2.0^{\circ} \mathrm{C}$ with steps of $0.5^{\circ} \mathrm{C}$, the amplification of drought severity under DA is found to vary among peatland regions, but remains small (less than $4 \%$ of change, Figure 2.2b). Again, the southern peatlands consistently show up as a sensitive region. The Air Hitam region shows a deviation of around $3.8 \%$ for all projected temperatures. The northern regions exhibit lesser changes in amplification of drought severity ( $<1.5 \%$ for all projected temperatures). We also quantified the impact of a temperature increase under intact forest (pristine conditions) that consistently gives similar results (Annex A: Figure A.4). The analysis shows that the increase of humanmodified drought due to global warming is estimated to be small. On the other hand, the results change notably when we examined projected precipitation impacts on drought amplification. Clearly, a decrease of the precipitation leads to an amplification of the drought severity in all peatland regions by at least by $9 \%$ (-5\% precipitation, Figure $2.2 \mathrm{c}$ ). All peatland regions exhibit a substantially decreasing amplification of drought severity (smaller human-modified drought) due to a $5 \%$ precipitation increase, with the largest impact in the Upper Kapuas region. The results show that a possible change in precipitation will have more influence on drought severity than that of a temperature increase. As climate models consistently project large rainfall changes over the tropics (Chadwick et al. 2015), likely extreme droughts will change as well, having a major impact on the occurrence of drought induced fires.

Peatlands in Southeast Asia are now deteriorating at an alarming rate and previous studies revealed that any disturbance of peatlands will accelerate the drought-fire risk (Wösten et al. 2006; Konecny et al. 2016). Our findings reveal that canalization of pristine peatlands amplifies drought severity, in particular when the landscape is cultivated for acacia (Figure 2.1). The human-modified drought that occurs under these conditions is at least three times greater than the climate-induced drought, which can be observed in intact forest. These findings prove that human interference frequently amplifies drought severity in the humid tropics. There is evidence that restoring drained peatlands helps to reduce drought severity by tens of percent. After restoration, some humanmodified drought likely will occur, but it may contribute to enhance biodiversity (Koh et al. 2011) and reduce the high costs of conservation (Fisher et al. 2011). Furthermore, the environment will benefit from the lower carbon emission from peatlands (Hooijer et al. 2010). Global warming has a smaller influence on drought severity than water management (controlled, uncontrolled drainage of intact forest). For instance, lowering of the canal water level by just $8 \%$ during the dry season (10 $\mathrm{cm}$ deeper) in drained acacia would increase drought severity by $23 \%$ in Southern Kalimantan. Deeper, uncontrolled drainage would even speed up the drying of the forest, potentially leading to widespread fire in the peatlands. Finally, our findings suggest that even if the $2^{\circ} \mathrm{C}$ global warming target is not exceeded, there will still be at least 19\% more change in drought severity (Figure 2.2a) in the tropical peatlands due to inadequate water management in large areas covered with forest estates and oil palm plantations. 

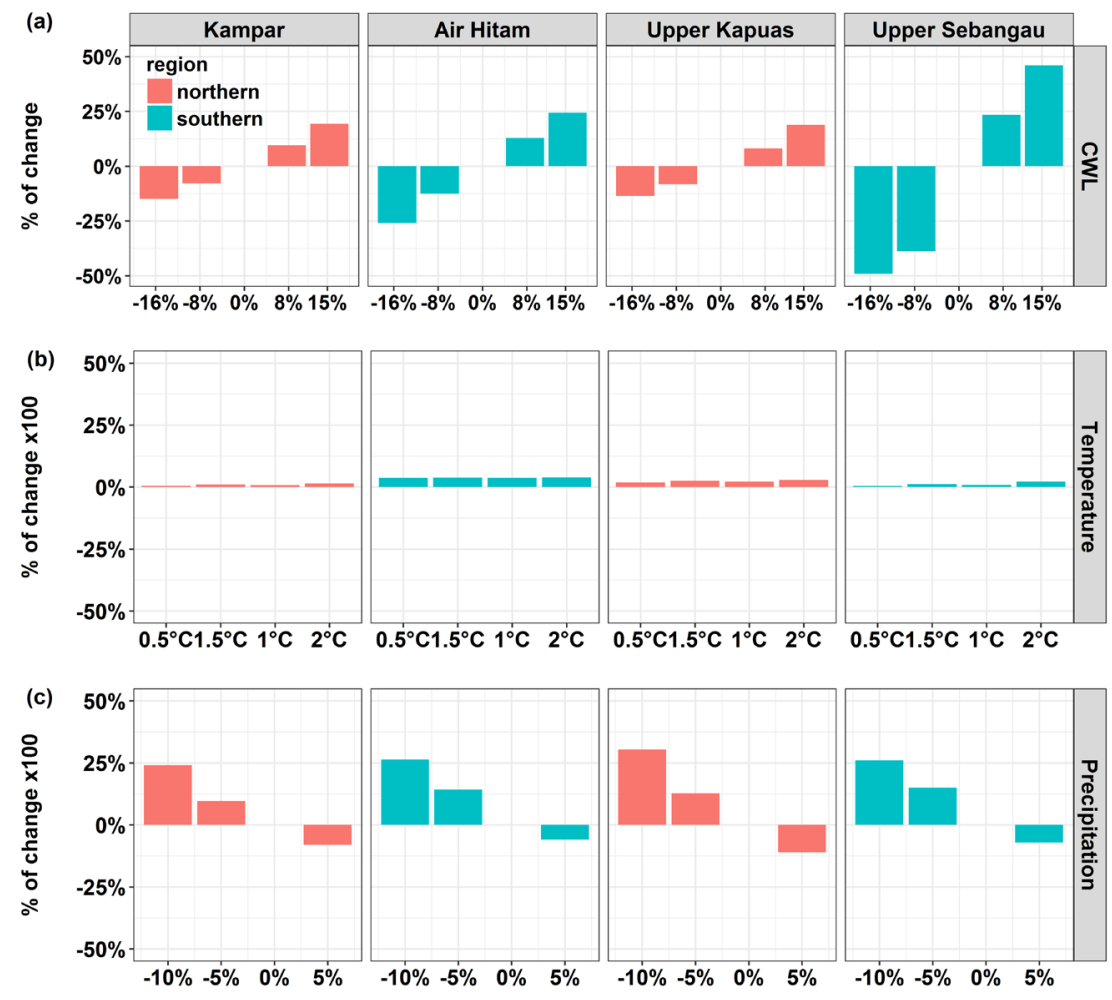

Figure 2.2. Changes in drought severity (amplification of the mean annual deviation in GWL) for drained acacia (DA): (a) water management option by changing dry season canal water levels (CWL) from $-15 \%$ to $15 \%$, (b) projected temperature increase within $2^{\circ} \mathrm{C}$, and (c) projected precipitation change over Southeast Asia from $-10 \%$ to $+5 \%$. 


\section{Chapter 3}

\section{A modified fire drought index}

In this chapter, we discuss how an existing empirical drought index, i.e. the KeetchByram Drought Index (KBDI) that is commonly used for assessing forest fire hazard, has been adjusted and modified for improved use in tropical wetland ecosystems. The improvement included: (i) adjustment of the drought factor to the local climate, and (ii) addition of the water table depth as a dynamic factor to control the drought index. We distinguished three different indices, the original Keetch-Byram Drought Index, the adjusted $\mathrm{KBDI}\left(\mathrm{KBDI}_{\mathrm{adj}}\right)$ that represents the original drought index, but including local climate information, and the modified KBDI (mKBDI) that considers both local climate information, and soil and hydrological characteristics. The mKBDI was developed and tested in a wetland forest of South Sumatra (Indonesia) from April 2009 to March 2011. During this period, hydrometeorological data were monitored and used to calculate the KBDI, KBDI ${ }_{\text {adj' }}$ and mKBDI. First, mKBDI was calibrated using observed soil moisture that was converted to an observed drought index ( $\mathrm{DI}_{\mathrm{obs}}$ ). The results indicate that performance of the $\mathrm{mKBDI}$ is encouraging based on the following: (i) its pattern followed the dynamics of $\mathrm{DI}_{\text {obs' }}$ (ii) prediction of frequency of fire danger classes, and (iii) statistical criteria. The mKBDI clearly outperformed KBDI and KBDI Furthermore, we found a critical water table depth when maximum fire danger is reached ( $0.85 \mathrm{~m}$ for the wetland forest of South Sumatra), below which danger does not increase anymore. The mKBDI could be more widely applied, if pedotransfer functions are developed that link easily-obtainable soil properties to the parameters of the water table factor. Our findings encourage land use planners, water managers and stakeholders (e.g. forest estate owners) to integrate local climate information, and soil and hydrological characteristics into the Keetch-Byram Drought Index to better predict fire danger, particularly in tropical wetland ecosystems.

This chapter is based on: Taufik, M., B. I. Setiawan, and H. A. J. Van Lanen. 2015. Modification of a fire drought index for tropical wetland ecosystems by including water table depth. Agricultural and Forest Meteorology 203: 1-10. doi:10.1016/j.agrformet.2014.12.006 


\subsection{Introduction}

Forest fire is a common phenomenon during dry seasons in equatorial rain forest regions, particularly in Sumatra and Borneo in Indonesia (Goldammer 2007; Miettinen et al. 2013). Land clearing activities meant to grow crops and to plant trees trigger fire during the dry season. It has become a critical problem in Southeast Asia, and previous studies report that it has a significant impact on socio-economic activities in the region (Salafsky 1994; Chokkalingam et al. 2005; Dennis et al. 2005). Additionally, it also influences human health (Dennekamp and Abramson 2011), particularly through increasing air pollution (Kunii et al. 2002; Marlier et al. 2013). In some circumstances fire has positive impacts; because it may help to maintain habitat types used by specific taxa (Cleary et al. 2004). However, it mainly leads to ecological and environmental degradation, such as biodiversity loss (Ager et al. 2007), and to significant change in the floristic and structure of natural forest ecosystems (Wallenius et al. 2007; Xaud et al. 2013). As fire has a significant impact on human activities and environment, it challenges scientists to understand fire behaviour (e.g. occurrence, ignition, intensity, potential spread), particularly related to weather (Wibowo et al. 1997; Petros et al. 2011; Arpaci et al. 2013), and to develop tools for management (Adams et al. 2013). Society and environment are anticipated to benefit from the increased knowledge and improved management tools.

Forest fire hazard often rises during dry seasons, which is associated with a rainfall deficit. As rainfall reduces, soil moisture depletes as a result of evapotranspiration. Fuels become drier, making them vulnerable to ignite and burn. Previous studies demonstrate that soil moisture deficits influence moisture content in dead fuels (necromass and surface litter, e.g. Pook and Gill 1993; Pellizzaro et al. 2007). Soil moisture deficit is therefore a good proxy for the fuel moisture content and hence to assess fire hazard potential. One of the drought indices specifically developed to assess fire hazard is the Keetch-Byram Drought Index (Keetch and Byram 1968). Several efforts have been carried out to show that the Keetch-Byram Drought Index (KBDI) is related to fuel moisture content in several ecosystems, particularly for shrubs (Pellizzaro et al. 2007) and savannah (Verbesselt et al. 2006).

The KBDI was developed for forest control management and fire hazard assessment in the USA, in particular Florida. The index is a cumulative estimate of moisture deficiency based on meteorological variables and an empirical approximation for moisture depletion in the upper soil and litter layer. It uses mean annual rainfall measured in Florida as a climate indicator (Keetch and Byram 1968). The KBDI has been widely used for assessing fire hazard because it is easy to calculate (Dimitrakopoulos and Bemmerzouk 2002) and it does not require a lot of data (i.e. daily maximum air temperature and rainfall at a nearby standard meteorological station). Several studies have applied the KBDI in other areas than Florida, such as Northern Eurasia (Groisman et al. 2007), Hawaii (Dolling et al. 2005), Australia (Finkele et al. 2006; Boer et al. 2009; Caccamo et al. 2012), Russia (MalevskyMalevich et al. 2007), Mediterranean regions (Petros et al. 2011), Southeast Asia, such as Indonesia (Buchholz and Weidemann 2000; Murdiyarso et al. 2002) and Malaysia (Ainuddin and Ampun 2008). Heim (2002) and Petros et al. (2011) indicate that the KBDI is widely used and accepted index for forest fire monitoring and prediction.

Although the KBDI has been broadly used, improvement of the KBDI model structure or its application is still necessary, especially for regions with climates, soils and hydrology distinct from those of Florida, such as tropical wetland ecosystems in Southeast Asia. Without any adjustment to the model structure, the application of the KBDI in other climates may still be problematic (Liu et al. 2010), as the drying rate in the index depends 
on the mean annual precipitation representative for Florida (Keetch and Byram 1968). These issues suggest that the wider applicability of the KBDI could be improved when the model would be adapted to accommodate other climate, soil and hydrological conditions than those in Florida.

The development of the KBDI for wetland ecosystems in Indonesia is a challenge because the tropical climate has an annual rainfall that is nearly twice that of Florida. These large differences in annual precipitation affect drying rates. In addition, locations in Indonesia (particularly in Sumatra and Borneo) that experience forest fires are predominantly wetlands. This is where fire has the most severe impacts on air pollution and greenhouse gas emissions. They also represent a 'last frontier' where non-wetland forests have already been destroyed and converted. The shallow water table that occurs there, supplies water into the surface layer through capillary rise (upward flow into the unsaturated soil). In dry seasons, water tables tend to decrease, causing the upper layer to dry. Hence the fuel becomes much more vulnerable to fire than in non-wetland conditions. However, currently no model structure is available that integrates the higher annual rainfall and the water table into the drought index for use in tropical wetland ecosystem. We anticipate that integrating these aspects in the KBDI will improve applicability in Southeast Asia and extend the previous studies (e.g. Buchholz and Weidemann 2000; Murdiyarso et al. 2002; Ainuddin and Ampun 2008). Therefore, the objective of this paper is: (i) to modify the fire drought index KBDI for climate, soil, and hydrological conditions representative for wetland areas in humid tropical climates, and (ii) to analyze the influence of the water table depth on the dynamics of the KBDI.

\subsection{The Keetch-Byram Drought Index}

\subsubsection{Original model}

The Keetch-Byram Drought Index (KBDI) uses a mathematical function to correlate weather conditions to potential fire hazard, which can be applied both to accidental and deliberate fire initiation. The index is a number that represents the net effect of evapotranspiration and precipitation, which might lead to a soil moisture deficit in the duff and upper soil layers. Actually, it is a hydrological approach toward fire hazard and its application is only limited to forests. It is based upon a rather simple representation of a forest, where the forest vegetation density is controlled by the mean annual rainfall, which controls the rate of soil moisture loss. The loss rate will decrease with lower forest vegetation density, hence with lower annual rainfall. The KBDI is based on 8 inches (203 mm) of soil water available for evapotranspiration (Keetch and Byram 1968). It is expressed in hundredths of an inch on a scale from 0 to 800 ( $\times 10^{-2}$ inch). In the metric system, the index is on scale from 0 to 203 (mm). Zero indicates no moisture depletion and 203 reflect the highest depletion, i.e. the maximum drought severity level. Hence it represents the highest fire hazard.

Mathematically, the KBDI is formulated as follows:

$$
\mathrm{KBDI}^{\mathrm{t}}=\mathrm{KBDI}^{\mathrm{t}-1}+\mathrm{DF}^{\mathrm{t}}-\mathrm{RF}^{\mathrm{t}}
$$

In general, the drought factor (DFt, Crane 1982) on a given day in the metric system is:

$$
\mathrm{DF}^{\mathrm{t}}=\left(203-\mathrm{KBDI}^{\mathrm{t}-1}\right) \frac{\left(0.968 \mathrm{e}^{0.0875 \mathrm{Tm}+1.552}-8.3\right) \times 10^{-3}}{1+10.88 \mathrm{e}^{-0.001736 \mathrm{Ro}}}
$$

The variables and units are provided in Table 3.1 . 
Chapter 3

Table 3.1. The symbols, description and units used for calculating the drought index, as described in Eq. 3.1-3.11.

\begin{tabular}{|c|c|c|}
\hline Symbols & Description & Units \\
\hline $\mathrm{KBDI}^{\mathrm{t}-1}$ & Moisture deficiency (KBDI at $\mathrm{t}-1$ ) & $\mathrm{mm}$ \\
\hline $\mathrm{KBDI}_{\mathrm{adj}}^{\mathrm{t}}$ & $\begin{array}{l}\text { Adjusted KBDI, which considers local climate information } \\
\text { (average annual rainfall and evapotranspiration) }\end{array}$ & $\mathrm{mm}$ \\
\hline mKBDI & $\begin{array}{l}\text { Modified KBDI, which considers local climate, soil and } \\
\text { hydrological factors }\end{array}$ & $\mathrm{mm}$ \\
\hline $\mathrm{t}$ & time increment & day \\
\hline DF & Drought factor & $\mathrm{mm}$ \\
\hline $\mathrm{T}_{\mathrm{m}}$ & Daily maximum air temperature & ${ }^{\circ} \mathrm{C}$ \\
\hline Ro & Average annual rainfall & $\mathrm{mm}$ \\
\hline $\mathrm{DF}_{\mathrm{adj}}^{\mathrm{t}}\left(\mathrm{R}_{0}\right)$ & Adjusted DF considering local average annual rainfall & $\mathrm{mm}$ \\
\hline $\operatorname{DF}_{\text {adj }}^{\mathrm{t}}\left(\mathrm{R}_{0}, \mathrm{ET}\right)$ & $\begin{array}{l}\text { Adjusted DF considering local average annual rainfall and } \\
\text { evapotranspiration }\end{array}$ & $\mathrm{mm}$ \\
\hline $\mathrm{RF}$ & Rainfall factor & $\mathrm{mm}$ \\
\hline $\mathrm{R}^{\mathrm{t}}$ & Daily rainfall at time $\mathrm{t}$ & $\mathrm{mm}$ \\
\hline $\mathrm{R}^{\mathrm{t}-1}$ & Daily rainfall at time $\mathrm{t}-1$ & $\mathrm{~mm}$ \\
\hline WTF & Water table factor & $\mathrm{mm}$ \\
\hline $\mathrm{aH}_{\mathrm{H}}$ & Maximum water table factor & $\mathrm{mm}$ \\
\hline $\mathrm{b}_{\mathrm{H}}$ & Correction factor & {$[-]$} \\
\hline$\theta(\mathrm{h})$ & Soil moisture content at $z=-h$, function of capillary rise & {$[-]$} \\
\hline$\theta_{\mathrm{r}}$ & Residual water content & {$[-]$} \\
\hline$\theta_{\mathrm{S}}$ & Saturated water content & {$[-]$} \\
\hline $\mathrm{h}$ & Daily water table depth & $\mathrm{m}$ \\
\hline$\alpha$ & Fitting parameter representing air entrance value & $\mathrm{m}$ \\
\hline $\mathrm{n}, \mathrm{m}$ & Fitting parameters of water retention curve & {$[-]$} \\
\hline DIobs & Observed drought index as function of soil moisture & $\mathrm{mm}$ \\
\hline $\operatorname{DImax}$ & Maximum observed drought index & $\mathrm{mm}$ \\
\hline$\theta^{\mathrm{t}}$ & Observed soil moisture content at time $\mathrm{t}$ & {$[-]$} \\
\hline
\end{tabular}

Rainfall is considered to reduce the index, if it is more than $5.1 \mathrm{~mm}$ (Eq. 3.3):

$\mathrm{RF}^{\mathrm{t}}=\left\{\begin{array}{lll}\left(\mathrm{R}^{\mathrm{t}}-5.1\right) & , \mathrm{R}^{\mathrm{t}} \geq 5.1 \mathrm{~mm} \quad, 1^{\text {st }} \text { rainy day } \\ \mathrm{R}^{\mathrm{t}} & , \mathrm{R}^{\mathrm{t}-1} \geq 5.1 \mathrm{~mm} \quad, 2^{\text {nd }} \text { and the next rainy days } \\ 0 & , \mathrm{R}^{\mathrm{t}}<5.1 \mathrm{~mm}\end{array}\right.$

\subsubsection{Model improvement}

Previous research has already indicated that the KBDI even in the USA is not everywhere a good indicator of the fire hazard, such as in the Mississippi region (Cooke et al. 2007; Choi 
et al. 2009) and the Georgia region (Chan et al. 2004). Thus, an improvement is necessary to account for other climatic conditions. Furthermore, capillary rise from the water table to the topsoil in wetlands also needs to be included. A modified KBDI is proposed that takes into account local climate information, as well as soil and hydrological characteristics.

\section{a. Improvement using local climate conditions}

Climate variables influence the development of the drought index KBDI over time. Keetch and Byram (1968) assumed that climate variables (particularly annual rainfall and evapotranspiration) determine how much water will be lost from the soil-duff layer by vegetation. As climate varies between locations, the amount of water lost to the atmosphere also differs between geographic regions. Although the model has been used for a while and it was criticized because of its reliability to predict fire hazard, model improvements were proposed not earlier than the last decade.

An improvement of the KBDI by employing local annual rainfall was proposed by Petros et al. (2011) for use in the Mediterranean region. It was triggered by a previous study (Spano et al. 2005), which applied the original model to this region and encountered problems, i.e. underestimation of the actual water loss, particularly in summer season. Petros et al. (2011) adjusted parameters of the DF by employing local annual rainfall of the Mediterranean region (Eq. 13-18 in the original KBDI, Keetch and Byram, 1968). They report that the adjusted KBDI performs better.

Adjustment of only annual rainfall remains questionable, because the DF is still calculated with the formula for the potential evapotranspiration corresponding to Florida's climate. In a response to this drawback, Snyder et al. (2006) utilized the Hargreaves-Samani evapotranspiration for computing the drying rate, and then scaled it into a drought factor for use in arid grasslands in California, USA.

In this paper, integration of both annual rainfall and revision of the calculation of the evapotranspiration was carried out in a stepwise procedure. The equatorial region in Southeast Asia receives huge amounts of rainfall throughout the year. Several studies report an amount of ca. 2000-3000 mm per year (Salafsky 1994; Walsh 1996; Chappel et al. 2009; Suhaila and Jemain 2011). Therefore, this rainfall should be employed in the drought factor of the original KBDI (Eq. 14-18, in Keetch and Byram 1968). By substituting this value, i.e. using inches (ca. 2500 mm), into Keetch and Byram's Eq. 16, it gives days. After adjusting the constants in Keetch and Byram's Eq. 18, the DF (Eq. 3.2) becomes:

$$
\mathrm{DF}_{\text {adj }}^{\mathrm{t}\left(\mathrm{R}_{\mathrm{O}}\right)}=\left(203-\mathrm{KBDI}^{\mathrm{t}-1}\right) \frac{\left(0.4982 \mathrm{e}^{0.0875 \mathrm{Tm}+1.552}-4.268\right) \times 10^{-3}}{1+10.88 \mathrm{e}^{-0.001736 \mathrm{Ro}}}
$$

The empirical equation to compute daily evapotranspiration as a function of maximum daily temperature (Figure 8 and Eq. 13, in Keetch and Byram 1968) gives an average daily evapotranspiration of only $3.6 \mathrm{~mm} /$ day. This value likely is $15 \%$ lower than evapotranspiration loss in the tropical rain forest of Borneo as reported by Kumagai et al. (2005). In other regions of Southeast Asia, in particular Peninsular Malaysia (Tani et al. 2003), a similar value was mentioned. Finally, the adjusted drought factor DF that considers both the modified average annual rainfall and evapotranspiration for use in the equatorial climate of Southeast Asia is as follows:

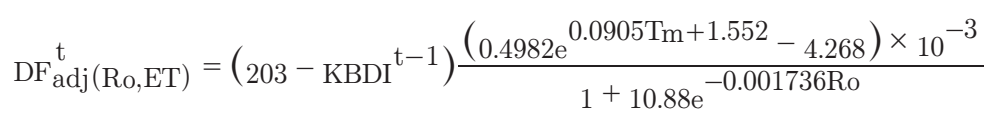


Chapter 3

Substituting Eq. (3.5) into Eq. (3.1) gives:

$$
\mathrm{KBDI}_{\mathrm{adj}}^{\mathrm{t}}=\mathrm{KBDI}_{\mathrm{adj}}^{\mathrm{t}-1}+\mathrm{DF}_{\mathrm{adj}(\mathrm{R} 0, \mathrm{ET})}^{\mathrm{t}}-\mathrm{RF}^{\mathrm{t}}
$$

\section{b. Improvement using soil and hydrological characteristics}

The development of soil moisture deficit over time does not only depend on climate, but also on soil and hydrological characteristics. Previous studies show that the soil type affects the sensitivity of the KBDI to estimate potential fire hazard potential, for example, in sandy soils in Arkansas, USA (Sparks et al. 2002), and in organic soils in the Pocosin wetland in North Carolina, USA (Reardon et al. 2009). To overcome this limitation, soil characteristics should be integrated into the so-far only climatologically-based drought index (Eq. 3.6) to better assess the dryness state of the fuel, as indicated by Pellizzaro et al. (2007). More recently, Reardon et al. (2009) suggest that further improvements to the KBDI should focus on soil hydrological characteristics that influence water storage and flow in the soil. So far, no modified KBDI exists that includes soil and hydrological conditions.

In this study we improved the drought index (i.e. mKBDI) by integrating water retention characteristics and groundwater table depth into the drought index's model structure. We propose to add a new variable to Eq. 3.6, i.e. the water table factor (WTF), which affects soil moisture depletion in wetland ecosystems, which typically are characterized by shallow water tables. In this type of ecosystems, soil water content in the upper layer is strongly influenced by water table depth (Jaber et al. 2006; Fan et al. 2007; Fan and Miguez-Macho 2011). Shallower water tables are associated with higher soil water contents, while deeper water tables generally correspond to lower soil water contents in the topsoil. By assuming that the soil water content above the water table depends only on the pressure head, the water retention equation introduced by Van Genuchten (1980) can be used to modify the KBDI (Eq. 3.7):

$$
\theta(\mathrm{h})=\left[1+(\mathrm{h} / \alpha)^{\mathrm{n}}\right]^{-\mathrm{m}}
$$

Assuming that other forces (such as osmotic forces) can be ignored and that equilibrium is an acceptable approximation, the pressure head in the topsoil is equal to the distance of the surface to the water table $(z=-h)$. A similar assumption was proposed by Weiss et al. (2006). Then, the water table factor (WTF) takes the following form (see also Setiawan et al. 2009):

$$
\mathrm{WTF}^{\mathrm{t}}=\mathrm{aH}_{\mathrm{H}}-\mathrm{b}_{\mathrm{H}} \times\left[\left(1-\theta(\mathrm{h})^{\mathrm{t}}\right) \times 203\right]
$$

Both assumptions greatly improve the practical applicability of the water table factor (WTF). Instead of hard to monitor soil moisture contents in the topsoil, the more easily to measure water table depths have to be obtained, and by applying the Van Genuchten equation, the water table depth can be converted into the soil moisture content of the topsoil. The number of 203 is the maximum drought index. In case of a zero water table ( $h=0$, water table exactly at the soil surface) or inundation, the maximum water table factor is equal to $a_{H}$. The parameter $b_{H}$ is a correction factor. The water table factor that describes upward flow has a similar role as the rainfall factor, which explains downward flow; both reduce the KBDI. The modified Keetch and Byram drought index (mKBDI) for use in tropical wetland ecosystems can be written as follows:

$$
\mathrm{mKBDI}=\mathrm{mKBDI}^{\mathrm{t}-1}+\mathrm{DF}_{\mathrm{adj}}^{\mathrm{t}}(\mathrm{Ro}, \mathrm{ET})-\mathrm{RF}^{\mathrm{t}}-\mathrm{WTF}^{\mathrm{t}}
$$


It is hypothesized that by taking into account climate information (i.e. average annual rainfall and daily evapotranspiration), soil and hydrological characteristics (i.e. the water retention and water table depth) the proposed modified index (Eq. 3.9) will allow a better assessment of potential fire hazard.

\subsection{Data and methods}

\subsubsection{Description of the study site}

The present study was carried out in a forest plantation located in the Ogan Komering Ilir District, South Sumatra, Indonesia. Since 2004, the study site was mostly planted with Acacia crassicarpa. Weather variables were monitored using an automatic weather station installed in the Baung station, geographically located at $105.3^{\circ}$ East and $2.74^{\circ}$ South (Figure 3.1). Physical soil properties, such as texture, volumetric water content, bulk density, and porosity were measured at this station, as reported by Setiawan et al. (2009). The soil contains $58 \%$ clay, $41 \%$ silt, and $1 \%$ sand. The measured volumetric water contents at saturation, field capacity and wilting point were, respectively, 0.592, 0.490 and $0.320 \mathrm{~m}^{3} / \mathrm{m}^{3}$.

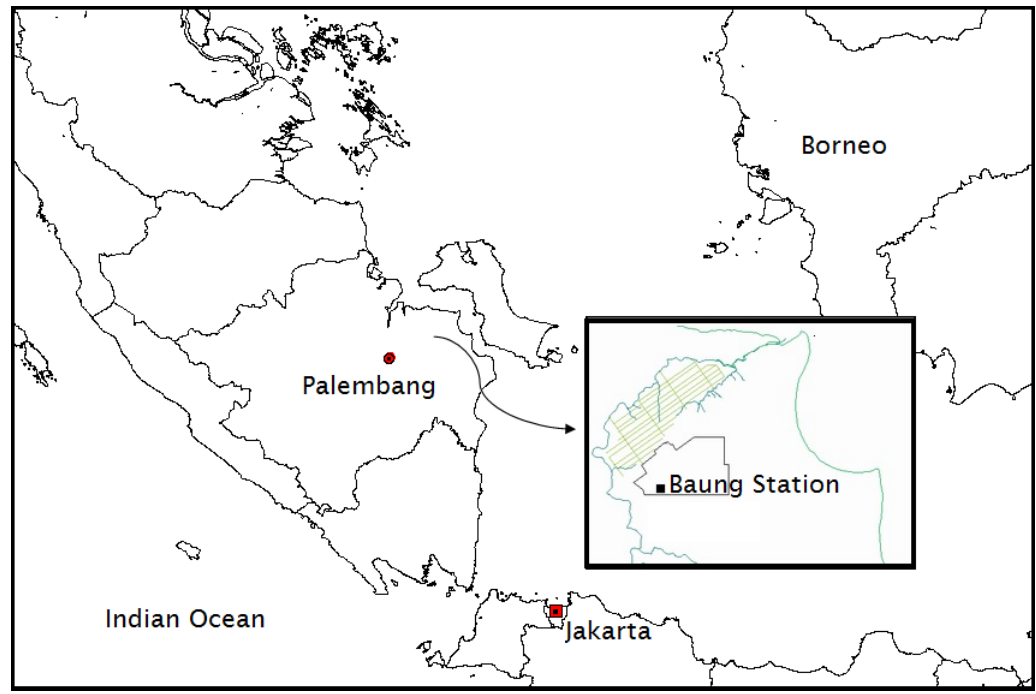

Figure 3.1. Location of the study site in South Sumatra, Indonesia.

\subsubsection{Data collection and analysis}

In the Baung station several hydro-meteorological variables were monitored, such as rainfall, air temperature, soil water content, and water table depth for the period 1 April 2009 - 15 March 2011. The meteorological variables were monitored using the Automatic Weather System Vantage Pro (Davis Instruments). The soil water content was measured using a soil moisture sensor (Decagon Devices), and the data were recorded using an Em50 digital data logger (Decagon Devices). The soil moisture sensor was inserted vertically to measure the volumetric water content at 5-10 cm depth at the meteorological station. The soil moisture sensor was calibrated against observed soil moisture (gravimetric method) of samples taken at different moisture conditions. The water table depth was measured using an automated monitoring well. We installed a TD Diver instrument (Van Essen Instruments) for monitoring the dynamics of the water table, using a BaroDiver and a Diver. The measurements were recorded at hourly intervals and downloaded using the LoggerDataManager (LDM, Van Essen Instruments). 
During the two-year observation period, the impact of two consecutive large scale oceanatmospheric interactions in the Pacific Ocean occurred at our study site, i.e. El Niño in 2009 and La Niña in 2010 (source: http://www.cpc.ncep.noaa.gov). Both phenomena have a contrasting impact on the Indonesian water cycle (Hendon 2003), i.e. El Niño is associated with a prolonged dry season, whereas La Niña triggers a longer lasting wet season.

\subsubsection{Model setup}

In this study we distinguished three different drought indices, namely the original model $(K B D I)$, the adjusted model $\left(K B D I_{\text {adj }}\right)$, and the modified KBDI (mKBDI). We applied Eqs. 3.1, 3.6 and 3.9, respectively. The $\mathrm{KBDI}$ and $\mathrm{KBDI}_{\text {adj }}$ calculations required daily rainfall and maximum air temperature. In addition, daily water table depth was required for the mKBDI computation. The calculation of the water table factor (Eq. 3.8) required the magnitude of parameters, $a_{H}$ and $b_{H}$. As a first step, any reasonable number was considered for both parameters, namely for $a_{H} 1-11$, and for $b_{H} 0.1-0.9$. Next, Eq. 3.9 was employed for computation of mKBDI.

It has been shown that KBDI should represent soil moisture conditions in the upper layer rather than in the deeper layer (Dimitrakopoulos and Bemmerzouk 2002). Therefore, it is assumed that the observed soil moisture in the upper soil was adequate for calibrating the parameters $\left(a_{H}\right.$ and $\left.b_{H}\right)$ of $m K B D I$. We employed the following procedure to calibrate the parameters of $\mathrm{mKBDI}$.

- Firstly, the observed soil water content $\left(\theta^{t}\right)$ was converted into a drought index $\left(\mathrm{DI}_{\mathrm{obs}}\right)$ that was scaled between 0 and $203 \mathrm{~mm}$ (Eq. 3.10). The maximum value $\left(D I_{\text {max }}=203\right)$ occurs when soil water reaches wilting point $\left(\theta_{\mathrm{r}}\right)$, and it is zero when the soil water content is close to saturation $\left(\theta_{\mathrm{S}}\right)$. The observed drought index $\left(\mathrm{DI}_{\mathrm{obs}}\right)$ is written as follows:

$$
\mathrm{DI}_{\mathrm{obs}}=\operatorname{DImax}\left[1-\left(\frac{\theta^{\mathrm{t}}-\theta_{\mathrm{r}}}{\theta_{\mathrm{s}}-\theta_{\mathrm{r}}}\right)\right]
$$

- Secondly, the parameters $a_{H}$ and $b_{H}$ of the water table factor were calibrated to minimize the deviation between $\mathrm{DI}_{\mathrm{obs}}$ and the mKBDI. Performance of mKBDI against $\mathrm{DI}_{\mathrm{obs}}$ was evaluated using three quantitative criteria for goodness of fit, including: (i) the Nash-Sutcliffe efficiency (nse), (ii) RMSE-observations standard deviation ratio $(r s r)$, and (iii) Percent Bias (pbias). nse is a normalized statistic that determines the relative magnitude of the explained variance compared to the observed data variance. rsr was developed to incorporate an error index. This normalized factor varies from an optimal value of 0 (perfect model) to a large positive value. pbias measures the average tendency of the simulated data to their observed counterparts. For a detailed explanation of these criteria, readers are referred to Moriasi et al. (2007). The mKBDI was supposed to perform well, if $n s e>0.65, r s r \leq 0.60$, and pbias is $\pm 25 \%$.

The drought index $\left(\mathrm{DI}_{\mathrm{obs}}\right.$ ) reflects the soil moisture deficit in the upper soil layers. The calculation of the KBDI usually starts with soil moisture at field capacity. Keetch and Byram (1968) assumed that field capacity is reached when weekly rainfall is about 150$200 \mathrm{~mm}$. Then KBDI is set to zero. As we measured soil moisture, the starting point for our calculation was observed soil moisture close to saturation. We have chosen saturation instead of field capacity because in a typical wetland ecosystem the water table is always close to surface. 
In the present study, we used four fire hazard classes, i.e. low (KBDI $\leq 100 \mathrm{~mm}$ ), moderate $(K B D I=101-150 \mathrm{~mm})$, high $(K B D I=151-175 \mathrm{~mm})$, and extreme (KBDI $\geq 175 \mathrm{~mm})$. Most studies in Southeast Asia use four fire hazard classes (Buchholz and Weidemann 2000; Murdiyarso et al. 2002; Ainuddin and Ampun 2008). The daily outcome of all three drought indices, i.e. the KBDI, the KBDIadj, and the mKBDI was allocated to one of the fire hazard classes and subsequently the frequency of occurrence among the classes was determined, and compared against the frequency of occurrence of $\mathrm{DI}_{\text {obs }}$.

\subsection{Results}

\subsubsection{Hydro-meteorological conditions at the study site}

Daily rainfall greatly varied during the observation period 1 April 2009 - 15 March 2011 (Figure 3.2a). In 2009, which was affected by the El Niño event, rainfall was below normal at the study site, and it prolonged the dry season. On other hand, the La Niña event supplied above-average rainfall throughout 2010. In 2009, there were only 56 out of 275 days with rainfall of more than $5.1 \mathrm{~mm}$ (Eq. 3.3). August - September 2009 were months with the lowest monthly rainfall, i.e. less than $35 \mathrm{~mm}$ each. Without the two rainfall events that were triggered by cloud seeding and that produced almost $90 \mathrm{~mm}$ in early October 2009, this month would also have been dry. The highest daily rainfall was $107 \mathrm{~mm}$ (April 2009). The total rainfall in 2009 was $1550 \mathrm{~mm}$ (9 months). The year 2010 received more rainfall with 109 out of 365 days with rainfall of more than $5.1 \mathrm{~mm}$ (Figure 3.2a). Only in July 2010, monthly rainfall was less than $100 \mathrm{~mm}$, which indicates no distinct dry season throughout 2010. In 2010, the study site received a huge amount of annual rainfall, about $15 \%$ more than normal $(2718 \mathrm{~mm})$. In 2011, 25 days had a daily rainfall larger than $5.1 \mathrm{~mm}$, and in total $404 \mathrm{~mm}$ (2.5 months) were recorded.

The daily maximum air temperature fluctuated from 25.3 to $34.9^{\circ} \mathrm{C}$ in the monitoring period. Lower air temperatures usually coincided with prolonged wet spells. For example, early and late 2010 the maximum air temperature dropped below $28^{\circ} \mathrm{C}$ (Figure $3.2 \mathrm{~b}$ ). On the other hand, prolonged dry spells had higher air temperatures. During the 2009 dry season, the maximum air temperature always was above $30^{\circ} \mathrm{C}$. Upper soil water content varied from 0.343 to $0.590 \mathrm{~m}^{3} / \mathrm{m}^{3}$ (Figure 3.2c) and followed the rainfall pattern. The lowest soil water contents occurred during periods of little rainfall (August - September 2009), when the minimum soil moisture reached $0.343 \mathrm{~m}^{3} / \mathrm{m}^{3}$. Occasionally, soil moisture was close to saturation, particularly after consecutive intense rainfall events, such as at the beginning of April 2009. In 2010, some decline of soil moisture below field capacity $(0.49$ $\mathrm{m}^{3} / \mathrm{m}^{3}$ ) occurred in July, August and November. It occasionally occurred in January February 2011 as well, as a response to a low rainfall period.

During the observation period, the water table depth at the study site varied from close to the soil surface $(-0.023 \mathrm{~m})$ to $-1.003 \mathrm{~m}$ below the soil surface (Figure $3.2 \mathrm{~d}$ ). A decline in water table depth occurred during the low rainfall period of August - September 2009 that coincided with the El-Niño event. In 2010, our observations showed no seasonal decline at all in the water table depth throughout the year. However, there was a sharp decline in the water table depth for a short period of time in July 2010, which was a response to 28 consecutive days with less than $5.1 \mathrm{~mm}$ of rain. Prolonged dry or wet spells greatly influenced the dynamics of the water table depth.

\subsubsection{Performance of drought indices}

\section{a. Original KBDI}

Computation of the KBDI using the original model structure (Eq. 3.1) resulted in a range 
from 0 to $199 \mathrm{~mm}$ (Figure 3.3b). After a day with heavy rainfall the KBDI sharply declined and reached zero. When no significant rainfall was observed for several days the KBDI quickly rose, which occurred for instance by the end of April 2009. The drought fire index is supposed to reflect the soil moisture content of the topsoil because that is a good proxy for the dryness of the fuel and hence of the potential fire hazard. Figure 3.3a shows that the performance of the KBDI is too flashy relative to the scaled observed soil moisture content of the topsoil ( $\left(\mathrm{II}_{\mathrm{obs}}\right)$. The disagreement of the KBDI with observed soil moisture also is illustrated by the negative nse (-6.95). It clearly shows that applying the KBDI with the original model structure does not result in a reliable prediction of the fire hazard at the study site.

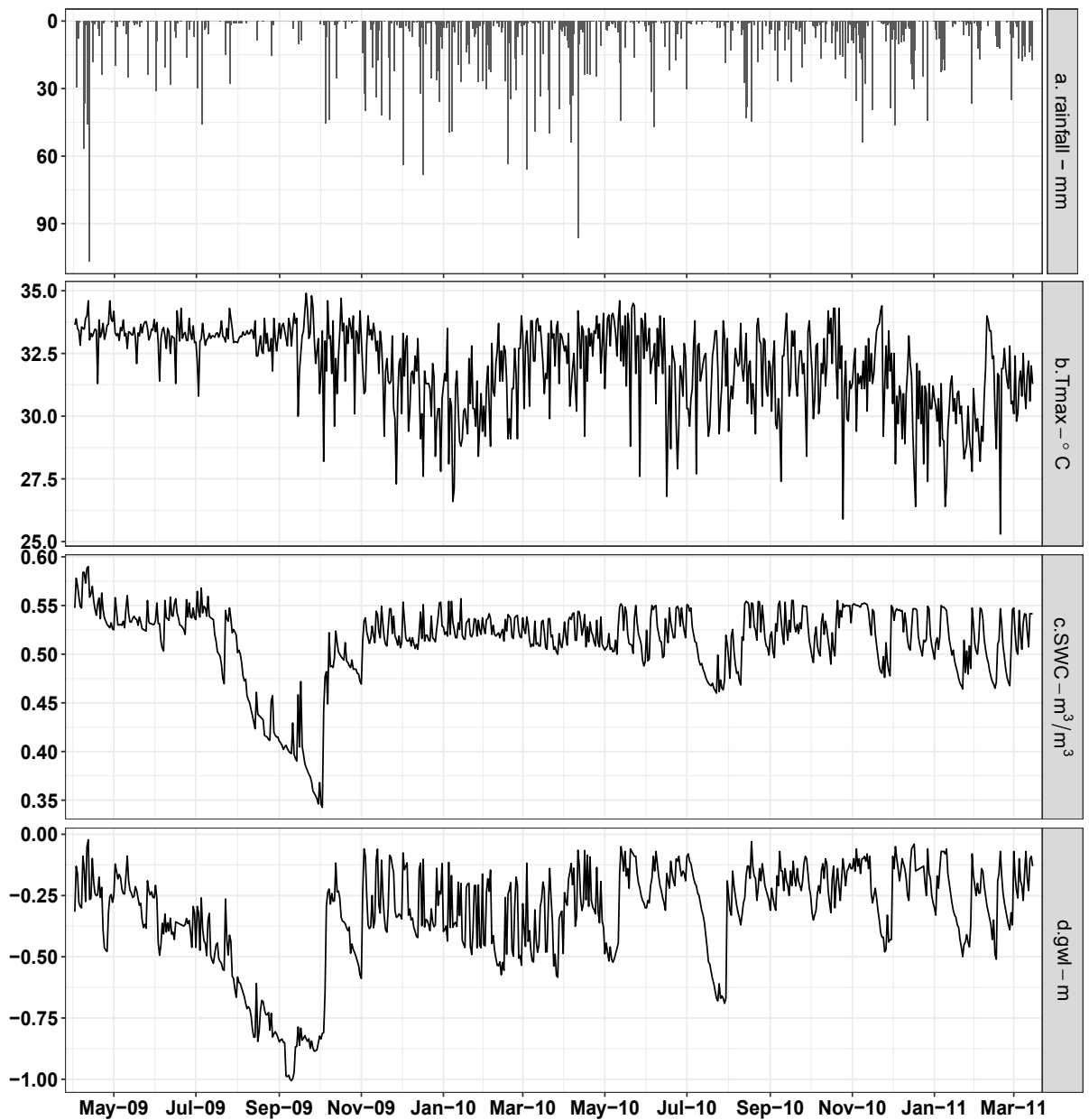

Figure 3.2. Daily observed (a) rainfall, (b) maximum air temperature, (c) soil water content, and (d) groundwater table depth during the monitoring period at the study site.

\section{b. Adjusted KBDI}

The $\mathrm{KBDI}_{\text {adj }}$ (Eq. 3.6 with) is always slightly lower than the KBDI using the original model structure (Figures 3.3b). However, both models tend to have a similar pattern and show a steep increase in response to dry spells. It inherently caused a substantial daily increase of fire hazard. However, when a heavy rainfall event occurred, both KBDI and KBDI ${ }_{\text {adj }}$ reduced 
significantly, which caused both to be too flashy in response to weather changes. The adjusted model seems, like the original KBDI, not to be a good indicator to assess forest fire hazard, as it is also indicated by the negative nse (-2.80). It is obvious that only adding local climate information (average annual rainfall and potential evapotranspiration) to the original model does not sufficiently improve the use of this drought index for fire hazard monitoring in tropical wetland ecosystems.

\section{c. Modified KBDI}

We anticipated a reasonable agreement between the modified drought index (mKBDI) and the observed drought index $\mathrm{DI}_{\text {obs }}$ (Eq. 3.10), because the latter was used to calibrate the parameters of the water table factor (Eq. 3.8) in such a way that the mKBDI and the $\mathrm{DI}_{\text {obs }}$ time series yield a good fit. We obtained through calibration the following expression for the water table factor (Eq. 3.8):

$$
\mathrm{WTF}^{\mathrm{t}}=10.64-0.283 \times\left[\left(1-\theta(\mathrm{h})^{\mathrm{t}}\right) \times 203\right]
$$

The maximum WTF for these local soil and hydrological characteristics, which occurred during very wet conditions and associated shallow water tables, was found to be $10.64 \mathrm{~mm}$.

It appeared that the pattern of the mKBDI and the DI $I_{\text {obs }}$ fit very well (Figure 3.3c), in particularly during the dry El Niño of 2009. The mKBDI did not respond to weather change (i.e. dry spells, rainfall events) so strongly as the KBDI and the KBDI adj In the last six months of the monitoring period there was some disagreement between the mKBDI and the $\mathrm{DI}_{\text {obs. }}$. However, it does hardly influence its performance as it was at the low fire hazard level. The agreement in patterns between the mKBDI and $\mathrm{DI}_{\text {obs }}$ was also confirmed by the goodness of fit. The nse was high (0.69), which indicated that the model reasonably assessed fire hazard. Additionally, the $r s r$ is very small (0.02) and the pbias is acceptable (16\%). These results clearly showed that performance of the drought index improved by integrating soil and hydrological factors.

\subsubsection{Response of drought index to hydrometeorological extremes}

As described in the previous section, the KBDI seems to react too flashy in response to wet and dry weather changes. For instance, by the end of April 2009, the KBDI drastically increased from low to moderate fire hazard just after nine days without rainfall (Figure 3.3b). Even in the La Niña year, when soil moisture content was always high, KBDI also predicted severe fire hazard as shown in early June 2010 and by the end of July 2010 (Figure 3.3b). A similar response was also presented by the KBDI ${ }_{\text {adj }}$. It clearly appears that the original model structure, which is only dependent on meteorological variables, caused too pronounced fluctuations of the drought index following dry and wet spells, even if the model structure was adjusted to the local climate $\left(\mathrm{KBDI}_{\mathrm{adj}}\right)$.

On other hand, the mKBDI smoothly rose and declined in response to dry and wet spells. It appeared that integrating soil and hydrological characteristics into the original model structure (Eq. 3.9) greatly reduced the dynamics of drought index. For instance, in the

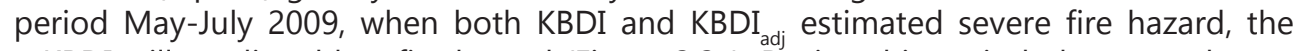
mKBDI still predicted low fire hazard (Figure 3.3c). During this period, the groundwater table was relatively close to the surface (Figure 3.2d), which still provided water to the topsoil through capillary rise. Moreover, the mKBDI did not sharply rise during a short dry period in July 2010, because the rather shallow water table reduced the impact of the dry weather on the soil water content of the topsoil. 

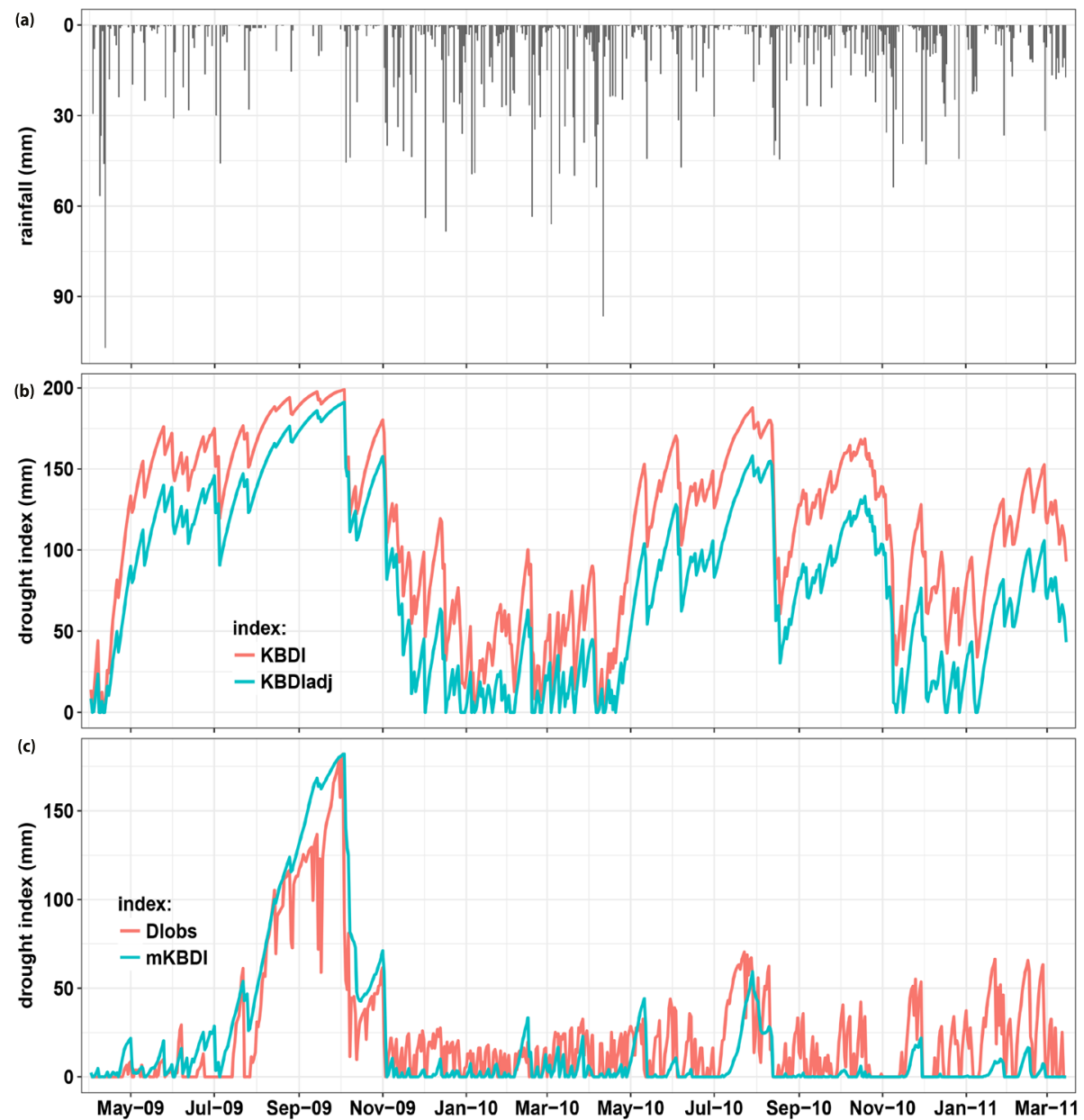

Figure 3.3. Temporal evolution of (a) rainfall during the observation period; (b) KBDI, $K B D I_{\text {adf }}$ and (c) $D I_{\text {obs }}$ and $m K B D I$.

The performance of all three drought indices was also investigated through the frequency distribution of the daily drought index over the four fire hazard classes. We assumed that the frequency distribution of the daily drought index obtained with the mKBDI (Table 3.2) described reality best, because it is closely associated with observed soil moisture contents of the topsoil. More than $90 \%$ of the daily mKBDI values were in the low fire hazard class and less than 5\% in the most severe classes (high and extreme fire hazard). In 2010 and 2011, the mKBDI was all the time in the low hazard class. Furthermore, most of the daily $\mathrm{KBDI}_{\text {adj }}$ were in the low fire hazard class $(64 \%)$, which seems to point at improvement of the original model by integrating local climate information. The KBDI ${ }_{\text {adj }}$ had not more than $11 \%$ of the days in the most severe fire hazard classes, whereas the original model still had $30 \%$ in this category. The KBDI adj overestimated the number of days with severe fire hazard by a factor two and it was more than 7 times higher with the KBDI relative to the mKBDI. 
Table 3.2. Frequency of drought indices (in \% of the days) for each fire hazard class, period 20092011.

\begin{tabular}{|c|c|c|c|c|}
\hline Range of KBDI & Fire hazard class & KBDI & KBDI $_{\text {adj }}$ & mKBDI \\
\hline $0-100$ & Low & 37 & 64 & 92 \\
\hline $101-150$ & Moderate & 33 & 26 & 4 \\
\hline $151-175$ & High & 18 & 6 & 3 \\
\hline$>175$ & Extreme & 12 & 4 & 1 \\
\hline
\end{tabular}

\subsection{Discussion}

This study was carried out in a forest plantation area situated in a humid tropical wetland ecosystem, Indonesia. Daily hydrometeorological data, including air temperature, rainfall, soil moisture and water table were analysed to develop the mKBDI. We will discuss the adjusted drought factor and the newly-proposed water table factor.

\subsubsection{Influence of drought factor}

It has been shown that the behaviour of the KBDI and $\mathrm{KBDI}_{\text {adj }}$ is mostly controlled by weather, which caused a too flashy nature. In the original model, the daily increase of the drought index is caused by the drought factor (Eq. 3.2), which is controlled by the daily maximum temperature and the drought index of the previous day.

Under wet conditions (KBDI $\approx 0 \mathrm{~mm}$ ) the drought factor DF of the original model is more sensitive to the maximum temperature than the adjusted KBDI. The DF of the adjusted model is about $40 \%$ lower than of the original model for the full range of $\mathrm{T}_{\max }$ (Figure 3.4a). When the soil becomes drier (KBDI $\approx 100 \mathrm{~mm}$ ) the DF obviously becomes lower, but the sensitivity is about the same. The higher DF of the original model will result by the onset of a drought (e.g. April 2009) in a faster increase of the KBDI (Figure 3.3b) than that of the adjusted model. After a while the larger increase of the KBDI counteracts, because the drought index of the previous day $\left(\mathrm{KBDI}^{\mathrm{t}-1}\right)$ reduces the growth of the DF. A more or less stable situation develops with a higher KBDI than $\mathrm{KBDI}_{\text {adj }}$ and a DF of the KBDI and the $\mathrm{KBDI}_{\mathrm{adj}}$ which are about similar (Figure 3.5a).

Adjustment of the DF seems to be a plausible solution given the drawbacks as reported by Petros et al. (2011). Liu et al. (2010) also indicated that adjustment to local climate is necessary to apply the index to regions with another climate than Florida. In this study, the high daily evapotranspiration from tropical lowland rainforests (Tani et al. 2003; Kumagai et al. 2005) and the average annual rainfall (Salafsky 1994; Walsh 1996; Chappel et al. 2009; Suhaila and Jemain 2011) reported for the Southeast Asia region were implemented into the drought factor (Eq. 3.5). Our findings indicate that adjustment of DF with the local climate slightly improves performance of the drought index $\left(\mathrm{KBDI}_{\mathrm{adj}}\right.$ Vs. KBDI). Although the $D F_{\text {adj(Ro,ET) }}$ is smaller than the $D F^{t}$ (Eq. 3.2) for the same $T_{\text {max }}$ (Figure 3.4a), the interplay between the DF and the drought index of the previous day (Eq. 3.2 and 3.5) prevents development of large differences between the drought indices. Hence, the adjusted KBDI still hardly represents actual upper soil conditions, particularly during longer dry spells, as for instance mid-June 2009 (Figure 3.3b). Snyder et al. (2006) confirm that although they improved the drought factor by introducing the Hargreaves-Samani approach to compute evapotranspiration, the $\mathrm{KBDI}_{\text {adj }}$ does not perform well for fire hazard assessment. Thus, these findings provide evidence that improvement of the fire drought index by solely integrating climate information is not sufficient. 
(a) drought factor

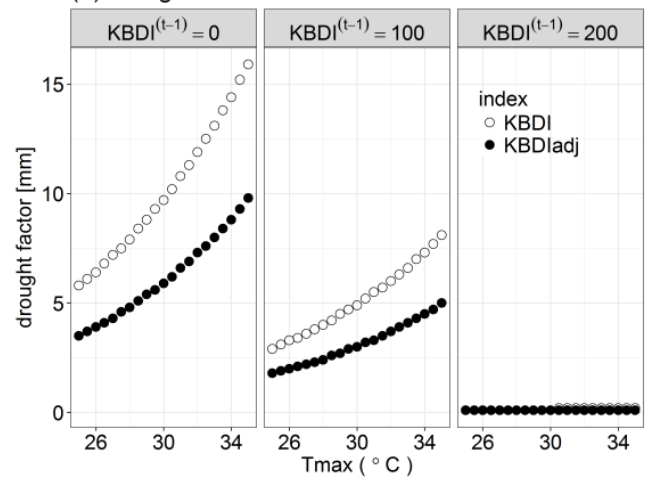

(b) water table factor

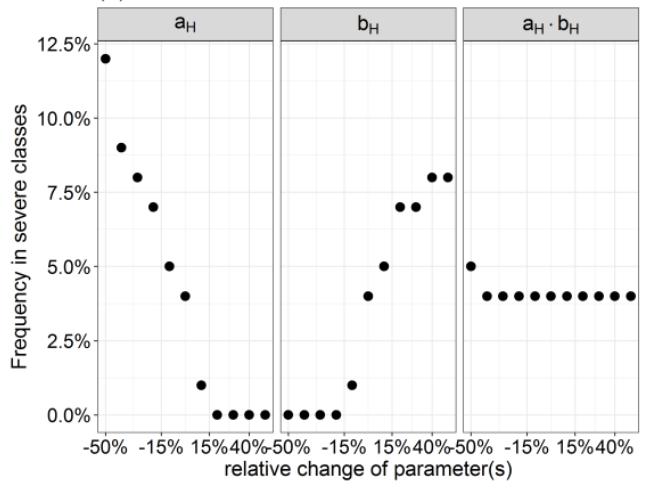

Figure 3.4. Sensitivity of (a) the drought factor, and (b) the water table factor. Graph a) provides the influence of the maximum temperature $\left(T_{\max }\right)$ and the drought index of the previous day $\left(K B D I^{-1}\right)$ on the drought factor DF for the original model and the adjusted model. Graph b) gives the change in the frequency of mKBDI occurring in the most severe fire hazard classes (high and extreme hazard) in response to changes in the parameters of the water table factor ( $a_{H}$ and $b_{H}$ single variable sensitivity; $a_{H} b_{H}$ bivariate sensitivity) throughout the study period.

\subsubsection{Influence of water table factor}

Most of the time the water table factor WTF varied between 4 and $9 \mathrm{~mm}$ (Figure 3.5c), which more or less compensated for a possible increase of the modified drought index (mKBDI) through the drought factor (Figure 3.5b). The WTF only decreased during a drought (e.g. July-October 2009 and July 2010). During the drier period of July 2010,

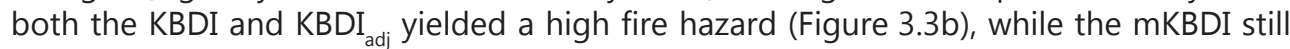
predicted low hazard. The shallow water table still supplied sufficient water into the upper layer, as shown by the high soil water content (Figure 3.2c). Clearly, the pattern of water table factor reflects water table depth. The deeper the water table is, the smaller the WTF (Figure 3.6).

Surprisingly, by integrating the water table factor into the model structure (Eq. 3.9), the behaviour of the drought factor drastically changed with respect to the adjusted model (Figure 3.5a), although Eq. 3.5 was used for both. A shallow water table leads to a higher drought factor, as happened in the period April-June 2009 (Figure 3.5a). In the model structure for the KBDI and the $\mathrm{KBDI}_{\text {adj }}$ the behaviour of the drought factor is only controlled by the increase of the drought index $\left(\mathrm{KBDI}^{\mathrm{t}-1}\right)$, whereas in the modified model structure (mKBDI), the water table factor cancels out the drought factor (Eq. 3.9). The different magnitudes of the DF for the KBDI ${ }_{\text {adj }}$ (rather low DF) and the mKBDI (rather high DF) clearly show up during a dry period, but still with shallow water tables (e.g. JulySeptember 2009). Eventually, both DFs become small when a drought proceeds and the water table drops (e.g. October 2009).

Our findings show that the position of the water table depth greatly determines the magnitude of the drought index, mKBDI. In dry seasons, deep water table depths will correspond to higher drought indexes. In 2010 and 2011, when the water table depth was close to the soil surface, clearly a low fire hazard class was found. The WTF also provides very relevant information about the critical water depth, below which the combined upward soil water flow and root water uptake (Sánchez-Pérez et al. 2008; Lowry and Loheide 2010) do not contribute anymore to moistening of the fuel layer. In this case it is $0.85 \mathrm{~m}$ below the soil surface (Figure 3.6). 

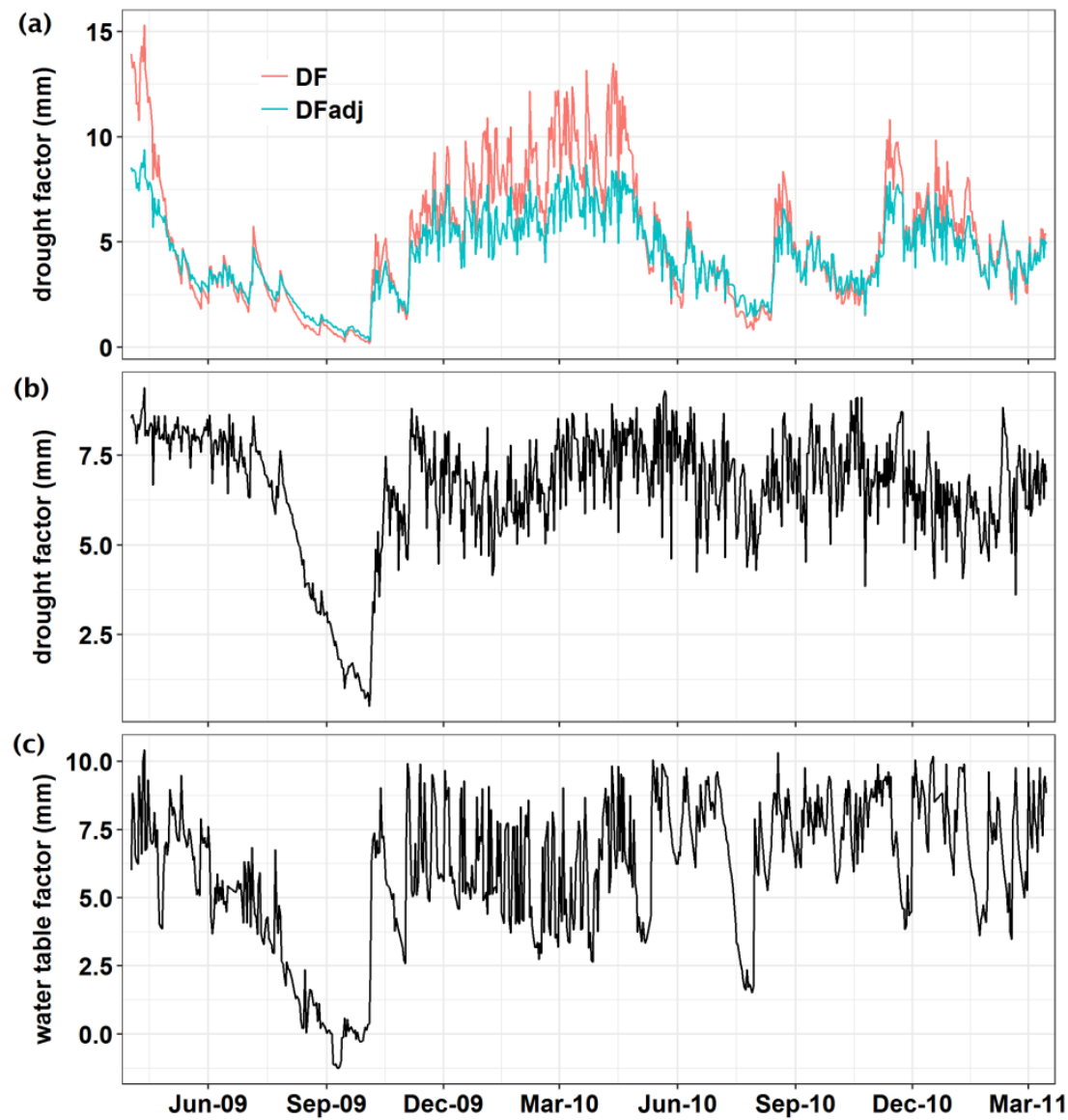

Figure 3.5. Temporal evolution of: a) the drought factor for KBD/ and KBDI ${ }_{\text {od/ }}^{\prime}$ b) drought factor for $m K B D l$, and c) water table factor.

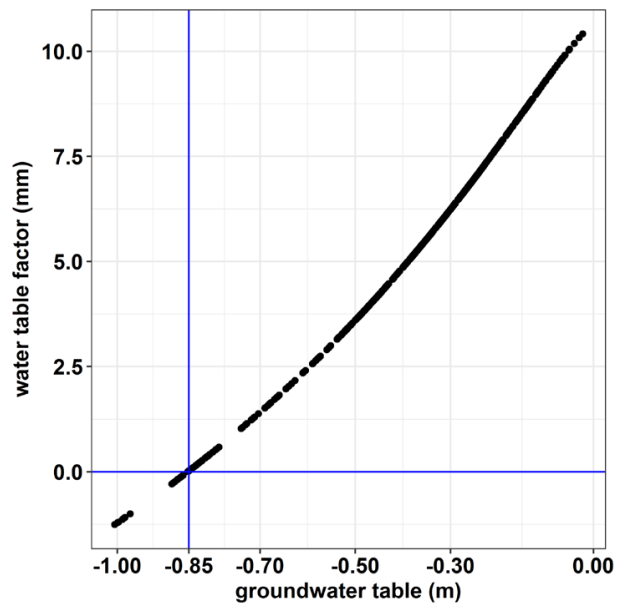

Figure 3.6. Relationship between groundwater table depth and water table factor. Intersection curve to $X$-axis indicates the critical groundwater table depth. 
This study addressed the weaknesses of the original KBDI when applied to areas with different soil and hydrology conditions than Florida, as indicated by Reardon et al. (2009). Our findings confirm that the performance of the drought index will improve by integrating soil characteristics, as suggested by Pellizzaro et al. (2007).

The sensitivity of the WTF parameters and was investigated, because no previous results were available yet. As reference, we used frequency of occurrence of the mKBDI in the severe fire hazard classes (high and extreme hazard), i.e. 4\% (Table 3.2). The parameters $a_{H}$ and $b_{H}$ were separately and jointly changed from $-50 \%$ to $+50 \%$ with steps of $10 \%$ (Figure $3.4 \mathrm{~b}$ ). For instance, if the value was reduced by $50 \%$, the site would experience more days in the severe fire hazard class (12\%). There is negative correlation between and the frequency of occurrence of the mKBDI in the severe fire hazard class. A larger implies a smaller WTF (Eq. 3.8) and hence a faster increase of the mKBDI. The parameter has a positive correlation with the frequency of occurrence of the mKBDI in the severe fire hazard class. A larger results into a higher WTF and consequently the frequency of occurrence of the mKBDI in the severe fire hazard class decreases. If both parameters were jointly changed (Figure 3.4b, right panel), the frequency of occurrence of the mKBDI in the severe fire hazard class hardly changes, which is obvious because of negative correlation of with WTF and the positive correlation of (Eq. 3.8).

\subsubsection{Applicability}

Application of the mKBDI rather than the original KBDI to assess fire hazard in tropical wetland ecosystems is promising. This model requires daily data of rainfall, air temperature, and water table depth. Daily rainfall and temperature are often monitored on a routine basis. Water table depths are mostly not routinely measured, although the installation of an observation well and the daily observation with a dipper is reasonably simple. In forest plantations located in wetland ecosystem, knowledge of groundwater table depth that is dynamically connected with water levels in the canal systems is of great importance, because it influences field operations, logistics and navigation in the area. Additionally, carbon releases associated with man-made wetland ecosystems also urge consideration of groundwater table depth, because it greatly influences carbon emission (Hooijer et al. 2010; Fan and Miguez-Macho 2011). Moreover, incorporating groundwater dynamics in land-climate model also emerges (Lam et al. 2011; Leung et al. 2011), which consequently need observed data for model calibration. Thus, it is anticipated groundwater table data will be more routinely measured in the near future.

A challenge is to obtain the water table factor parameters, i.e. $a_{H}$ and $b_{H}$ (Eq. 3.11), which were proposed in this study. This requires additional information on soil properties (e.g. soil texture, organic matter content) and time series of daily soil water content for a period that contains one or more dry periods. The parameters should be connected to soil properties and the water table regime. So far, it is unknown to what extent both parameters are transferable. We anticipate that for a limited number of locations in tropical wetland systems that differ in soil and hydrological conditions, the parameters need to be calibrated, as done in this study. In the next phase, pedotransfer functions (Bouma and Van Lanen 1987; Wösten et al. 1995) can be used that translate easy to obtain at-site information on soil and groundwater table regime into the two water table factor parameters. The sensitivity analysis of and has shown that uncertainties up to $50 \%$ in these parameters generate a frequency of occurrence of the mKBDI in the severe fire hazard class, which are more realistic than using the original Keetch-Byram Drought Index that does not consider soil and hydrological information. 
The parameters of the water table factor also provide extremely important information about the critical depth below which the groundwater table does not supply soil water to the top-layer ( $0.85 \mathrm{~m}$ in our study) and hence fire hazard significantly increases. Being able to determine the groundwater table depth that helps to reduce fire hazard levels supports stakeholders, for example forest estate managers, to improve management of their land and water. In the value-chain to action (Van Noordwijk et al. 2014) it is identified as helping to develop their understanding regarding what is behind the hazard and it provides a simple and easy to observe metric to assess fire hazard. It can lead to action to be more alert; in particular with unintentional fire initiation. Large-scale water table depth monitoring could lead to a higher alert phase for emergency services (e.g. fire department). Too frequent water tables below the critical water table could be an incentive for policy makers to steer towards another land use (e.g. rewetting, afforestation) in the peatlands of Indonesia. 


\section{Chapter 4 \\ Fire hazard in human-modified wetlands}

Vast areas of wetlands in Southeast Asia are undergoing a transformation process to human-modified ecosystems. Expansion of agricultural cropland and forest plantations changes the landscape of wetlands there. Here we present observation-based modeling findings that contribute to the evidence of increased fire hazard due to canalization in tropical wetland ecosystems. Two wetland conditions were tested, namely natural drainage and canal drainage, using a hydrological model and a well-known drought-fire index. Our results show that canalization has amplified fire susceptibility at least by four times. Canal drainage triggers the fire season to start earlier than under natural wetland conditions, indicating that the canal water level regime is a key variable controlling fire hazard. Furthermore, the findings derived from the modeling experiment have practical relevance for public and private sectors, as well as for water managers and policy makers, who deal with canalization of tropical wetlands, and suggest that improved water management can reduce fire susceptibility.

This chapter is based on: Taufik, M., B. I. Setiawan, and H. A. J. Van Lanen. 2017. Increased fire hazard in humanmodified wetlands in Southeast Asia. AMBIO, in review 


\subsection{Introduction}

Tropical wetland ecosystems typically have shallow groundwater tables throughout the year that support a wealth of endemic species because of their anaerobic, and frequently extreme acidic and nutrient poor conditions (Yule 2008; Evers et al. 2017). Recent literature explains that tropical wetlands in Southeast Asia, including peat swamps, are biodiversity hotspots (Kier et al. 2005; Yule 2008; Sodhi et al. 2010; Evers et al. 2017) both for endemic flora and fauna. Additionally, these ecosystems store huge amounts of carbon (Page et al. 2011), especially in belowground biomass, which potentially alters global climate when changed.

Recent human activities in Southeast Asian tropical wetland ecosystems are increasingly changing the landscape from natural forest into export-oriented agricultural cropland and forestry. In many cases, these changes can be attributed to clearance of natural forest. Land-use change (LUC) in the last two decades has reduced wetland forest cover by $36 \%$ in Indonesia and Malaysia (Miettinen et al. 2012). This reduction included various measures to create favorable conditions for agronomy and forestry practices in wetlands, among others drainage through canalization. Canalization is common practice to drain excessive water, making wetland suitable for agriculture and forestry purposes. By draining water, the groundwater table depth declines (Hirano et al. 2012; Ishii et al. 2016), depending on the water level in the canal and subsurface characteristics.

Furthermore, climate variability mainly induced by El Niño has increased the pressure on the often drier wetland ecosystems. The extent and severity of wildfires has increased during El Niño events (Wooster et al. 2012; Taufik et al. 2017). During El Niño, prolonged low precipitation led to lower groundwater tables in wetland ecosystems, which created a drier environment that favors extensive fires to burn in disturbed tropical forests. More than 2.6 million hectares of crops and forests were burnt by the 2015 fires (Tacconi 2016), the second worst fires of the past two decades in Southeast Asia. Studies reported that fire susceptibility increased in human-modified wetlands with canalization (Hoscilo et al. 2011; Konecny et al. 2016).

Although there has been growing interest in wetland ecosystem studies, fire-drought research that integrates groundwater as a key variable for fire hazard in wetlands is limited. Current research mostly uses soil moisture deficiency derived from only climate information, such as the Keetch-Byram Drought Index-KBDI (Petros et al. 2011) and the Fire Weather Index-FWI (Amiro et al. 2005), as a proxy for flammability. In wetlands, however, groundwater tables greatly influence soil moisture dynamics, hence the fire hazard (Wösten et al. 2008; Taufik et al. 2015; Takeuchi et al. 2016; Taufik et al. 2017). Obviously, the closer the groundwater table to the surface, the lower the fire hazard is, as reported by Wösten et al. (2008) and Takeuchi et al. (2016). The position of the groundwater table varies in response to wet and dry spells. Occasionally, the groundwater table substantially declines during a prolonged drought, which coincides with strong El Niño events (e.g. 1997/1998 and 2015). As expansion of land for product-oriented export (oil palm, fiber) takes place, humans now also play a key role in groundwater dynamics in wetland ecosystems through building canal networks (Ritzema et al. 2014). This requires research that explores the interplay of humans and fires occurring in the changing landscapes of tropical wetland ecosystems. The question remains how to quantify the impact of human interference on increased fire hazard and how large the amplification of fire hazard caused by human interference actually is? 


\subsection{Materials and methods}

\subsubsection{Original model}

Our study area is a wetland ecosystem in South Sumatra, Indonesia, within the evergreen humid climate zone, that generally experiences some water shortage during the dry season. The area receives a mean precipitation of $2540 \mathrm{~mm}$ annually and $1700 \mathrm{~mm}$ during the wet season. The peak dry season occurs from August to September, when the median monthly rainfall is below $100 \mathrm{~mm}$. The study region was burnt during the 1997/1998 El Niño due to wildfires. In the late 2000s, the region has been planted with a fast-growing monoculture forest plantation (i.e. Acacia crassicarpa). To create favorable conditions for root development, water and nutrient uptake, excessive water in the wetlands is drained through canalization. Additionally, the canals are of importance for transportation, logging, and logistics.

The area is characterized by mineral soils, which mainly consist of silty clay, and sand at very few places. In the study site of Baung (105.3 $3^{\circ}$ East and $2.74^{\circ}$ South), we built a mini-AWS (automatic weather station) to monitor daily weather (rainfall and air temperature) and soil moisture. Groundwater tables were monitored every hour with a pressure transducer (TD Diver, Van Essen Instruments). For details on the area, monitoring and soil characteristics, readers are referred to Taufik et al. (2015). The data monitoring at the site lasted for two years, covering two contrasting ENSO conditions, that is, in 2009 (El Niño, dry) and in 2010 (La Niña, wet).

\subsubsection{SWAP model and data}

SWAP (Soil Water Atmosphere Plant) is a one-dimensional, vertically oriented model to simulate transport of water, solutes and heat in the vadose zone in interaction with vegetation development and subsurface hydrology (Kroes et al. 2008). Its model domain covers the zone between the groundwater table and the soil surface on which vegetation can grow and water ponding may occur. Water balance components and groundwater levels are simulated by numerically solving soil moisture flow using the Richards equation (Van Dam and Feddes 2000). The top boundary condition of SWAP consists of precipitation and evapotranspiration, which is driven by weather and the interplay between weather, vegetation and soil conditions. As a lower boundary condition, among others, different drainage conditions can be included in the SWAP model. For example, natural drainage or human-modified drainage systems can be implemented in the model through the lateral drainage option.

To simulate groundwater levels, SWAP requires various inputs. It needs daily weather data (e.g. precipitation, reference evapotranspiration). Daily weather data from the Baung weather station was used for the model calibration in addition to soil hydraulic properties, groundwater levels, and water levels in the canal. With this weather data, we calculated reference evapotranspiration based on the Penman-Monteith FAO method (Allen et al. 1998). SWAP simulates actual daily soil evaporation and transpiration by combining reference evapotranspiration with information on vegetation development stage, crop coefficient, soil/vegetation cover and soil moisture. We used a crop coefficient of 1.05 for the wetland conditions, which is about the median of the range in the coefficient previously reported (Allen et al. 1998; Sun et al. 2011). Further, we assumed no change in vegetation development stage of the mature monoculture forestry, i.e. we applied a constant soil cover fraction of $80 \%$ by the acacia canopy.

For the lower boundary condition, we assumed that there is no relevant subsurface flow in the deep aquifer. The drainage system controls via the shallow aquifer (saturated flow), 
the interaction between soil water in the vertical column and surface water (canal). Two types of drainage system were defined, i.e. natural drainage and human-modified drainage through wetland canalization. The canalization creates deep open channels in wetlands that reach depths up to $6 \mathrm{~m}$ depending on operational purposes, such as water transport and water management. During the wet season, the canal water level is close to the surface, whereas it may substantially decline during the dry season. In the study site, controlled drainage is applied through canal blocking (e.g. Ritzema et al. 2014) to ideally maintain groundwater tables in the range of $40 \mathrm{~cm}$ to $90 \mathrm{~cm}$. When we use canalization in this paper, we refer to controlled drainage (i.e. reference situation), unless it is stated clearly otherwise. For natural drainage, we used a surface water depth of 50 and $100 \mathrm{~cm}$ during the wet and dry season, respectively $(130 \mathrm{~cm}$ during the dry season for strong El Niño years), which drives water losses via the natural drainage system that usually can be found in this kind of regions.

\subsubsection{Model calibration}

For the calibration process, we used the available daily weather and groundwater table data from almost 2 years of observations (Taufik et al. 2015), i.e. from 1 April 2009 to 15 March 2011. This observed data is important, as it covers a period with climate extremes. Both the 2009 El Niño and the 2010 La Niña are included. We applied two approaches for assessing model performance. First, we used a visual inspection of its performance. This approach aims to detect model behavior, and to obtain an overview of the overall performance (Bennett et al. 2013). Then we applied five statistical criteria of goodness of fit (see Bennett et al. 2013) including percent bias (pbias), RMSE-observations standard deviation ratio ( $(s)$ ), index agreement (Id) coefficient of correlation ( $r)$, and Kling Gupta Efficiency $(\mathrm{kge})$.

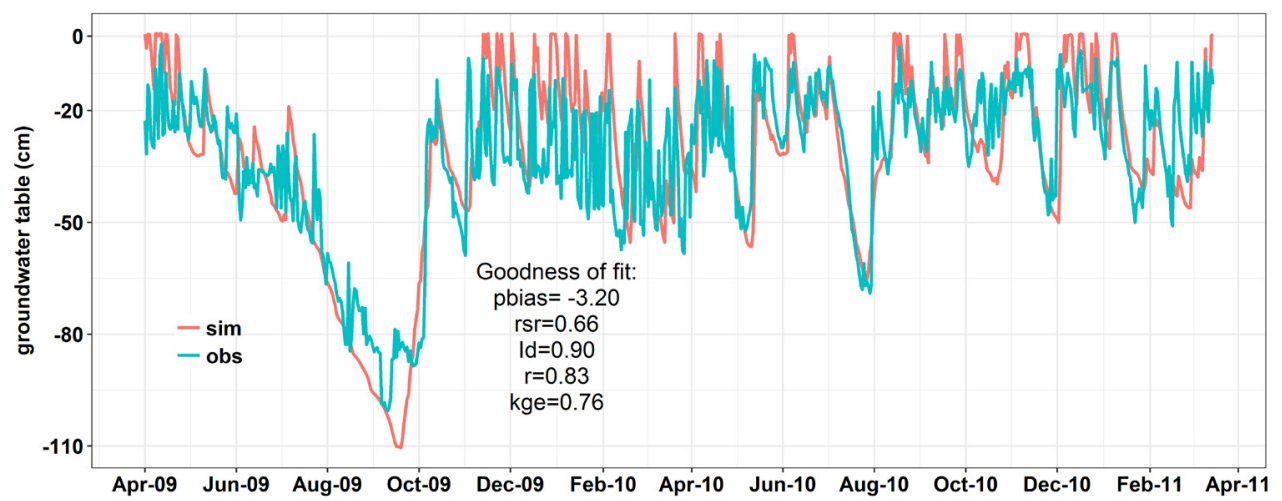

Figure 4.1. Hydrograph of observed (obs) and simulated (sim) groundwater tables with the SWAP model during the calibration period. This graph shows that the model performed well in simulating groundwater table in particular for the dry season, but it slightly overestimates the shallow levels in the wet season, which are controlled by local site conditions. Goodness of fit measures is provided: percent of bias (pbias), RMSE-observations standard deviation ratio (rsr), index of agreement (Id), coefficient of correlation ( $r$ ), and Kling Gupta Efficiency (kge). The smaller the pbias and rsr, the better model performs. On other hand, the model performs well if the Id, $r$, and kge are high.

Our calibration showed that the SWAP model performed reasonably well in simulating groundwater tables (Figure 4.1). The onset of the groundwater table drop and its recovery are well simulated, whereas there is some overestimation of the groundwater table during the La Niña year in 2010. The reasonably well model performance is reflected in the high kge, Id, and r, and low pbias and rsr (Figure 4.1). By means of this calibration, we 
determined the values of the key model input data for SWAP, namely canal water level $(C W L)$ regime and drainage resistance (DR). The CWL should be not deeper than $130 \mathrm{~cm}$ below the surface during the dry season. For the other seasons, we applied a canal water level closer to the surface, namely 50 and $80 \mathrm{~cm}$ below the surface during the wet and intermediate season (May/June), respectively. The calibrated DR was 200 days for the study site. The drainage resistance determines how easy water flows through the groundwater system to the drainage system. The lower the resistance, the easier water flows. The natural situation is characterized by a higher drainage resistance than human-modified drainage, because of the longer distance between natural channels compared to the drainage canals. We anticipated that the drainage resistance is around three times higher (600 days).

\subsubsection{Fire hazard assessment}

We used the modified Keetch-Byram Drought Index (mKBDI) to assess daily fire hazard and the associated fire hazard class (i.e. low, moderate, and high). The fire hazard class follows previous research in Southeast Asia (Ainuddin and Ampun 2008; Taufik et al. 2015). The daily time-step calculation of the mKBDI is as follows (Taufik et al. 2015):

$$
\text { mKBDI }=\operatorname{mKBDI}^{\mathrm{t}-1}+\mathrm{DF}^{\mathrm{t}}-\mathrm{RF}^{\mathrm{t}}-\mathrm{WTF}^{\mathrm{t}}
$$

Here DF is the drought factor, RF is the rainfall factor, and WTF is the water table factor on day t. For details on how to calculate the DF, RF, and WTF for the modified KBDI, readers are referred to Taufik et al. (2015). The mKBDI is scaled from zero to 203 as maximum value (see Chapter 3: Section 3.2). $\mathrm{mKBDI}=0$ is reached during prolonged heavy wet spells, whereas long-lasting hot and dry spells create favorable conditions for mKBDI to reach its maximum value. The groundwater level also affects the fire hazard, i.e. shallow groundwater tables reduce fire hazard through capillary rise. When the groundwater level drops below a critical threshold (e.g. $85 \mathrm{~cm}$ below surface in the study site, Taufik et al. 2015) it does not reduce fire hazard because capillary rise cannot sufficiently feed the topsoil anymore.

Eventually, the probability of daily fire hazard was assessed using weather data from 1980 to 2015 for two drainage conditions, i.e. natural drainage and canal drainage. The SWAP simulation is a modeling experiment that generates groundwater tables using the mature forestry plantation as reference and climate variability as reflected by the daily climate data from 1980 to 2015. The emphasis in this study is to explore the probabilities of groundwater table depths and associated fire hazards for the current state of plantation rather than to reconstruct historic fire hazards also considering the plantation development. The long time series of weather data for simulation of groundwater levels, and hence, the fire hazard was obtained from the nearby climate station Kenten (latitude/longitude are $2.93^{\circ}$ South/ $104.77^{\circ}$ East) in South Sumatra, Indonesia. There is no difference in input data for the calculation of fire hazard (Eq. 4.1) for the two scenarios, except for the water table factor. WTF was computed using different simulated groundwater table series based on the two scenarios used in this study, i.e. natural and canal drainage. Then, one of the three fire hazards classes was assigned to each day, namely low, moderate or high fire hazard.

\subsubsection{Verification of fire hazard}

To test the performance of the mKBDI, we used monthly fire area burnt derived from the Global Fire Emission Dataset-GFED (Giglio et al. 2013). The GFED is at $0.25^{\circ}$ resolution, which is available from 1996 onward. The drought index (i.e. mKBDI) reflects dryness over 
a large area and not specifically the Baung station site. Therefore we used nine GFED grid cells (total area: $6971 \mathrm{~km}^{2}$ ) surrounding the site for verification. We verified performance of mKBDI (mean monthly) for the canal drainage situation in 1996-2015, as this represented the climate situation that actually occurred. The canalization in the region started well before our fire hazard verification period, i.e. in the 1990s. Totally there are 240 data points, that is, months for verification.

\subsection{Results}

\subsubsection{Simulated groundwater tables}

Deep groundwater levels hardly occur under natural drainage. Only about $1.9 \%$ of the time the simulated daily water table is deeper than the critical threshold (i.e. $0.85 \mathrm{~m}$ ), whereas this is about 34\% of the time under canal drainage (Figure 4.2). Furthermore, the SWAP simulations also show that ponding is normal for wetland ecosystems under natural drainage, whereas the ponding period becomes substantially shorter under canal drainage (eight times shorter). Ponding in excess of $0.10 \mathrm{~m}$ depth does not occur under canal drainage at the investigated site.

On a monthly scale, the groundwater level is always below the surface during the period August-October under natural drainage. In this period, the minimum groundwater level occasionally reaches the critical threshold (-0.85 m, Figure 4.2). On the other hand, canal drainage causes lower groundwater levels below the surface throughout the whole year. Groundwater gradually starts to decline in May, and will reach its deepest levels in October. In the period July-October, the median groundwater level is below the critical threshold and in November it is still very close. This is clear evidence that canalization prolongs periods with low groundwater, hence it increases dry conditions that favour fire.

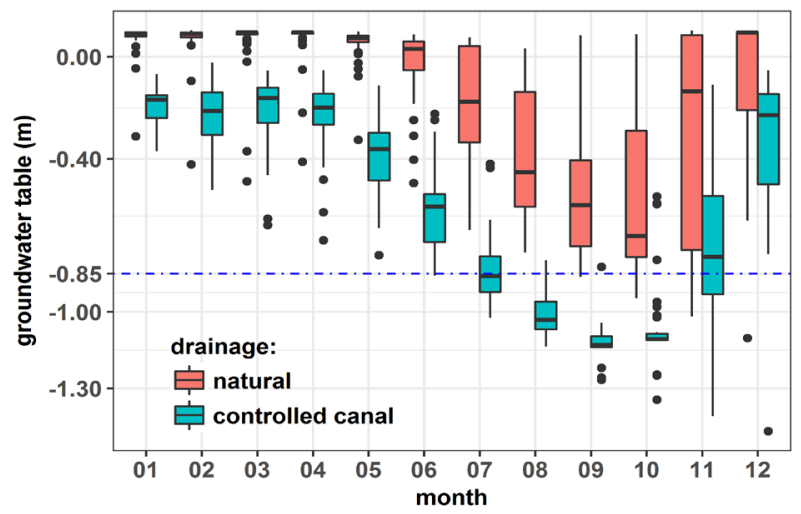

Figure 4.2. Monthly groundwater tables for two drainage conditions during 1980-2015. The boxplot indicates the median, and the $25 \%$ and $75 \%$ quantiles. The dots indicate outliers.

\subsubsection{Verification of fire hazard}

Our analysis showed that fire events (expressed as area burnt) were reported for all three fire hazard classes derived from the mKBDI (Table 4.1). Totally 172 out of 240 months were assigned to the low hazard class, 23 months were in the moderate class, and the remaining (45) were categorized as having a high probability of fire. Of the 172 months that were reported to have a low level, 68\% (117) of the months had zero burnt area, whereas only one month had an area burnt larger than 5000 ha (Table 4.1). On the other hand, months with high fire hazard probability were characterized by large area burnt (>5000 ha, 22 months). 
Table 4.1. The size distribution of observed monthly area burnt (total of nine grid cells, in ha) for the three different predicted fire hazard classes, 1996-2015. The class is derived from the mKBDI under canal drainage.

\begin{tabular}{|l|c|c|c|c|c|}
\hline \multirow{2}{*}{$\begin{array}{l}\text { Predicted Hazard } \\
\text { class }\end{array}$} & \multicolumn{5}{|c|}{ Observed area burnt (ha) } \\
\cline { 2 - 6 } & 0 & $0-100$ & $100-5000$ & $>5000$ & Total \\
\hline Low & 117 & 22 & 32 & 1 & 172 \\
\hline Moderate & 6 & 2 & 15 & 0 & 23 \\
\hline High & 7 & 3 & 13 & 22 & 45 \\
\hline
\end{tabular}

Few small areas burnt ( $<100$ ha, 3 months) were reported when the mKBDI of a certain month is in the high class. For the moderate probability on fire, most of the months had an area burnt of 100-5000 ha. This verification demonstrates that mKBDI is able to classify fire events in three different hazard levels based on the size of area burnt. In summary, the mKBDI is useful to identify large area burnt that is characterized by the high fire class.

\subsubsection{Fire hazard behaviour}

Wetland ecosystems store huge volumes of water in their soils because of the high rainfall both monthly and annually, and the restricted drainage under natural conditions creates an environment that is little prone to fire. Mostly (about $90 \%$ of the time) fire hazard under natural drainage is at a low level at the investigated site, and $3.8 \%$ of the time at a high level, which obviously is during a prolonged dry season (Table 4.2). With drainage by canalization, low fire hazard level conditions drop to $72.2 \%$ of the time. Canalization causes lower groundwater levels during the dry season, leading to an increased presence of the high fire hazard level from $3.8 \%$ under natural drainage to $17.1 \%$ of the time. Clearly, there is an amplification of fire susceptibility by 4.5 times when wetland forest is drained.

Table 4.2. Fire hazard (\% of time) using weather data from 1980-2015. Two different types of climatic years are introduced: normal and El Niño years. Fire hazard is clustered in three classes.

\begin{tabular}{|l|c|c|c|c|c|c|}
\hline \multirow{2}{*}{ Hazard class } & \multicolumn{5}{|c|}{ Drainage conditions } \\
\cline { 2 - 7 } & \multicolumn{4}{|c|}{ Natural } & \multicolumn{3}{c|}{ Controlled canal } \\
\cline { 2 - 7 } & Normal & El Niño & Total & Normal & El Niño & Total \\
\hline Low & 61.2 & 28.9 & 90.1 & 49.1 & 23.1 & 72.2 \\
\hline Moderate & 2.1 & 4.0 & 6.0 & 7.0 & 3.7 & 10.7 \\
\hline High & 0.6 & 3.2 & 3.8 & 7.9 & 9.2 & 17.1 \\
\hline
\end{tabular}

Hardly any high fire hazard is reported for normal years and natural drainage conditions $(0.6 \%)$, whereas this is $7.9 \%$ of the time under canal drainage (Table 4.2$)$. Most high fire hazard conditions under controlled canal drainage events (9.2\%) coincide with El Niño. This provides evidence that drainage strongly influences fire hazard, and that El Niño intensifies this hazard.

Fire behavior is strongly controlled by groundwater level. As anticipated, we found a strong correlation of the groundwater level and KBDI with $r=-0.85$ and -0.88 for natural and canal drainage, respectively. Other variables, such as daily rainfall, were only weakly correlated to fire hazard level (not shown). This correlation means that during prolonged periods with low groundwater levels, high fire level is expected to occur. 
Under natural conditions, monthly averaged groundwater levels decline during the period July-October, but they rarely exceed the critical threshold (Figure 4.2, natural). This little drawdown hardly creates conditions that favor high fire hazard. Totally only $3.8 \%$ (503 days ) of the days are in the high fire hazard class (Table 4.2) that occurs only in 11 out of 36 years. The remaining years have predominantly a low fire hazard level. During warm ENSO years the fire susceptibility increases more than five-fold ( $3.2 \%$ versus $0.6 \%$ ). Table 4.3 provides the distribution of the average number of days with a high fire hazard level for each month (15-94\% of days, dependent on the month) in those years when fires occur (3-31\% of the years). If we exclude August and December, because of the low number of years when fires occur in these months $(<10 \%)$, the fraction of days with a high fire hazard level is $40-64 \%$ in the years with fires (22-31\%, Table 4.3). High fire hazard level in December occurred only in 1 year (3\%) during the very strong 2015 El Niño; almost the entire month (94\%) was at a high fire hazard level.

Table 4.3. Distribution of high fire risk days (average number of days per month, in \%) over the months, and the number of years (\%) that high fire risk happens for two drainage conditions using weather data from 1980-2015.

\begin{tabular}{|c|c|c|c|c|}
\hline \multirow{2}{*}{ Month } & \multicolumn{4}{|c|}{ Drainage conditions } \\
\cline { 2 - 5 } & $\begin{array}{c}\text { Natural } \\
\text { high fire level } \\
\text { days (\%) }\end{array}$ & $\begin{array}{c}\text { number of } \\
\text { years (\%) }\end{array}$ & $\begin{array}{c}\text { high fire level } \\
\text { days (\%) }\end{array}$ & $\begin{array}{c}\text { number of } \\
\text { years (\%) }\end{array}$ \\
\hline June & - & - & 3 & 3 \\
\hline July & - & - & 41 & 25 \\
\hline August & 15 & 8 & 66 & 64 \\
\hline September & 40 & 25 & 73 & 89 \\
\hline October & 64 & 31 & 71 & 83 \\
\hline November & 56 & 22 & 70 & 36 \\
\hline December & 94 & 3 & 55 & 6 \\
\hline
\end{tabular}

Canalization, however, leads to low groundwater levels during the dry season, which can go well below the critical threshold (Figure 4.2, controlled canal). About $33 \%$ of the time the groundwater level is below the threshold, which leads to an increased frequency of days with a high fire hazard level (Table 4.2). High fire hazard level is nearly recorded annually (32 out of 36 years) in the period 1980-2015. This implies that about $88 \%$ of the years are at a high hazard level, which is about 2.4 times higher than under natural drainage conditions. Seasonally, high fire hazard levels frequently occur during the period July-November, but occasionally they also occur in June and December (Table 4.3). The mean number of high fire hazard level days in the period August-October under canal drainage conditions is 21.4 days per month (66-73\% of the days) for those years that fires occur. Moreover, under canalization, the fire season comes at least one month earlier, starting in July (June not considered because of the low number of years), whereas the fire season under natural drainage conditions starts in August (Table 4.3). This is evidence that canalization lengthens the period with a high fire hazard level in addition to the substantially larger number of fire years.

\subsection{Discussion and conclusions}

This research contributes to the emerging literature that attempts to quantify the interplay of humans on hydrological processes in tropical forest wetlands, including fire 
hazard, using an observation-based modeling experiment. We applied the SWAP model, which showed reasonable agreement with 2 year of observations, to simulate time series of daily groundwater tables for a wetland ecosystem in South Sumatra with input of 36 years of daily weather data. Two wetland drainage conditions were introduced for the SWAP simulation, i.e. natural and canal drainage conditions for a mature acacia plantation. Of the two wetland drainage types tested, canal drainage generates longer periods with low groundwater levels (Figure 4.2, controlled canal). Next, we calculated the daily modified KBDI using the simulated water tables to assess daily fire hazard for each drainage condition. Our verification of the simulated fire hazard level by using 20 years of observed monthly area burnt revealed that fire may occur on each day irrespective of the estimated fire hazard level, but a large area burnt ( $>5000 \mathrm{ha}$ ) clearly occurs only when the fire hazard level is high, and the opposite, no or a small area burnt occurs when the fire hazard level is low.

Hydrological studies in tropical wetlands found very low groundwater levels during the dry season due to canalization, for instance, in the ex-Mega Rice Project, Central Kalimantan, Indonesia. This is consistent with our substantial difference (between natural and canal drainage) in number of days with groundwater levels below the critical threshold (i.e. 24\%). Prolonged low groundwater levels create conditions that favor wildfire. For a peat-swamp forest in Kalimantan, Wösten et al. (2008) show that the probability of high fire hazard increases when the groundwater level drops below $40 \mathrm{~cm}$. Other studies under similar hydroclimatological conditions used a groundwater table depth of $100 \mathrm{~cm}$ as critical threshold for fire (Wösten et al. 2006; Takeuchi et al. 2016). Here, we apply $85 \mathrm{~cm}$ as critical groundwater level (See Section 4.2.4) for identifying high fire hazard. Clearly, the critical groundwater depth is not constant for all wet tropical ecosystems, but depends among others on soil properties (Taufik et al. 2015).

Although there is substantial understanding on how low precipitation enhances fire hazard, our results highlight the fact that efforts to understand fire hazard without examining the role of groundwater table depth miss a critical contributor to fire hazard in wetland ecosystems (Wösten et al. 2006; Wösten et al. 2008; Takeuchi et al. 2016; Taufik et al. 2017). Our finding supports this claim by the following: (i) drainage conditions clearly affect fire hazard given the same rainfall input, i.e. canal drainage has lower groundwater levels, and hence higher fire hazard than natural drainage, and (ii) controlled drainage through canal blocking causes high fire hazard to come at least one month earlier. This outcome confirms a recent study, which reported increased fire susceptibility in drained wetlands (Konecny et al. 2016).

Our findings show that there is substantial amplification of fire hazard when natural forest is drained for agronomy. First, the frequency of high fire levels increases by 4.5 times (Table 4.2). The increase means that fire susceptibility under drained conditions is higher, and occurs in the dry season for 9 out of 10 years. In addition, the number of days experiencing high fire hazard levels has risen by $70 \%$ in the period August-October (Table 4.3). The number of years having a high fire hazard level rose 3.6 times. Further, our modeling experiment reveals that drainage lengthens the period with high fire hazard level through an earlier start of the fire season. The amplification applies for controlled drainage conditions, therefore the question remains how large the amplification will be in case of uncontrolled drainage in this type of ecosystem.

Our modeling experiment shows that, if the drainage is uncontrolled (with canal water levels reaching $3 \mathrm{~m}$ depth during the dry season), prolonged low groundwater tables 
are inevitable. Hence, days with high fire hazard will increase substantially, from $17 \%$ (controlled drainage) to almost $40 \%$ (Figure 4.3). In other words, without improved water management, the expected frequency of high fire hazard levels will be more than twice as high (relative to the reference), and will occur each year. The very low groundwater levels likely will influence the endemic flora and fauna (Kier et al. 2005; Yule 2008; Sodhi et al. 2010) that can only survive under un-impacted hydrological conditions (Evers et al. 2017). A lot of effort has been proposed to restore degraded wetland, including canal blocking (Ritzema et al. 2014; Ishii et al. 2016), with the purpose to maintain groundwater levels as close as possible to natural conditions. Improved water management is anticipated to provide an adequate basis for endemic biodiversity and additionally to control wildland fires. However, maintaining groundwater levels as high as possible needs to be negotiated with the agronomy sector, because it likely has detrimental effects. The application of the proposed analysis tools (SWAP and $\mathrm{mKBDI}$ ) provides guidance for best practice water management, including a critical canal water level during the dry season to avoid a substantial increase of days with a high fire hazard. The canal water levels should be kept as high as possible during the dry and intermediate season to avoid high fire hazard levels. For instance, if the levels are not allowed to go deeper than $150 \mathrm{~cm}$ below the surface during the peak dry season (August-October), the expected occurrence frequency of high fire hazard levels would be kept below $20 \%$, which might be an acceptable compromise, although it is still 6 times larger than under natural conditions.

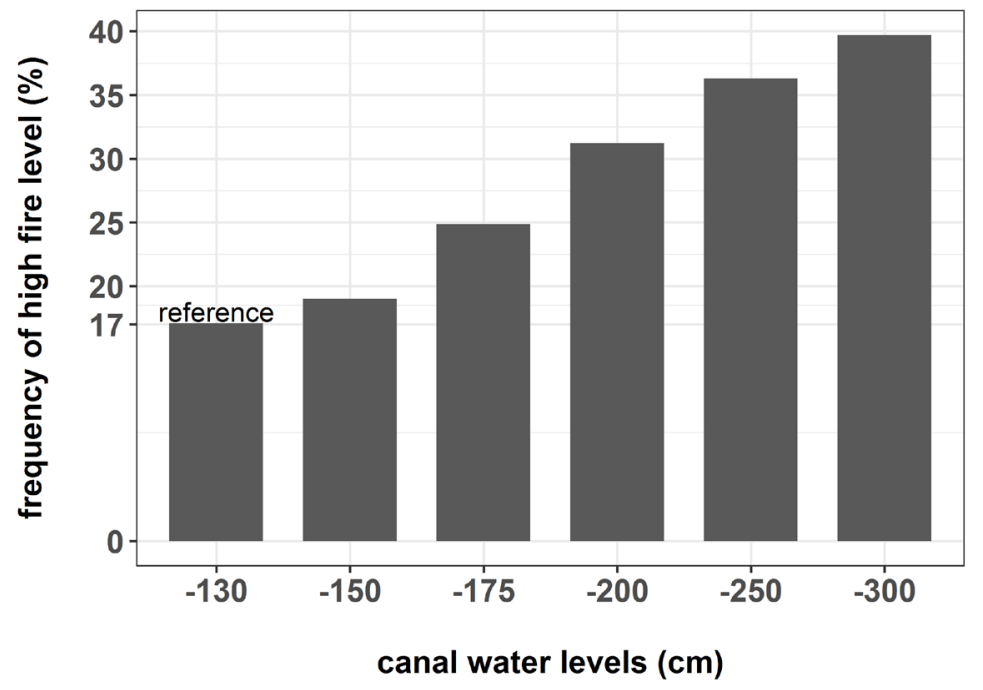

Figure 4.3. Impact of water management on high fire hazard frequency (\% of the time). The deeper canal water levels during the dry season reflect uncontrolled drainage condition (reference represents controlled drainage). $X$-axis values indicate maximum depth of the surface canal water level (CWL) below soil surface in the dry season.

A number of caveats should be considered. For example, our study uses an observation-driven modelling approach that analyses groundwater level dynamics under current climate variability, but it did not explicitly attempt to reconstruct actual historic conditions (e.g. acacia plantation development), nor did it explore future climates that may favour fire susceptibility. Likewise, we used a one-dimensional vertical water flow model and a drainage boundary conditions (Cauchy type) to simulate groundwater tables (Van Dam and Feddes 2000; Kroes et al. 2008; Van Dam et al. 2008) instead of a (pseudo) three 
dimensional model (e.g. Wösten et al. 2006; Ishii et al. 2016), which may introduce some uncertainty. Although our calibration period captures both climate extreme conditions (El Niño and La Niña) our calibration results may disregard the influence of decadal climate variability on groundwater table dynamics. Long term monitoring of groundwater levels could help reduce the uncertainty in calibrated parameters. However, we believe that given the observed data used from years with climate extremes, this modeling-monitoring study contributes towards better understanding on the interplay between human and natural disturbances in the fragile ecosystems of tropical wetlands in Southeast Asia. Moreover, our findings offer valuable science-based evidence to policymakers in the region to regulate and promote sustainable wetland utilization. 


\section{Chapter 5 \\ Hydrological drought understanding for wildfire area burnt prediction}

Borneo's diverse ecosystems, which experience typical humid tropical conditions, are deteriorating rapidly as the area is experiencing recurrent large-scale wildfires, affecting atmospheric composition (Thompson et al. 2001; Page et al. 2002; Novelli et al. 2003; Huijnen et al. 2016) and influencing regional climate processes (Hoffmann et al. 2003; Van der Molen et al. 2006). Studies suggest that climate-driven drought regulates wildfires (Page et al. 2002; Van der Werf et al. 2008a; Fu et al. 2013; Jolly et al. 2015), but these overlook subsurface processes leading to hydrological drought, an important driver. Here, we show that models which include hydrological processes better predict area burnt than those solely based on climate data. We report that the Borneo landscape (Kier et al. 2005) has experienced a substantial hydrological drying trend since the early 20th century, leading to progressive tree mortality, more severe than in other tropical regions (Phillips et al. 2010). This has caused massive wildfires in lowland Borneo during the last two decades, which we show are clustered in years with large areas of hydrological drought coinciding with strong El Niño events. Statistical modelling evidence shows amplifying wildfires and greater area burnt in response to El Niño Southern Oscillation (ENSO) strength, when hydrology is considered. These results highlight the importance of considering hydrological drought for wildfire prediction, and we recommend that hydrology should be considered in future studies of the impact of projected ENSO strength, including effects on tropical ecosystems, and biodiversity conservation.

This chapter is based on: Taufik, M., P. J. J. F. Torfs, R. Uijlenhoet, P. D. Jones, D. Murdiyarso, and H. A. J. Van Lanen. 2017. Amplification of wildfire area burnt by hydrological drought in the humid tropics. Nature Climate Change 7: 428-431. doi:10.1038/nclimate3280 


\subsection{Introduction}

Host for 10,000 plant species in its lowland rainforest alone (Kier et al. 2005) and ca. 5000 vascular plants in mountainous regions (Beaman 2005), Borneo's ecosystems are deteriorating at an alarming rate. An important cause is large-scale wildfires, which frequently coincide with prolonged ENSO-driven droughts. Impacts in Borneo are exemplary for other biodiversity hotspots in the humid tropics, e.g. the Amazon (Hoffmann et al. 2003; Fu et al. 2013). Future droughts in wet tropical regions will likely increase in frequency and severity (Dai 2013), and hence the fire risk (Hoffmann et al. 2003; Fernandes et al. 2017). Therefore, a better understanding of fire area burnt of tropical humid ecosystems during droughts is urgently required. Direct and indirect impacts of ENSO-drought driven wildfires have already been investigated (Thompson et al. 2001; Page et al. 2002; Novelli et al. 2003; Marlier et al. 2013), but possible long-term drying trends and the associated amplification of ENSO-driven droughts, as well as the area burnt by wildfires and the underlying hydrological mechanism have not been quantified yet. We show that including hydrology improves predictions of area burnt, which so far are typically based on meteorology only. This is essential to predict future fire extent particularly during strong ENSO-driven droughts.

\subsection{Results and discussions}

\subsubsection{How does hydrological drought drive wildfire?}

In the humid tropical environment of Borneo, groundwater dynamics is a key hydrological variable to understand the mechanism of the drought-fire link (Figure 5.1). Groundwater table fluctuations influence hydrological drying of fuels and the organic soil. The deeper the groundwater table is, the more fire-prone the humid tropics become (Wösten et al. 2008; Hoscilo et al. 2011; Taufik et al. 2015; Turetsky et al. 2015). Climate variability related to ENSO-drought (Page et al. 2002; Van der Werf et al. 2008a) is the main driver of wildfire in Borneo, by reducing groundwater recharge that feeds the groundwater table, which creates dry conditions for usually human-induced fire ignition. Once the fire is lit, it can escape in an uncontrolled way mainly during a prolonged (hydrological) drought, which happens during a strong El Niño event. Human activities through land-use change and associated drainage and land-clearing immediately following deforestation or long fallow periods create favourable conditions for the fires and amplify the hydrological drying processes in the above-ground fuels and the underlying organic soil (Figure 5.1). In regions with few observations, like Borneo, a water balance model can help us to understand the hydrological drought-fire mechanism. We selected groundwater recharge as a key hydrological variable that integrates precipitation, actual evapotranspiration and changes in soil moisture content (Figure 5.1). Hence, it is expected to be a stronger explanatory factor to characterize drought than just the precipitation anomaly (meteorological drought) or the soil moisture anomaly. We hypothesize that periods with low groundwater recharge will create conditions for a greater area burnt.

\subsubsection{Has hydrological drought become more severe and hence created conditions for more extended wildfires?}

First, to explore the spatially-distributed hydrological drought in Borneo, we analysed time-series of monthly climate data provided by the Climatic Research Unit-CRU (Harris et al. 2014) for the period 1901-2015. We simulated the transient monthly water balance (Eq. 5.1) to derive groundwater recharge at the $0.5^{\circ}$ latitude/longitude grid scale. Subsequently, we applied the threshold approach with the $80^{\text {th }}$ percentile (Van Loon and Van Lanen 2012) to derive hydrological drought, i.e. drought in groundwater recharge 
across Borneo. Here we report that there has been a drying trend in Borneo since the early $20^{\text {th }}$ century, as indicated by the proportion of the annual area in drought (Annex C: Figure C.1) expressed as the annual maximum and annual mean (Annex B: Eqs. B.2 and B.3). The monthly groundwater recharge has been derived as follows:

$$
\text { rch }=\text { pre }- \text { eta } \pm \text { ds }
$$

Here $r c h$ is monthly recharge, pre is monthly precipitation, eta is monthly actual evapotranspiration, and $d s$ is change in monthly soil moisture [units: $\mathrm{mm}$ ].

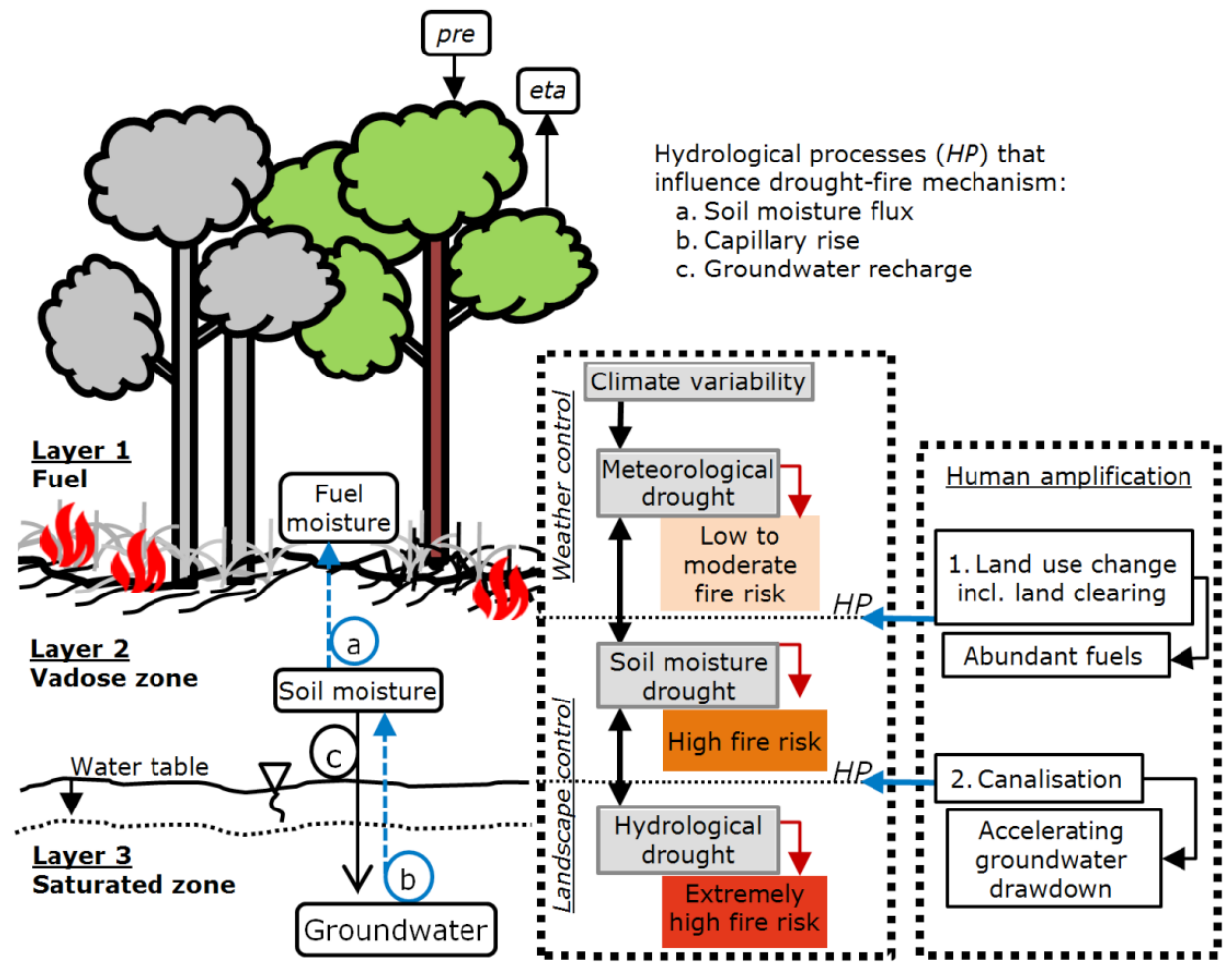

Figure 5.1. The mechanisms of the drought-fire link are explained through the dynamics of the groundwater table fluctuation. This responds to three hydrological processes (HP) that are driven by weather changes: soil moisture (a), capillary rise (b) and groundwater recharge (c). During a period with no rainfall (meteorological drought), soil moisture is depleted (soil moisture drought) to fulfil the evapotranspiration flux, hence groundwater recharge is reduced or even becomes negative (capillary rise, b). Short meteorological drought is characterised by low fire risk. When the meteorological drought lasts longer, the continuous capillary rise accelerates groundwater table decline (hydrological drought), until a depth where the capillary rise becomes insufficient to feed soil moisture (layer 2). Then the soil moisture flux (a) is affected, which leads to drying out the organic topsoil and the above-ground fuels stimulating drought stress. This stress leads to shedding of leaves by the evergreen forest and to accumulation of dry litter on the forest floor (fuel layer). Further persistent moisture depletion will ease ignition in layer 1 (usually human-induced) and subsequent spreading of fire. The combined effect of drying out the above-ground fuels and hydrological drought leads to low moisture in the organic soil (layer 2), which substantially favours peat smouldering combustion (extremely high fire risk). Human activities through land clearing change land use, and wetland canalisation accelerate the (hydrological) drying process (in layers 1 and 2) by providing abundant fuels and lowering of groundwater tables. 


\subsubsection{Does hydrological drought amplify wildfire?}

To explore the link between hydrological drought and fire in Borneo, we analysed the monthly fire area burnt from the Global Fire Emission Dataset, GFED4 (Giglio et al. 2013) for the period $1996-2015$ with a $0.25^{\circ}$ spatial resolution. This fire area burnt has been aggregated to $0.5^{\circ}$ grid cells. We classified years in this period into drought and nondrought years. A drought year is defined as a year with prolonged and spatially extensive hydrological drought events (see Annex B). Our analysis illustrates that wildfires occur annually, i.e. also in non-drought years, but that amplification of wildfires occurs during drought years. In drought years, maximum area burnt is significantly larger (Figure 5.2a), namely almost 10 times relative to non-drought years. The larger the area in drought, the higher the annual area burnt. Furthermore, very large fire extents (i.e. area burnt $>10,000$ ha) were hardly detected for non-drought years, while 14 times as many events occurred during drought years (Figure 5.2b). Additionally, our grid-scale analysis shows that largescale wildfire is mainly widespread in the eastern and southern parts of Borneo during drought years (Figure 5.2c), where prolonged hydrological drought events are more likely to occur (Annex C: Figure C.2). This finding proves that hydrological drought amplifies wildfires in terms of area burnt and frequency of very large wildfire events.

Wildfires are usually explained through the occurrence and severity of meteorological drought i.e. below-normal precipitation (Hoffmann et al. 2003; Van der Werf et al. 2008a; Fu et al. 2013; Jolly et al. 2015). However, so far no model to predict wildfire area burnt has been developed that includes hydrology. There are indications that by integrating hydrological variables, fire occurrence is better identified (Taufik et al. 2015; Yang et al. 2015). To develop a predictive model for wildfire area burnt, we explored statistical relationships between the fire area burnt (response $Y$ ) from GFED4 (Giglio et al. 2013) and independent predictors $(X)$, which were obtained and derived from water balance components (Eq. 5.1), fire weather system indices (FWI), and ENSO (see Annex B) for the period 1996-2015. Three different approaches were used to establish statistical relationships (i.e. models): a linear approach, a non-linear approach with local regression (loess, Cleveland and Devlin 1988), and a non-linear approach with random forest (Breiman 2001). We note that all data sources are independently derived, with the GFED4 derived from remotely-sensed data; FWI from the Global Fire Weather Database GFWED, (Field et al. 2015), ENSO derived from sea surface temperature at the Pacific Ocean; and CRU climate data derived from interpolated station climate data. We clearly distinguished between models that are solely based on climate (i.e. precipitation, FWI, and ENSO) and models that also integrate hydrological variables, such as groundwater recharge, as predictors. In total, over 300 statistical relationships have been investigated. Our analysis shows that non-linear models using loess better predict area burnt than the two other approaches for any combination of predictors used in this study (Annex C: Figure C.3).

\subsubsection{To what extent does hydrology contribute to the quantification of the area burnt by wildfire?}

To assess whether statistical models integrating hydrology perform better than models using climate only, we clustered the predictive models into two ensembles of models (see Annex B), i.e. climate-oriented models (CLIM) and hydroclimate-oriented models (H-CLIM). We applied three different goodness-of-fit criteria (see Annex B) for the assessment of model performance. Our model assessment (Annex C: Figure C. 4) shows that H-CLIM performed better in terms of any goodness-of-fit (GOF) measure used; the median of all GOF values is employed as a measure in hydrology (Moriasi et al. 2007). Furthermore, the variance of the residuals for the ensemble of $\mathrm{H}$-CLIM models is significantly lower $(30 \%$, 
$\alpha=0.01$ ) than that of CLIM. The reduced variance provides additional evidence that by integrating hydrological variables, model uncertainty is significantly reduced.

(a) annual max

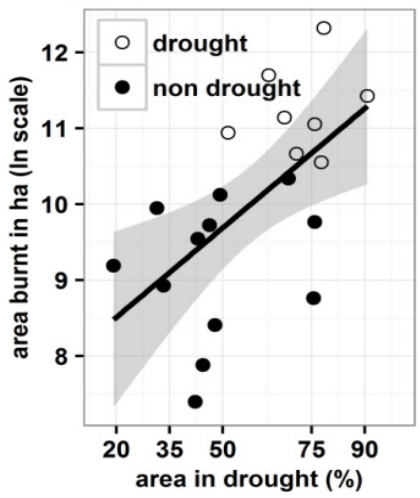

(b) very large wildfires

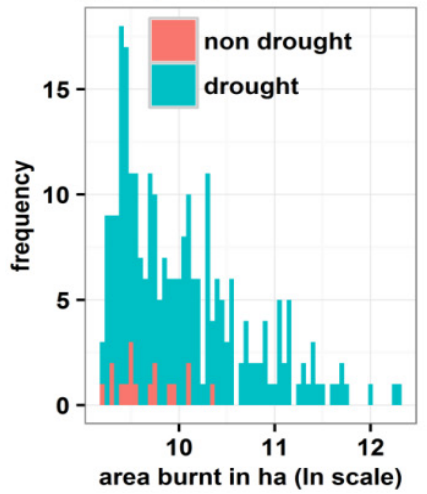

(c) spatial distribution

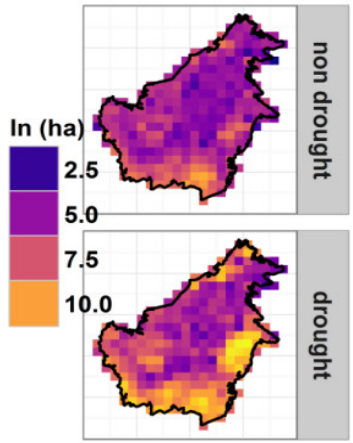

Figure 5.2. Area burnt by wildfires in Borneo during drought and non-drought years for the period 1996-2015. (a) Relation between the annual maximum of area burnt and the percentage of the annual maximum area in drought. The graph indicates that area burnt increases substantially during drought years. The grey shaded area indicates the 95\% confidence interval. (b) Frequency of area burnt by very large wildfires (>10,000 ha). (c) Spatial distribution of the maximum value of wildfire area burnt at $0.5^{\circ}$ spatial resolution. The figures clearly show that during hydrological drought years, fire area burnt expands. The unit of area burnt is in ha (natural logarithmic).

\subsubsection{Does hydrology matter for the prediction of wildfire area burnt under various ENSO strengths?}

To understand to what extent the wildfire area burnt is attributable to the warm phase of ENSO (El Niño) and how much hydrology adds, we applied both model ensembles (CLIM and H-CLIM) to estimate the mean and the maximum of the area burnt per grid cell for 1950-1995. For each year El Niño strength was assigned to one of the four classes (i.e. weak, moderate, strong and very strong, see Annex B). Our analysis shows that the mean annual area burnt predicted by the $\mathrm{H}$-CLIM model ensemble was larger than that predicted by the CLIM model ensemble for any El Niño strength (Figure 5.3, upper row). The predicted area burnt is at least $15 \%$ greater. In particular, for years with a very strong El Niño the difference in area burnt between CLIM and H-CLIM ensembles is large. The predicted maximum annual area burnt is even 154-275\% larger for strong and very strong ENSO conditions when hydrology is integrated (Figure 5.3, lower row). If climate-oriented models (i.e. the CLIM ensemble) are applied for predicting area burnt (specifically under extreme El Niño events in the future), the estimate tends to substantially underestimate the possible very large area burnt that may occur. Because extreme El Niño events are more frequently projected in the future (Cai et al. 2014; Cai et al. 2015), promoting prolonged dry seasons and impacting wildfire area burnt, use of the appropriate prediction tools that integrate all drivers with hydrology being one of the most important, is crucial.

This research improves the assessment of wildfire area burnt in humid tropical ecosystems. So far, climate-driven prolonged drought is used as the only driver for wildfire occurrence and strength in the humid tropics, such as the Amazon (Hoffmann et al. 2003; Fu et al. 2013) and Borneo (Page et al. 2002; Hoffmann et al. 2003; Van der Werf et al. 2008a). Our findings provide a promising direction to improved prediction of area burnt in other humid tropical areas beyond Borneo for various El Niño strengths. Hydrological drought 


\section{Chapter 5}

has never been considered, so far, as an indicator for strategic policy formulation, and the results indicate that the approach offers a powerful tool to improve planning and strategies to adapt to climate change. Most practically, such a tool may be adopted in the ambitious government effort in Indonesia to restore two million hectares of degraded peatland by 2020, among others by rewetting drained peatlands.
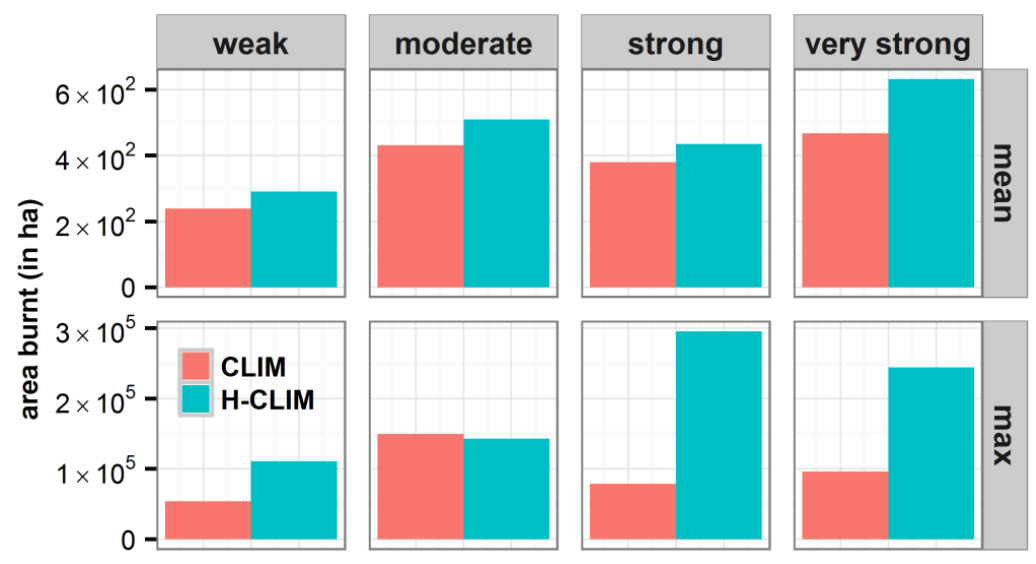

Figure 5.3. Predicted area burnt forvarious El Niño strengths (see Annex B) using two model ensembles (CLIM and H-CLIM). For each ensemble, two different predictions are provided, namely the mean (upper) and maximum (lower) values of all grid cells for 1950-1995. It appears that predicted area burnt by using the CLIM model ensemble is substantially smaller than that by applying the H-CLIM model ensemble, except for the moderate El Niño strength. By including hydrological processes, a greater area burnt is predicted; the CLIM model ensemble tends to underestimate the area burnt. 


\section{Chapter 6 Synthesis}

\subsection{General discussion}

To improve understanding of hydrological drought and associated wildfire, this thesis has addressed four research questions regarding the importance of hydrology for wildfire in the humid tropics (Section 1.7). Here, the results presented in the previous chapters are discussed in the light of those four research questions.

\subsubsection{To what extent does hydrology add to a better prediction of the fire hazard in the humid tropics?}

The importance of integrating hydrology to better predict fire hazard was tested on a large scale, that is, the humid Island of Borneo (Chapter 5). In the region, fire is rather difficult to predict, because fire is not solely driven by weather variability, as illustrated by the prediction of a low Fire Weather Index (FWI) during the fire season (Bedia et al. 2015). Instead of using only a climate-centric approach, some studies indicated that groundwater table dynamics maybe of importance for identifying fire hazard (Wösten et al. 2008; Turetsky et al. 2015). Because of a lack of groundwater table observations in Borneo, we used modelled groundwater recharge as a proxy to explain the groundwater dynamics that influences drying processes in the upper soil layer. Hundreds of statistical models were tested, that is, models with not more than climate variables, and others that also use soil and hydrological information, including models that integrate groundwater recharge, for prediction of fire area burnt at $0.5^{\circ}$ grid scale (Annex C: Figure C.3). The findings revealed that models that integrate hydrological variables are better in the prediction of area burnt (Annex C: Figure C.5).

To understand how much hydrology adds to area-burnt prediction, the indicators and indices (Annex C: Figure C.5) were clustered into two model ensembles of best performing models, namely a climate-oriented ensemble (CLIM) and a hydroclimateoriented ensemble (H-CLIM). The selected model ensembles and their performance in area burnt prediction are provided in Figure 6.1a. The results show that the CLIM ensemble likely underestimates area burnt (lower Kling-Gupta efficiency $k g e$ and Nash-Sutcliffe efficiency $n s e$, and higher RMSE-standard deviation ratio $r s r_{\text {, Figure }}$ 6.1a), whereas the $\mathrm{H}$-CLIM ensemble prediction is much closer to the actual burnt area. During the very strong El Niño of 1982/1983, wildfires (incl. land and forest) 
occurred over an area of 3.5 million ha (Malingreau et al. 1985). The CLIM model ensemble deviated by $60 \%$ from the actual area burnt reported, whereas the difference for $\mathrm{H}$-CLIM was only $14 \%$. This indicates that the CLIM models likely underestimate the area burnt.
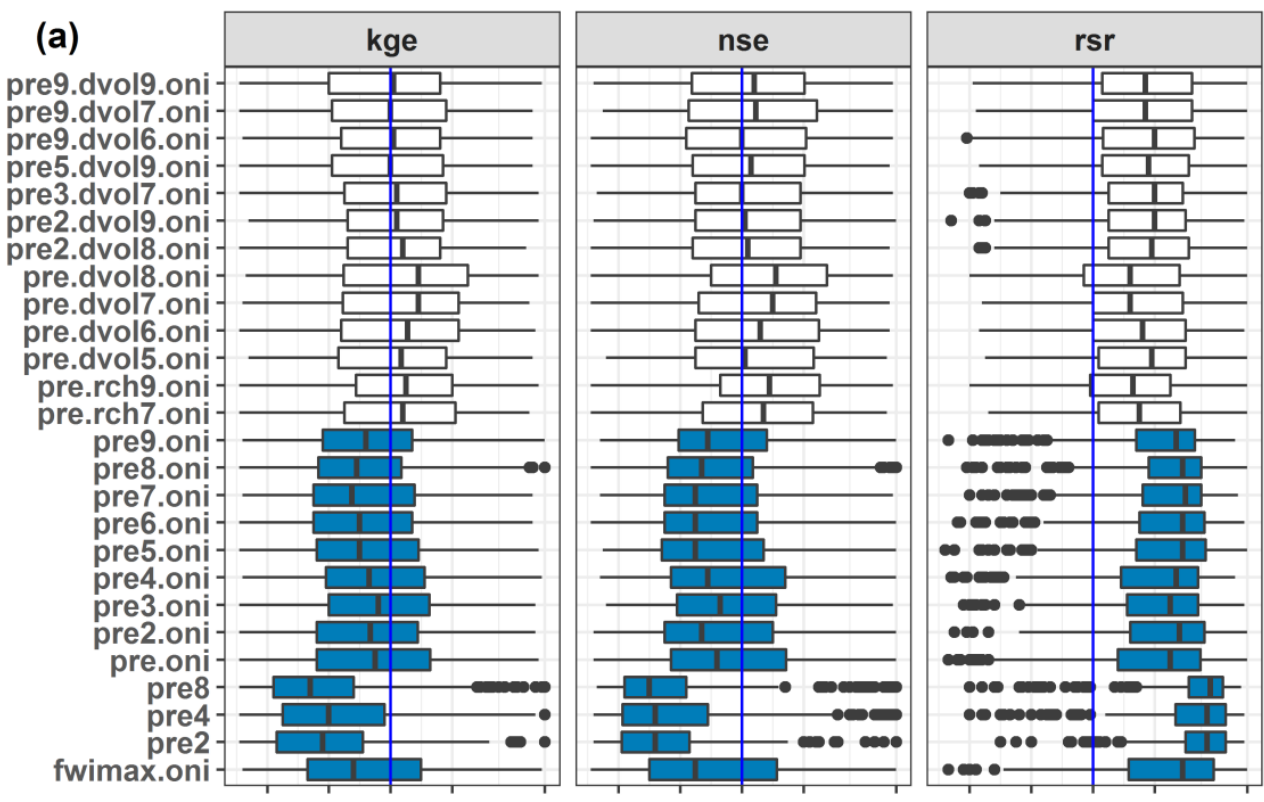

(b)

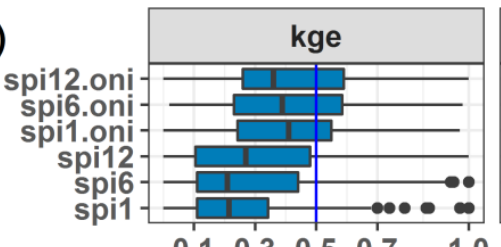

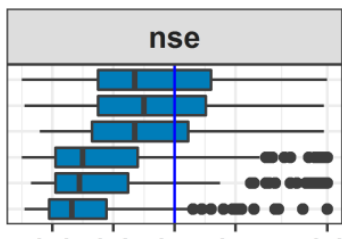

$\begin{array}{lllll}0.1 & 0.3 & 0.5 & 0.7 & 1.0\end{array}$

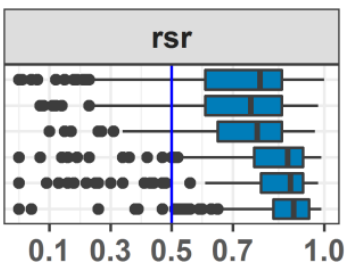

Figure 6.1 Goodness of fit (GoF) of the prediction models using loess (Chapter 5: Annex C): Kling-Gupta efficiency (kge); Nash-Sutcliffe efficiency (nse); and RMSE-standard deviation ratio (rsr). The goodness of fit is presented as boxplots: for kge and nse the closer to 1 the better the performance of the model, for the rsr the opposite holds. The boxplot indicates the median, and the $25 \%$ and $75 \%$ quantiles. The dots indicate outliers. The white and blue boxplots represent best performing members of the H-CLIM and CLIM ensembles, respectively. (a) From the 26 selected models, the top 13 are the ensemble members of H-CLIM, and the bottom 13 are the ensemble members of CLIM; (b) Performance of models based on the Standardized Precipitation Indices (SPI). Along the $y$-axis different combinations of indicators and indices are listed (see Annex C: Table C.2 for a description of the acronyms). Vertical lines in GoF are used as guidance for which models statistically perform better.

In addition to the large-scale analysis, integration of hydrological variables to improve prediction of fire hazard was tested at the local scale. Chapter 3 discusses the integration of soil and hydrological properties (i.e. water retention and groundwater table depth) into the model structure of the Keetch-Byram Drought Index (KBDI). This integration into the model structure is implemented in the so-called water table factor (WTF, Equation 3.8). The modified index (mKBDI) smoothly rises and declines in response to dry and wet 
spells, whereas the original and the adjusted indices were too flashy following weather changes too directly. The mKBDI fits well with the observed soil moisture pattern in the fire-relevant upper layers (Figure 3.3c), in particular when the high fire hazard class in El Niño years is predicted. Moreover, the WTF provides very relevant information about the critical water depth, below which the upward soil water flow (capillary rise) has a negligible contribution to moistening the fuel layer, and hence fire hazard significantly increases. In the marine clay soil in south Sumatra the critical water depth appears to be $85 \mathrm{~cm}$ below the soil surface (Figure 3.6).

\subsubsection{How do the existing drought-related indices perform in predicting fire hazard, and can these indices be made more reliable by including hydrology?}

Existing, widely-applied drought-fire indices, such as the Keetch-Byram Drought Index (KBDI), or Fire Weather Index (FWI), are based on a climate-centered approach by only using daily weather data (Di Giuseppe et al. 2016). The KBDI employs a rather simple calculation method using only two weather variables, namely the daily maximum temperature and precipitation. The FWI calculation is more complex, that is, prediction of the six components of the FWI (namely, the fine fuel moisture code, duff moisture code, drought code, initial spread index, and build-up index). No subsurface information is required that addresses hydrological processes. Both indices have some drawbacks when the indices are applied to other climate and soil regimes, because the indices were calibrated against local climate. In this thesis, a modified KBDI was tested at a local scale under tropical wetland conditions (Chapter 3).

In Section 6.1.1, it was demonstrated that integrating hydrological variables improves prediction of the fire hazard (Figure 6.1a). This thesis investigated the increase of performance of a well-known drought-fire index (KBDI) at the local scale. The original index (KBDI) showed large disagreement with the observed soil moisture, as illustrated by a negative nse (Section 3.4.2.a). The performance of the index improved when the groundwater table depth was introduced into the model structure. Other criteria used (such as rsr, and percent bias pbias) showed that the modified KBDI, mKBDI, performed substantially better than the original index.

At large scale, drought indicators and indices were tested to predict fire area burnt at $0.5^{0} \mathrm{grid}$ resolution for the whole of Borneo (Section 6.1.1). The findings revealed that applying only a climate-centered approach (namely FWI), did not perform well in prediction of the monthly area burnt (Chapter 5 ). Next, the widely known index recommended by WMO (2012), that is, the Standardized Precipitation Index (SPI) was tested as well. The SPI is regularly used to assess drought impacts, among others wildfire (Gudmundsson et al. 2014). The SPI provides information on how many standard deviations the precipitation in a certain period deviates from the historic median (McKee et al. 1993). The precipitation is accumulated over one or several months ( $\mathrm{SPi}-\mathrm{x}, \mathrm{x}=1,2, \ldots 24$ months) to find the best relationship between the impact and the precipitation. In this study, several accumulation periods (1, 6 and 12 months) were tested, some in combination with the Oceanic Niño Index (ONI). The statistical criteria revealed a low performance of the various loess models using SPI to predict area burnt relative to the models of the $\mathrm{H}$-CLIM ensemble (Figure 6.1b). 


\subsubsection{What are the characteristics of hydrological drought for the humid tropics, that is, for climate-induced, human-modified conditions and possibly human- induced drought conditions?}

In the Southeast Asia region, drought as a natural hazard gets less attention from society than drought related impacts (such as, fire, tree mortality, agricultural loss). Most studies used precipitation as indicator for drought events related to the ecophysiology of tropical forest (e.g. Walsh and Newbery 1999; Phillips et al. 2010), whereas hydrology matters (Section 6.1.2). Since the 1980s, the Southeast Asia region is under pressure by human activities, including land-use change (Field et al. 2009; Gaveau et al. 2014; Margono et al. 2014), which involves canalization in many cases (Wösten et al. 2006; Hooijer et al. 2010; Jaenicke et al. 2010; Page and Hooijer 2016). Yet, quantification of human activities on drought development, particularly climate-induced and human-modified hydrological drought (Section 1.6), remains a research challenge. In this thesis, new findings on the characteristics of hydrological drought, taking into account human influences, are discussed in terms of drought duration and severity. The characteristics were quantified based on the variable threshold approach (Van Loon et al. 2010) using the $80^{\text {th }}$ percentile of the hydrological variables.

In this study, hydrological drought is assessed through two variables, namely groundwater recharge and groundwater levels. Chapter 5 focuses on groundwater recharge that is derived from long-term climate data (1901-2015), whereas Chapter 2 uses groundwater levels (1980-2015). First, climate-induced drought was identified through drought duration. For drought in groundwater recharge, the mean duration is shorter than 4 months (Figure 6.2a), whereas the duration becomes at least one month longer in groundwater drought (see Table 2.2). This finding illustrates that drought propagates through the hydrological cycle. Through drought propagation (Peters et al. 2003; Peters et al. 2005; Van Loon and Van Lanen 2012), the duration of groundwater drought is longer than that of meteorological drought, also in Borneo (Walsh 1996; Walsh and Newbery 1999).

In addition to drought duration, climate-induced drought severity was assessed. It varies throughout the humid tropics, including Borneo. Surprisingly, the heart of Borneo with its high monthly precipitation shows the most severe droughts (Figure 6.2b), while mean durations are rather short (Figure 6.2a). On other hand, eastern Borneo faces a lower severity, although this region experiences longer droughts. The discrepancies in severity are related to the different variable thresholds (i.e. $80^{\text {th }}$ percentile) between the regions (examples for a grid cell from each region are given in Figures $6.2 \mathrm{c}$ and $6.2 \mathrm{~d}$ ). Regions having a high monthly recharge naturally will have a higher drought threshold (Figures 6.2c) implying a greater severity (shaded area of Figure 6.2c) when a drought strikes than dryer regions with lower recharge (Figure 6.2d). For groundwater drought, the severity (expressed as mean annual deviation of the groundwater threshold level) of northern peatland regions is higher than of the southern regions (Table 2.2). One reason for this is that the northern regions typically have two dry seasons leading to lowering groundwater levels twice annually, whereas the southern regions only have one dry season (Aldrian and Susanto 2003). 
(a)

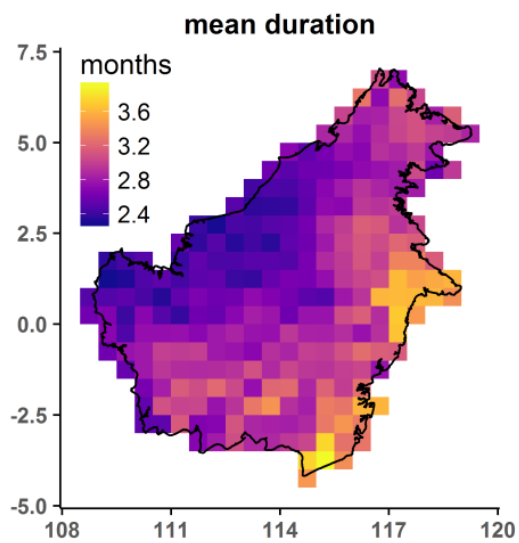

(c)

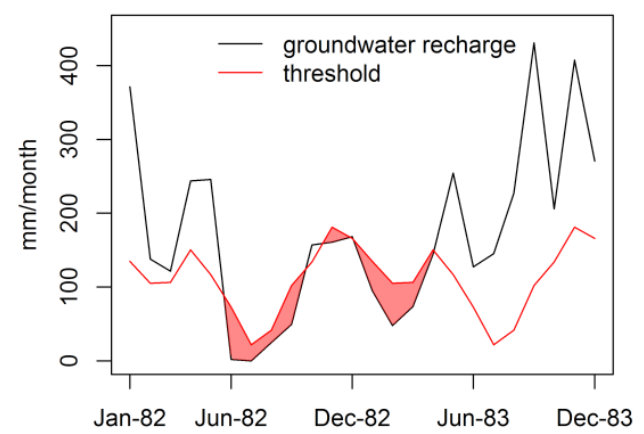

(b)

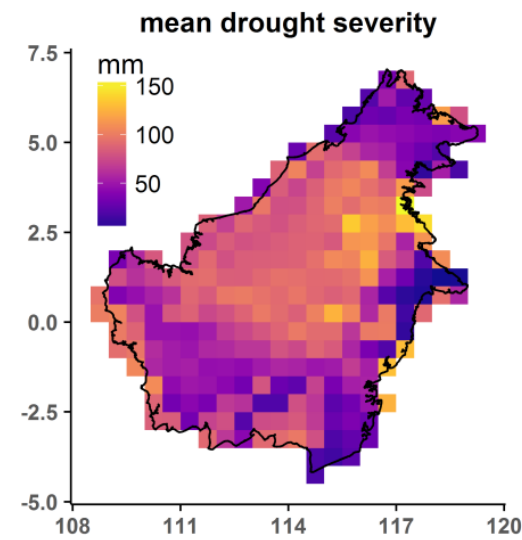

(d)

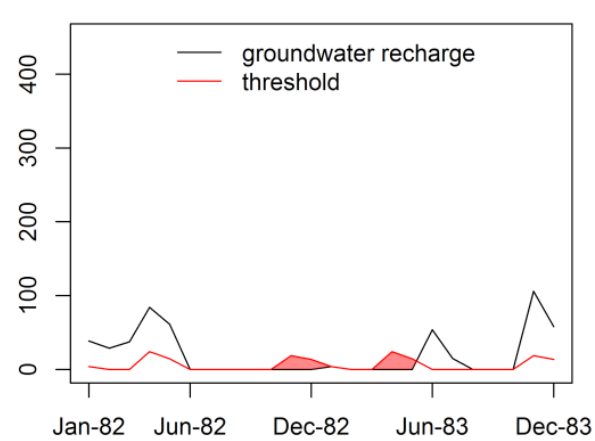

Figure 6.2 Hydrological drought characteristics for 1901-2015. Spatial distribution of: (a) mean duration; and (b) mean severity. Temporal evolution of drought severity (shaded-red area) for a grid cell in: (c) heart Borneo (grid 117); and (d) eastern Borneo (grid 125). The threshold (red line) is based on the $80^{\text {th }}$ percentile of the monthly frequency curve for groundwater recharge.

Human-modified drought was first analyzed by investigating canalization in peatland (Chapter 2). Clearly, drought severity is amplified when peatland is drained. The amplification points out how many times the human-modified drought is larger than the climate-induced drought. The analysis shows that the southern regions (which are lower in severity) are more sensitive to human interference, i.e. the amplification in severity due to canalization (compared to natural conditions) is more than twice as high in the southern regions. The amplification markedly enhances when drained forest is converted into plantation (more than 3 and 4 times for the northern and southern regions, respectively). By this transformation to drained acacia, the human-induced drought solely contributes at least $65 \%$ of the drought events for the selected peatland regions in Sumatra and Kalimantan (Chapter 2). The high drought severity due to canalization leads to an enhancement of fire susceptibility conditions, as reported for the region (Hoscilo et al. 2011; Konecny et al. 2016). 


\subsubsection{How can water management mitigate hydrological drought and associated fire hazard?}

Transformation of tropical peatlands into plantations, including canalization has resulted into more severe hydrological droughts and enhanced fire hazard (Sections 6.1.3, Chapters 2 and 4). In this thesis, a rather simple approach was used, namely a sensitivity analysis on the canal water level regime $(C W L)$, to quantify the impact of water management on reducing drought severity. The dry season CWL (Table 2.1) was changed from 110 to $-150 \mathrm{~cm}$ with a step of $10 \mathrm{~cm}$ (reference is $130 \mathrm{~cm}$ below soil surface, which holds for controlled drainage conditions). Obviously, the closer the CWL to the surface, the higher the groundwater table in the peatland would be. By implementing a higher surface water level during the dry season (increasing canal water level by $20 \mathrm{~cm},+15 \%$ ), the drought severity would reduce by at least $14 \%$ (expressed as deviation of groundwater level from normal). The reduction of severity even reaches $26 \%$ in Air Hitam, and goes up to $49 \%$ in Upper Sebangau (Figure 2.2). Peatland in the southern regions is more sensitive to changes in canal water level regime than that in the northern regions.

The fire hazard was assessed with the mKBDI that integrates groundwater table depth (Section 6.1.2 and Chapter 4). The modelling experiment shows that if drainage is uncontrolled, prolonged low groundwater tables are inevitable. Hence, days with high fire hazard will substantially increase from $17 \%$ (controlled drainage) to $40 \%$ (Figure 4.3). The canal water levels should be controlled and kept as high as possible during the dry and intermediate season to avoid high fire hazard. For instance, the levels should not go deeper than $150 \mathrm{~cm}$ below the surface during the peak dry season (August-October) to keep high fire hazard conditions below $20 \%$ of the time, which might be an acceptable target, although it is still 6 times bigger than under natural conditions.

\subsection{Cross-cutting issues}

The groundwater table is a key hydrological variable in the humid tropics and can be controlled by managing surface water levels under human-modified drought conditions (Section 6.1.3). Throughout the year groundwater tables vary depending on rainfall and evapotranspiration, and furthermore their dynamics are controlled by subsurface processes, that is storage, a vertical flux in the soil, and a predominantly horizontal flux in the groundwater system (Figure 6.3). In this thesis the vertical flux and its link with hydrological drought have been studied through the groundwater recharge (Chapter 5). The horizontal flux is calculated by using the difference between the water table and canal water level that varies over time, and the drainage resistance (Chapters 2 and 4), which approaches the complex lateral flow from land to the surface water system (rivers, canals). Groundwater table drawdown is inevitable when the land is drained through canals, which influences drought characteristics (Chapter 2) and fire hazard (Chapter 4).

Figure 6.3 illustrates how the groundwater table dynamics control drought development and fire hazard in the humid tropics. In the classical approach (i.e. climate-induced drought only), drought in the humid tropics occurs only due to a period with low rainfall (meteorological drought), see Sections 6.1.1 and 6.1.2. As the dry season continues, drought propagates through the hydrological cycle, causing a decline in groundwater table, which leads to groundwater drought. Human activities can amplify the drying process in peatland by land-use change and canalization (human-modified drought, even human-induced drought may occur, Sections 1.6 and 6.1.3). Land-use change leads to change in the surface energy and water balances, which, for instance, may result in an increased sensible heat flux and reduced latent heat flux to the atmosphere (Bonan 
2008). Canalization accelerates the drying process during low-rainfall periods by draining massive water volumes out of the peatland leading to a prolonged lowering of the groundwater table. In this thesis, I discuss how human activities (land-use change and canalization) may change the characteristics of natural groundwater drought (i.e. climateinduced drought), and how these can amplify the drought and fire hazard in the humid tropics (human-modified drought, human-induced drought). These types of drought are described through the groundwater drought using two variables, namely groundwater recharge and groundwater table depth.

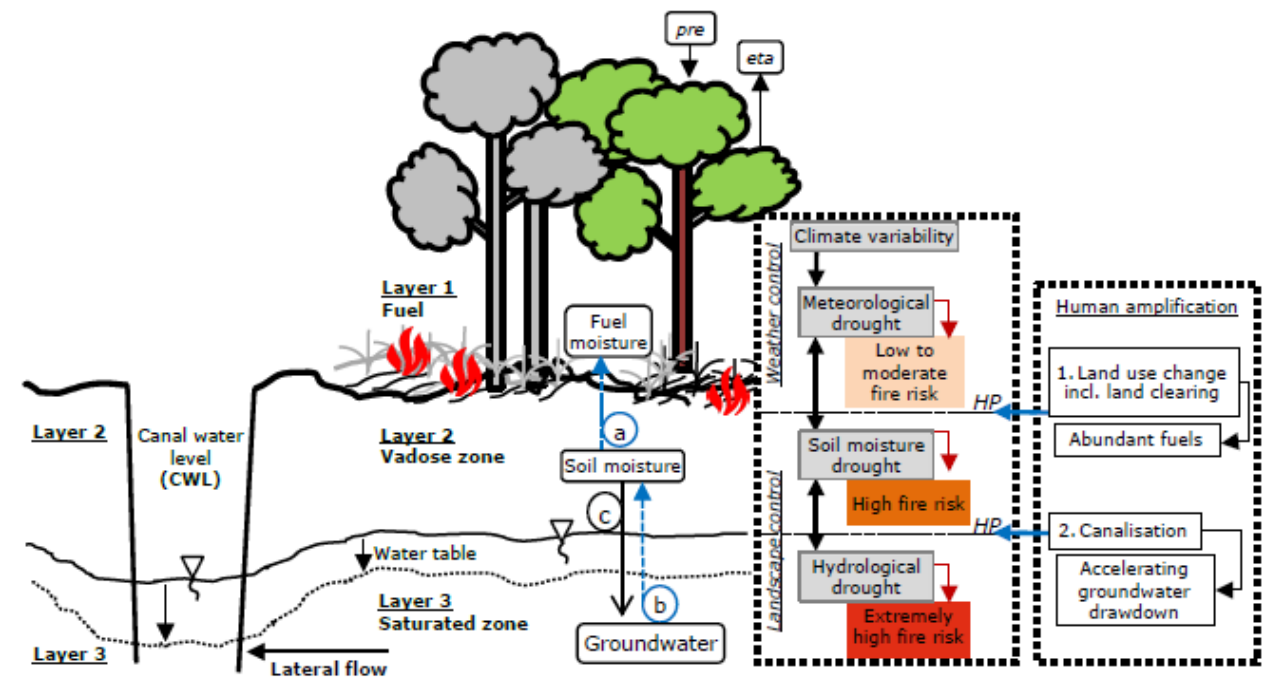

Figure 6.3. Drought-fire mechanism in the humid tropics (extended from Taufik et al. 2017).

Lowering of groundwater tables in peatland means an increase of fire hazard, as previously indicated (Wösten et al. 2008; Hoscilo et al. 2011; Konecny et al. 2016). Under pristine conditions, ponding is a typical hydrological phenomenon in wetlands (Jauhiainen et al. 2008; Evers et al. 2017; Hidayat et al. 2017), implying water above the soil surface, which makes the wetland more fire-resistant. Groundwater table depth is a key variable and is integrated into the KBDI model structure at the local scale. It appeared to perform well testing against observed soil moisture (Figure 3.3c). At the large scale of entire Borneo, groundwater recharge, and its variability, was introduced as a proxy for groundwater dynamics. Overall, there is statistical evidence (Annex C: Figure C.5) that hydrology adds (groundwater recharge) and that it would improve the performance of drought-fire indicators and indices to predict area burnt. Existing fire-drought indices, such as FWI and SPI, do not perform well to predict area burnt in the humid tropics, which is confirmed by the GoF criteria (Figure 6.1).

The outcome of the modelling experiment on drought in groundwater and the associated fire hazard (Chapter 2) also depends on the drainage resistance (DR). The resistance determines the easiness with which groundwater flows into the drainage system, and therefore it controls groundwater table dynamics in wetlands. Hardly any research has been performed on measuring the drainage resistance in tropical wetlands. In this thesis, I relied on the calibration process to fine-tune the magnitude of the resistance. Next, to explore if the employed SWAP model was robust, the sensitivity of the model was 
investigated through changes in the resistance. The resistance was changed by $50 \%$ (-50\% to $+50 \%$ ) with steps of $10 \%$ with respect to the reference. For instance, if the resistance was reduced by $50 \%$, the drought severity hardly changes for natural conditions (Figure 6.4a), but it increases markedly for the acacia plantation with canal drainage. The result reveals that the drainage resistance of peatland is rather sensitive, as shown by the large amplification of drought severity (Figure 6.4a), namely 4 times (DR: -50\%) under drained conditions.

(a). Severity

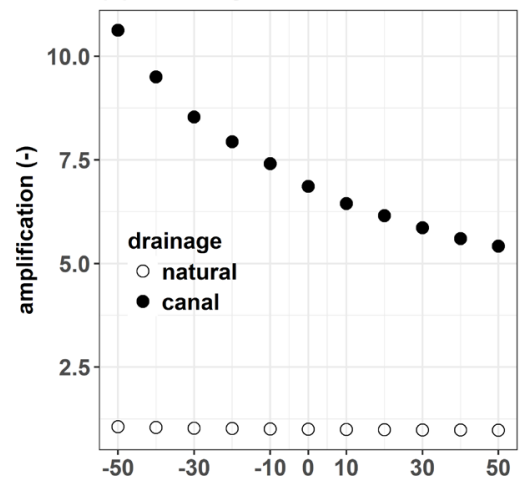

(b) Fire hazard

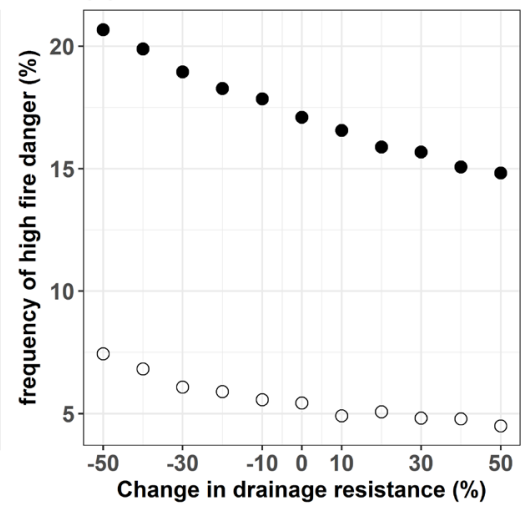

Figure 6.4. Influence of the drainage resistance of intact forest (natural) and drained acacia (canal) on: (a) amplification of hydrological drought severity, and (b) frequency (\% of time) of high fire hazard. The reference drainage resistance is 200 days ( $x=0$ in graph).

The change in drainage resistance affects the drought severity and hence the fire hazard. For the exploration of the fire hazard, the resistance was also changed by $+/-50 \%$. When the DR would be $50 \%$ smaller, more days in the high fire hazard class would occur, i.e. $21 \%$ and $7 \%$ (relative to the reference, Chapter 4 ) for canal and natural drainage, respectively. On the other hand, fewer days in the high fire class are anticipated with a gradual increase of the resistance. For example, a change in the resistance of up to $50 \%$ would lead to a reduction of fire hazard to $15 \%$ and $3 \%$ (Figure $6.4 \mathrm{~b}$ ) for canal and natural drainage conditions, respectively. Although, the drought severity and fire hazard are sensitive to the drainage resistance, the modelling experiment demonstrated that changes in drainage resistance do not noticeably change the difference in magnitude of high fire risk between canal and natural drainage. This implies that the chosen drainage resistance does not change the key message that canal drainage considerably amplifies fire hazard.

\subsection{Relevant research findings}

Several points can be highlighted:

- Restoration (controlled drainage) can reduce the drought severity of peatland (Chapter 2). Restoration means rewetting of the peatland surface layers through higher groundwater tables, which depend on the canal water regime. The shallower the canal water level is, in particular during the intermediate and dry season, the higher the groundwater table is expected to be during the most sensitive period. Restoration may provide a living room to some endemic species, and in the longrun the restored forest may act as biodiversity refuge (Underwood et al. 2014). 
However, it is important to note here that restoration efforts may not be able to allow a complete return to pristine conditions. Hence, some endemic species that only survive on un-impacted hydrology (Posa et al. 2011; Evers et al. 2017) may still be in danger. Until the condition of un-impacted hydrology (poor drainage) is achieved, the peatlands face high drought severity, hence they are more fire-prone (Hoscilo et al. 2011; Konecny et al. 2016).

- Water management that implements canal blocking is able to rewet the 'drying' wetland surface layers, which will reduce fire susceptibility (Chapter 4). If the waterlogging or flooding period is only short, intense aerobic decomposition will occur (Jauhiainen et al. 2008) leading to high carbon emissions that affect the regional climate (Page et al. 2011; Turetsky et al. 2015). In addition, (uncontrolled) canal drainage had a negative impact on the physical peat structure (Jauhiainen et al. 2008), which became more dense, and led to peat subsidence (Ritzema et al. 2014) adjacent to the canal. Recovery of the pristine peatland surface next to the canals will be impossible or will take substantial time, even under controlled drainage.

- Peatland utilization under human civilization is inevitable. Peatland should be wisely exploited to find synergy between ecology and human needs. As previously shown, canalization has remarkably increased drought severity and the associated fire hazard. Therefore a more balanced water management is first priority. Our findings even indicate that water management has more impact on drought severity than that of the projected climate change, even under $2^{\circ} \mathrm{C}$ of global warming (Chapter 2: Figure 2.2). Lowering of groundwater tables in peatland through canalization has benefitted crop productivity. However, it has large ecological consequences, such as: (i) a more fire-prone peatland (Chapter 4), (ii) a significantly-reduced number of endemic species (Yule 2008; Sodhi et al. 2010; Koh et al. 2011; Evers et al. 2017), and (iii) an elevated carbon emission (Hooijer et al. 2010; Page and Hooijer 2016). The $30 \%$ concession area reserved for conservation in the plantation is one promising step to achieve the long-term goal of substantial peatland restoration.

- This research is based upon a rather simple approach in modelling groundwater table dynamics. I employed a one-dimensional hydrological model, namely the SWAP (Soil Water Atmosphere Plant) model to simulate time series of daily groundwater tables (Chapters 2 and 4). The SWAP model focusses on the unsaturated zone, and the model does not explicitly include the saturated groundwater system. The latter may be interpreted as a drawback of the SWAP model. Pseudo 3D models, such as MODFLOW, are widely used to model groundwater dynamics with an emphasis on the saturated zone, but the conceptualization of the unsaturated zone is rather simple. In addition, MODFLOW needs a lot of geo-hydrological input data, including stream-aquifer data, which usually are not available in poorly gauged environments, such as our study sites (Sleedoorn 2017). The calibration of the SWAP model, however, (Annex A: Table A.1 and Figure A.2) has demonstrated the capability of the model in poorly gauged environments in the humid tropics.

- $\quad$ Both simplicity and practicability of the model to be selected for fire hazard studies should be considered. Our approach in modelling fire hazard (Chapters 3 and 4) is based upon a simple approach. In Chapter 3, we modified a simple widely-used drought-fire index by integrating ground water table depth (as a proxy of soil moisture) into the model structure. This integration has an important practical meaning. Measurement of groundwater tables in the field is much easier and cheaper than 
monitoring soil moisture content. Further, Chapter 5 shows a simple approach to predict fire area burnt by integrating hydrological indicators and drought indices as predictor, which are derived from a simple soil water balance model. This integration substantially improved prediction of area burnt. On the other hand, models that provide complex drought-fire indices, such as the FWI do not perform as well, as the prediction based on the simple soil water balance (Figure 6.3, Annex C: Figure C.5).

\subsection{Outlook}

- As vast areas of wetland (including peatlands) in Indonesia have been converted to forest and oil-palm plantations with long-term concessions (>50 years), sustainable, integrated water management is key to build synergy between ecology and economy. Future research should be directed to find win-win solutions between ecology and economy. For instance, through identifying the critical depth of groundwater table that still supports acceptable root development of plantations, but minimizes carbon emission and loss of endemic species. The $30 \%$ concession area for conservation is one step forward to achieve long-term restoration goals. This conservation effort should be accountable and credible. Research findings on restoration achievements need to be publicly available to direct future conservation strategies in degraded tropical wetland.

- The Indonesian Government Decree requires that every concession should have a MRV (Monitoring, Reporting, and Verification) procedure on environmental variables, such as groundwater table depth, surface water level and peat subsidence. These MRVs will provide long-term data for research activities. Leading academic bodies (universities, research institutes) dealing with tropical studies (biodiversity, ecology, and environment) should take the initiative to develop and implement research collaborations with the private sector, e.g. forest estates with a concession. This would make data accessible, even from remote wetlands.

- In addition to monitoring environmental variables, more thematic data should be collated and become available, that is, the hydrogeological framework (aquifers, aquitards), drainage network (current, resistances), hydraulic properties of groundwater system (saturated conductivities, storativities), soil physical properties (water retention, unsaturated conductivities), elevation, and land use (current, historic). For instance, soil water retention data under different hydrological regimes in the humid tropics are required. This will be easier achieved if good research collaboration is established with the estates having concessions. Hydrological properties of peat soils differ from mineral soils, and not enough data are available yet. Therefore, more future research on peat soils is needed to better predict fire hazard.

- This research used a one-dimensional vertical water flow model to simulate groundwater tables (Van Dam and Feddes 2000; Kroes et al. 2008; Van Dam et al. 2008) instead of a (pseudo) three-dimensional model (Ishii et al. 2016), which may introduce some uncertainty. Although our calibration period includes both climate extremes (El Niño and La Nina), our calibration result may disregard the influence of decadal climate variability on groundwater table dynamics. Further investigation using a complex water flow model, such as The Netherlands Hydrological Instrument (De Lange et al. 2014) that considers the full complexity of the water system (fully coupled vadose zone, groundwater, surface water) may help to overcome the 
limitations of our modeling approach. However, this requires first that the abovementioned monitoring and thematic data will become available. Understanding of the complex water system through a hydrological 3D model in wetlands is a prerequisite for identifying and implementing targeted water management options.

- This research has demonstrated that hydrology matters for predicting fire hazard, specifically in the humid tropics. Chapter 3 has discussed the improvement of the KBDI for fire hazard assessment. For area burnt prediction, however, there still remain research challenges to integrate hydrological variables into drought-fire indices, such as FWI. In Chapter 5, it is shown that the FWI still requires significant improvement to accurately predict area burnt. 


\section{Annexes}

A. Supplementary material for Chapter 2

B. Methods for Chapter $\mathbf{5}$

C. Supplementary material for Chapter $\mathbf{5}$ 


\section{A. Supplementary material for Chapter 2}

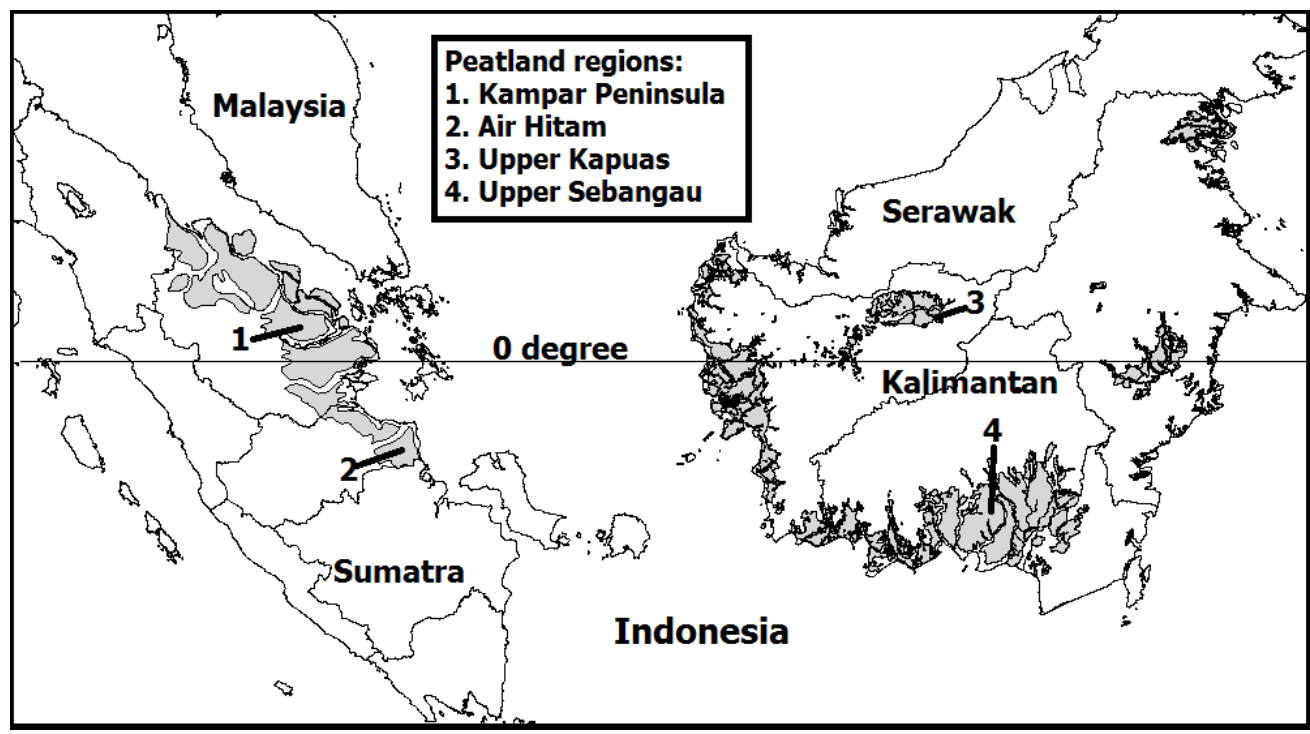

Figure A.1. Study sites in peatland regions of Southeast Asia: 1. Kampar Peninsula, 2. Air Hitam, 3. Upper Kapuas, and 4. Upper Sebangau. 


\section{Annexes}

Table A.1. Properties of the selected 12 groundwater levels monitoring sites distributed over the various land-use types for calibration. The last columns provide Goodness-of-fit criteria (model calibration). The five selected land-use types are indicated in bold.

\begin{tabular}{|c|c|c|c|c|c|c|c|c|c|c|c|c|c|c|}
\hline $\mathrm{N}$ & Code & Land-use & Region & Sites & Island & Calibration & 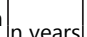 & drai & Source & \multicolumn{5}{|c|}{ Goodness-of-fit } \\
\hline & & & & & & Period & & & & (\%) & Id & $r$ & $r^{2}$ & kge \\
\hline 1 & Ka1 & $\begin{array}{l}\text { Drained } \\
\text { forest }\end{array}$ & Kampar & DW018 & Sumatra & $\begin{array}{c}\text { Jan } 12- \\
\text { Dec } 14\end{array}$ & 3 & $\begin{array}{l}\text { controlled } \\
\text { canal }\end{array}$ & $\begin{array}{l}\text { (Setiawan } \\
\text { et al. 2016) }\end{array}$ & 12.7 & 0.85 & 0.75 & 0.56 & 0.71 \\
\hline 2 & $\mathrm{Ka} 2$ & $\begin{array}{l}\text { Drained } \\
\text { forest }\end{array}$ & Kampar & DW030 & Sumatra & $\begin{array}{c}\text { May } 11- \\
\text { Dec } 14\end{array}$ & 3.5 & $\begin{array}{c}\text { controlled } \\
\text { canal }\end{array}$ & $\begin{array}{l}\text { (Setiawan } \\
\text { et al. 2016) }\end{array}$ & 9.5 & 0.84 & 0.72 & 0.52 & 0.70 \\
\hline 3 & Ka3 & $\begin{array}{c}\text { Drained } \\
\text { acacia }\end{array}$ & Kampar & DW012 & Sumatra & $\begin{array}{l}\text { May } 11- \\
\text { Dec } 14\end{array}$ & 3.5 & $\begin{array}{c}\text { controlled } \\
\text { canal }\end{array}$ & $\begin{array}{l}\text { (Setiawan } \\
\text { et al. 2016) }\end{array}$ & 1.5 & 0.90 & 0.82 & 0.67 & 0.79 \\
\hline 4 & $\mathrm{Ka} 4$ & $\begin{array}{c}\text { Drained } \\
\text { acacia }\end{array}$ & Kampar & DW027 & Sumatra & $\begin{array}{c}\text { Jan } 12- \\
\text { Dec } 14\end{array}$ & 3 & $\begin{array}{l}\text { controlled } \\
\text { canal }\end{array}$ & $\begin{array}{c}\text { (Setiawan } \\
\text { et al. 2016) }\end{array}$ & 8.3 & 0.76 & 0.65 & 0.42 & 0.46 \\
\hline 5 & $\mathrm{Ka} 5$ & $\begin{array}{c}\text { Drained } \\
\text { acacia }\end{array}$ & Kampar & Dumai & Sumatra & $\begin{array}{l}\text { Nov } 09- \\
\text { Oct } 10\end{array}$ & 1 & $\begin{array}{c}\text { controlled } \\
\text { canal }\end{array}$ & $\begin{array}{c}\text { (Kozan } \\
2016)\end{array}$ & 4.1 & 0.74 & 0.61 & 0.37 & 0.39 \\
\hline 6 & AH1 & $\begin{array}{l}\text { Intact } \\
\text { forest }\end{array}$ & Air Hitam & $\begin{array}{c}\text { Air } \\
\text { Hitam }\end{array}$ & Sumatra & $\begin{array}{l}\text { Oct } 03- \\
\text { Oct } 04\end{array}$ & 1 & natural & $\begin{array}{c}\text { (Wösten et } \\
\text { al. 2006) }\end{array}$ & 13.9 & 0.92 & 0.90 & 0.80 & 0.55 \\
\hline 7 & Bi1 & $\begin{array}{l}\text { Logged } \\
\text { forest }\end{array}$ & $\begin{array}{l}\text { Upper } \\
\text { Kapuas }\end{array}$ & gwl12 & Borneo & $\begin{array}{c}\text { Jan } 14- \\
\text { Apr } 15\end{array}$ & 1.5 & natural & This study & -8.2 & 0.66 & 0.59 & 0.34 & 0.09 \\
\hline 8 & $\mathrm{Bi} 2$ & $\begin{array}{l}\text { Logged } \\
\text { forest }\end{array}$ & $\begin{array}{l}\text { Upper } \\
\text { Kapuas }\end{array}$ & gwl13 & Borneo & $\begin{array}{c}\text { Jan } 14- \\
\text { Apr } 15\end{array}$ & 1.5 & natural & This study & -0.4 & 0.78 & 0.72 & 0.52 & 0.23 \\
\hline 9 & $\mathrm{Bi} 3$ & $\begin{array}{l}\text { Logged } \\
\text { forest }\end{array}$ & $\begin{array}{l}\text { Upper } \\
\text { Kapuas }\end{array}$ & gwl14 & Borneo & $\begin{array}{c}\text { Jan } 14- \\
\text { Apr } 15\end{array}$ & 1.5 & natural & This study & -8.4 & 0.86 & 0.76 & 0.58 & 0.64 \\
\hline 10 & SF1 & $\begin{array}{l}\text { Intact } \\
\text { forest }\end{array}$ & $\begin{array}{c}\text { Upper } \\
\text { Sebangau }\end{array}$ & UF & Borneo & $\begin{array}{c}\text { Jan } 97- \\
\text { Dec } 07\end{array}$ & 11 & natural & $\begin{array}{l}\text { (Hirano et } \\
\text { al. 2012) }\end{array}$ & -22.5 & 0.91 & 0.85 & 0.73 & 0.61 \\
\hline 11 & $\mathrm{BC} 1$ & $\begin{array}{c}\text { Restored } \\
\text { forest }\end{array}$ & $\begin{array}{c}\text { Upper } \\
\text { Sebangau }\end{array}$ & swtr4 & Borneo & $\begin{array}{c}\text { Mar } 10- \\
\text { May } 12\end{array}$ & 2 & $\begin{array}{c}\text { controlled } \\
\text { canal }\end{array}$ & $\begin{array}{c}\text { (Ishii et al. } \\
2016)\end{array}$ & $\mid-18.3$ & 0.89 & 0.83 & 0.69 & 0.61 \\
\hline 12 & BC2 & $\begin{array}{c}\text { Restored } \\
\text { forest }\end{array}$ & $\begin{array}{c}\text { Upper } \\
\text { Sebangau }\end{array}$ & well9 & Borneo & $\begin{array}{l}\text { Jul } 10- \\
\text { Feb } 12\end{array}$ & 1.5 & $\begin{array}{c}\text { controlled } \\
\text { canal }\end{array}$ & $\begin{array}{c}\text { (Ishii et al. } \\
2016)\end{array}$ & -9 & 0.90 & 0.87 & 0.75 & 0.59 \\
\hline
\end{tabular}


a. Observation

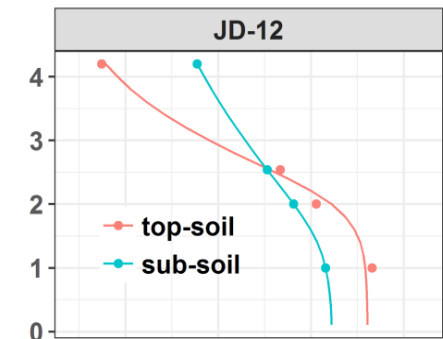

는

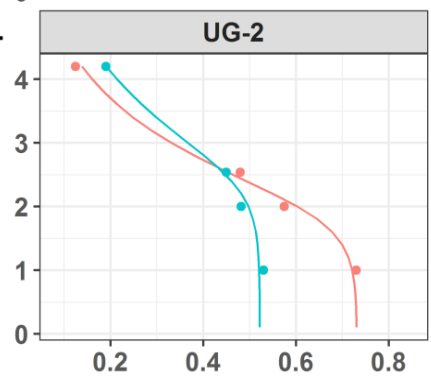

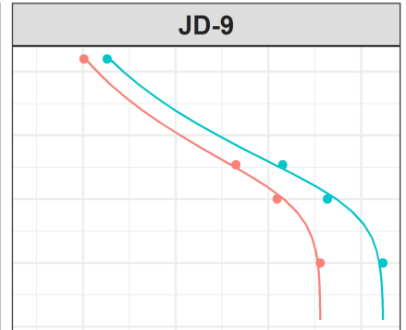

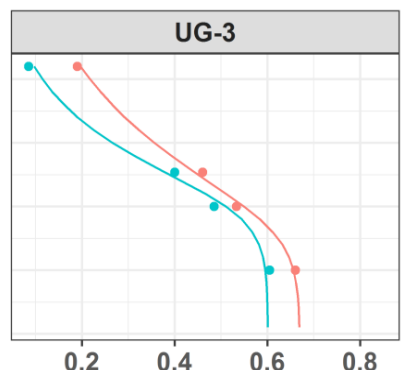

volumetric water content $\left(\mathrm{cm}^{3} / \mathrm{cm}^{3}\right)$
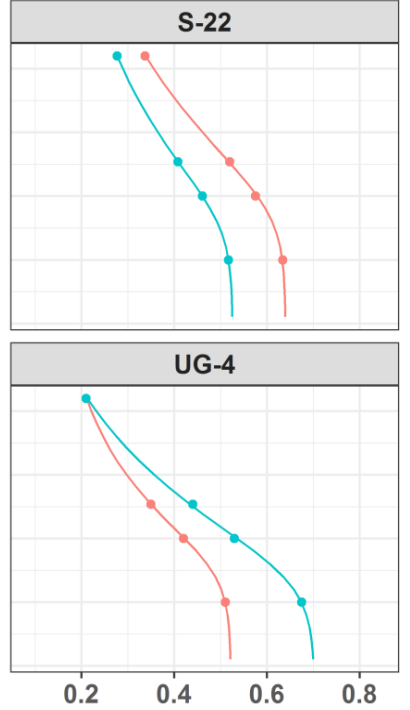

b. Model

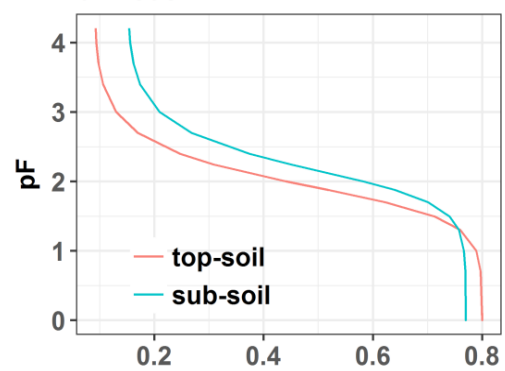

volumetric water content $\left(\mathrm{cm}^{3} / \mathrm{cm}^{3}\right)$

Figure A.2. Soil water retention curves: a) observed (dots), b) model. The curve is predicted by the Van Genuchten equation. The generic characteristics of soil water retention are derived from the slightly modified observed characteristics knowing that data taken from ca. $200 \mathrm{~cm}^{3}$ of peat ring samples (Konecny et al. 2016) may not represent the characteristics for each layer, as tropical peat bulk density varies across peatland surface and down profiles (Page et al. 2011). We assumed that the peatland has a saturated hydraulic conductivity of $30 \mathrm{~m} /$ day (Wösten et al. 2006). 


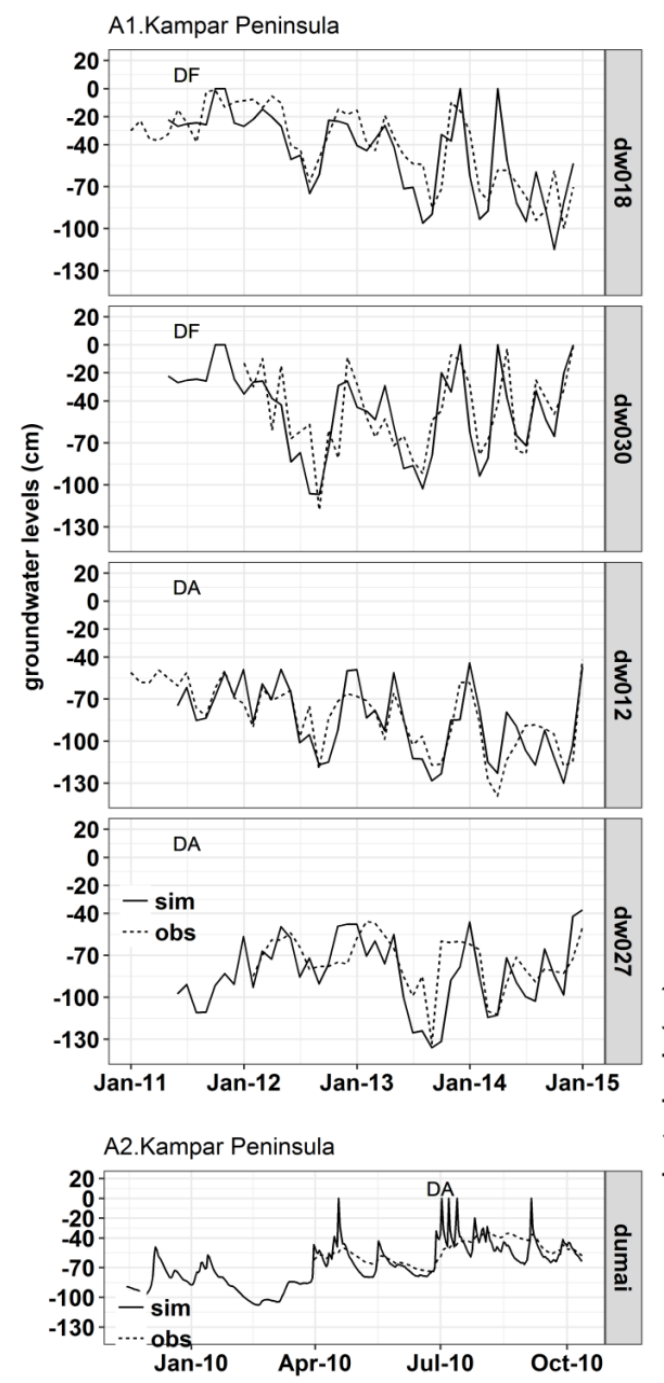

C. Upper Kapuas: Bika

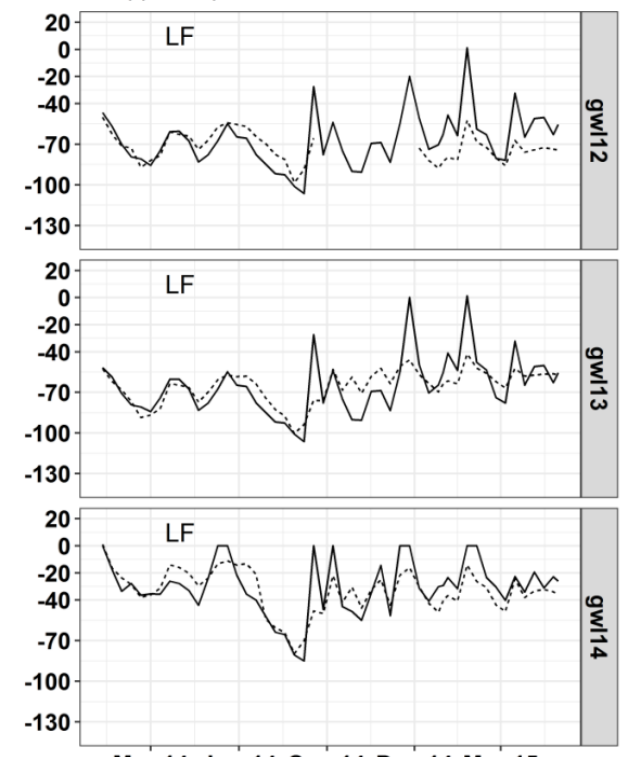

Mar-14 Jun-14 Sep-14 Dec-14 Mar-15

D.1 Upper Sebangau: Blok C

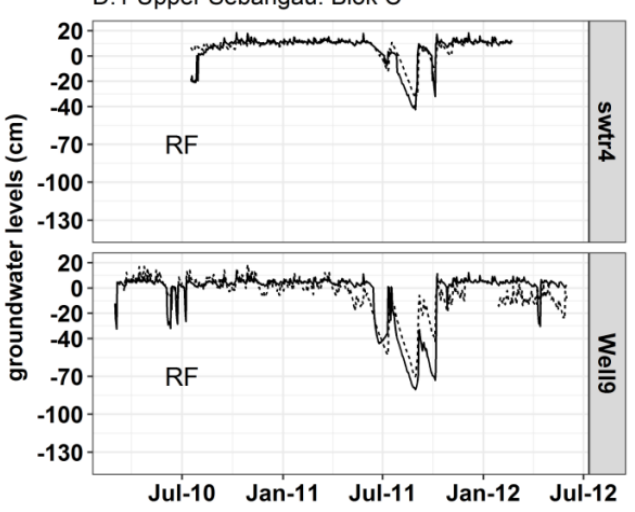

B. Air Hitam
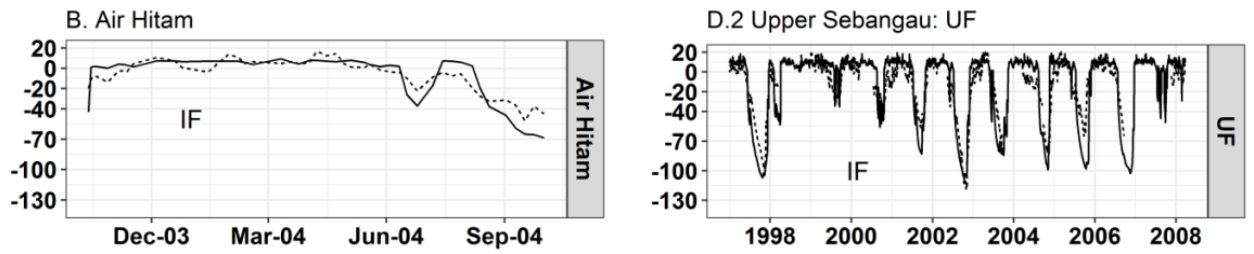

Figure A.3. Hydrograph of observed (dots) and model for groundwater levels in four Southeast Asia's peatland regions. Six land-use types are identified, namely IF: intact forest, RF: restored forest, DF: drained forest, LF: logged forest, and DA: drained acacia. 
(a)
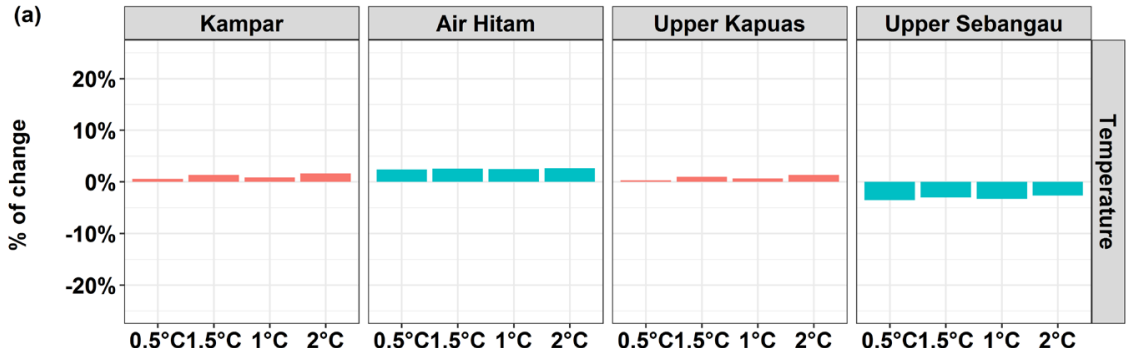

(b)
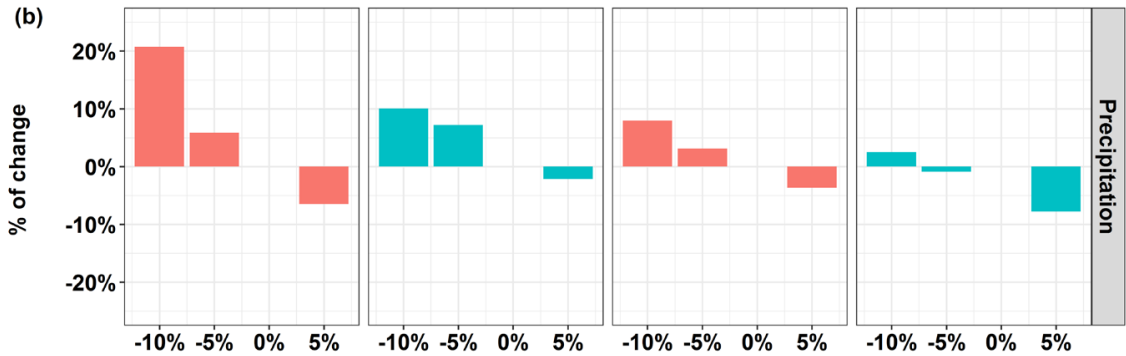

Figure A.4. Changes in drought severity (amplification of the mean annual deviation in GWL) for intact Forest (IF). (a) projected warming temperature to be $2^{\circ} \mathrm{C}$. (b) projected precipitation over Southeast Asia from $-10 \%$ to $+5 \%$. 


\section{B. Methods for Chapter 5}

Soil water balance model. Borneo has been subdivided into 270 grid cells $\left(0.5^{\circ}\right)$. For each grid cell, we applied a simple soil water balance model (Van Lanen et al. 2013; Wanders and Van Lanen 2015) to simulate transient soil water storage, actual evapotranspiration, and groundwater recharge (Eq. 5.1), with as input precipitation and reference potential evapotranspiration from the CRU dataset (Harris et al. 2014). For a detailed explanation about the soil water balance model, readers may refer to (Van Lanen et al. 2013; Wanders and Van Lanen 2015). The recharge simulation identifies droughts using the land use from 2007 as reference (Hoekman et al. 2010) and the climate variability as reflected in the monthly climate data from 1901 to 2015. Land use in 2007 included 2.3\% of the area classified as oil palm plantation. In 2010, this increased to $4 \%$ of Borneo (Koh et al. 2011)and is projected to increase in the coming decades (Carlson et al. 2012). The emphasis in this study is on climate variability rather than on land use change, although the latter may influence wildfires as well (Langner et al. 2007) through providing favorable conditions. Likely, the area burnt will increase and the importance of hydrology will become even more distinct, if more peatland is converted into large-scale plantations.

Area in hydrological drought. Drought events were derived from time series of groundwater recharge using the threshold level approach, where the threshold is taken to be the $80^{\text {th }}$ percentile of the cumulative duration curve (Van Loon and Van Lanen 2012) of groundwater recharge. Drought was defined as the period when the recharge is continuously below this threshold value. We applied different monthly variable thresholds for each grid cell, representative for its own soil-hydrological properties and given precipitation. Deficit in groundwater recharge (def) is the hydrological drought characteristic we used in this study. Then we also counted the proportion of grid cells for Borneo, for which the monthly recharge was below the threshold, and we defined this proportion as the area in drought. The monthly percentage area in drought $\left(A D_{m}\right)$ for the whole of Borneo for month $m$ and year $i$ is calculated as follows:

$$
\mathrm{ADm}, \mathrm{i}=100 \times \frac{1}{\mathrm{Ng}} \Sigma_{\mathrm{g}=1}^{\mathrm{Ng}} \operatorname{defg}, \mathrm{m}, \mathrm{i}
$$

where: def ${ }_{g, m}$ describes whether a grid cell $g$ for month $m$ and year $i$ is in drought (0: no drought, 1 : drought), $\mathrm{N}_{g}^{g, m}$ is number of grid cells covering Borneo. For each year $i$, two metrics of area in drought were used, namely the annual max ( $\left.A D_{-} \_\mathrm{mx}\right)$ and annual mean ( $\left.A D_{-} \mathrm{ave}\right)$ :

$$
\begin{aligned}
\mathrm{AD}-\operatorname{mxi} & =\max (\mathrm{ADm}, \mathrm{i}) \\
\mathrm{AD}-a v e \mathrm{i} & =\operatorname{mean}(\mathrm{ADm}, \mathrm{i})
\end{aligned}
$$

Where: $A D_{-} m x_{i}$ and $A D_{-}$ave $e_{i}$ describe the annual maximum and annual mean area in drought, which are the maximum area occurring in one of the months in a year and the mean of the areas in drought derived from the 12 monthly values for each year.

Drought and non-drought years. Drought was defined as the period with a deficit in the groundwater recharge over a large area. This definition was introduced to avoid taking into account droughts that cover only a small area (Tallaksen et al. 2009). Borneo is well-known as an ENSOdriven drought region (Page et al. 2002; Wooster et al. 2012), therefore we defined a drought year as a year with a warm ENSO event (classification is available at http://ggweather.com/enso/oni.htm). Our analysis shows that in warm ENSO years, hydrological drought occurred extensively throughout Borneo in more than $50 \%$ of the area. For example, during the ENSO-drought in $2015,50 \%$ of Borneo experienced hydrological drought for 2-consecutive months. There were seven warm ENSO years, i.e. 1997-98, 2002, 2004, 2006, 2009, and 2015. For a non-warm ENSO year, we assumed that at least $40 \%$ of Borneo had to be in drought to be selected as a drought year. This drought should occur as an uninterrupted event for at least two consecutive months. Under this definition, only one year was identified as a drought year, i.e. 2014. In total we identified eight out of 20 as drought years in the period for which observed area burnt was available (1996-2015, see Annex C: Table C.1).

Statistical analysis. We used three different statistical approaches to predict monthly area burnt (response Y) given by independent predictors (). There were two types of predictors, namely predictors based only on climate information (e.g. precipitation, fire weather system 
indices, and an El Niño/ ENSO indicator), and predictors including hydrological information (e.g. groundwater recharge) to complement climate predictors (Annex C: Table C.2). From the water balance components (Chapter 5: Eq. 5.1), predictors were derived, such as the total two consecutive months with deficit recharge, and FWI (Annex C: Figure C.3). We used the Oceanic Niño Index (ONI, data available at http://ggweather.com/enso/oni.htm) as an ENSO predictor. Subsequently, three statistical approaches were explored, namely linear models, non-linear models using local regression fitting loess (Cleveland and Devlin 1988), and random forest (Breiman 2001) as predictive models. The period 1996-2015 was used for model calibration, as data on area burnt were available from GFED4 (Giglio et al. 2013).

We hypothesize that wildfires occur during a drought, when prolonged below normal precipitation occurs. A threshold of $100 \mathrm{~mm} / \mathrm{month}$ is commonly used to detect drought events in the forest ecosystem in Borneo (Walsh 1996; Walsh and Newbery 1999; Newbery and Lingenfelder 2004). Here, we used low groundwater recharge instead to detect drought-fire connectivity. The prediction of area burnt was performed when the groundwater recharge is below $20 \mathrm{~mm} / \mathrm{month}$. This number reflects soil moisture depletion and groundwater drawdown due to limited water input. Furthermore, we applied the Nash-Sutcliffe Efficiency (nse) criterion to assess model performance. nse indicates the fraction of the variance of the observations explained by the model and is widely applied in hydrology (Moriasi et al. 2007; Gupta et al. 2009). The assessment confirmed that by using the loess approach, the area burnt is better identified than by using other models (Annex C: Figure C.3).

To assess whether hydrological predictors perform better than climate ones, we clustered the loess models into two groups, i.e. a climate-oriented ensemble (CLIM) and a hydroclimate-oriented ensemble (H-CLIM). Here, we have chosen the Kling-Gupta Efficiency (kge) (Gupta et al. 2009), as a combined measure of bias, correlation and scale between observed and model data, and the RMSEobservation standard deviation ratio, rsr (Moriasi et al. 2007) to complement the nse criterion to assess model performance. Moreover, we tested the variance of the residuals for both groups of ensembles with the chi-square test (using $\alpha=0.01$ ) to evaluate their performance. We used the $R$ statistical computing language (R Development Core Team 2011) to perform all statistical analyses. Finally, we utilized the ggplot2 package (Wickham 2009) to visualize data and information.

Model selection procedures. To identify the best explanatory statistical relationships, we used criteria widely used in hydrology (Moriasi et al. 2007) for a monthly time step simulation. The performance of a statistical model is considered acceptable if the nse $>=0.5$ and the $r s r<0.7$. The kge should greater than 0.5 , as well. By applying these criteria we found 24 models that performed well in which all of them belong to HCLIM. To reduce the number of models in the ensemble, we added that the variance of the chosen model should be below the $80^{\text {th }}$ percentile of all models' variance. By applying this selection procedure, we identified 13 ensemble members that performed well for H-CLIM. On other hand, for CLIM we selected the best 13 models with full record length (1950-1995) as model ensemble. These best-performing models are labelled in the Annex C (Figure C.5).

There are not many independent data for the area burnt to verify that the ensemble of $\mathrm{H}$-CLIM models performs better than the CLIM one. During the very strong El-Nino of 1982/1983 (Malingreau et al. 1985), wildfires (incl. land and forest) occurred over an area of 3.5 million ha. The CLIM model ensemble deviated by $60 \%$ from the actual area burnt reported, whereas the difference for $\mathrm{H}$-CLIM was only $14 \%$. This means that the CLIM models very likely underestimate the area burnt.

ENSO classes. We used the ONI for the period 1950-2015 to categorize the years as very strong, strong, moderate, or weak El Niño years (classification is available at http://ggweather.com/enso/ oni.htm). Based on El Niño strength, we classified the years 1982-83 and 1997-98 as very strong El Niño years, while 1965-66 and 1972-73 were categorized as strong El Niño years. The years 1991-92 and 2009-10 represent moderate El Niño years. Years 1976-77 and 2006-07 are the best examples of weak El Niño events. Finally, we applied both the CLIM and H-CLIM model ensemble members to estimate wildfire area burnt for these different ENSO classes. 
Annexes

\section{Supplementary material for Chapter 5}

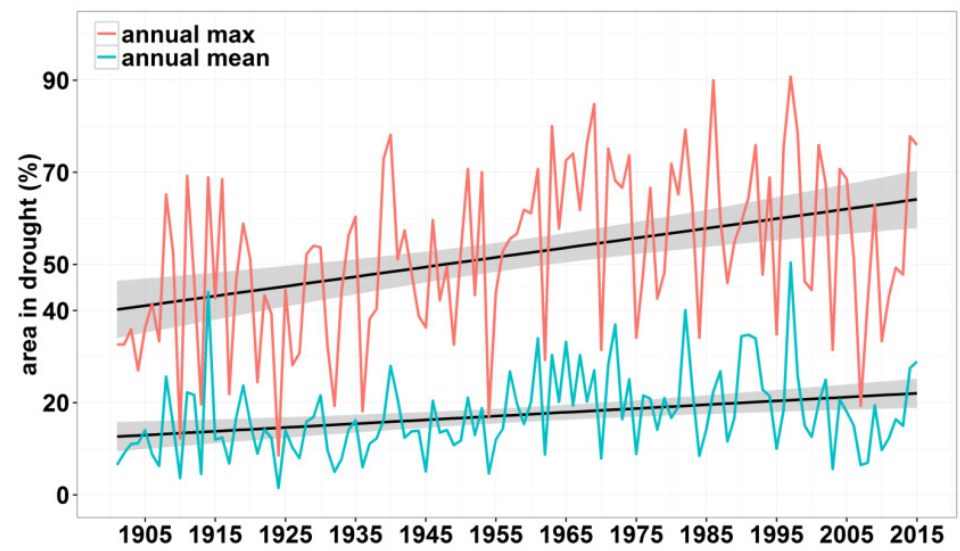

Figure C.1. Time series of area in hydrological drought for 1901-2015 across Borneo. Two metrics were identified based upon monthly values: annual maximum and annual mean of area in drought, which are the maximum area occurring in one of the months in a year and the mean area in drought derived from the 12 monthly values for each year (Methods, Eqs. 2-4). It appears that the century wide trend in annual max (in terms of affected area) is stronger than of the annual mean area. The slope of the trend line is significantly positive, as can be seen from the 95\% confidence intervals (grey-shaded area in the graph). This finding provides evidence that there has been a drying trend since the start of the last century.

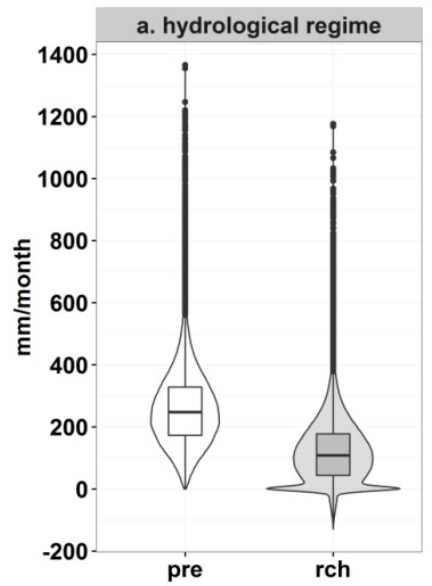

b. drought duration, period: 1901-2015

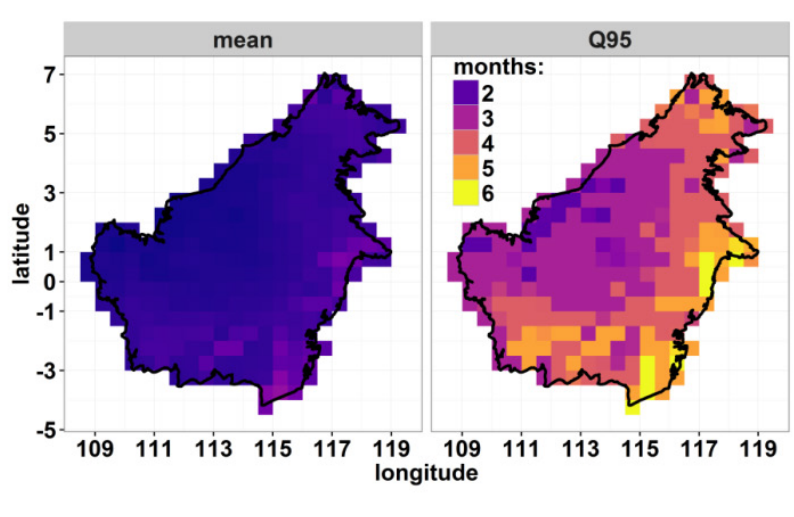

Figure C.2. Hydroclimate and drought in Borneo: (a) Violin and box plots showing the distribution of precipitation (pre, white) and recharge (rch, grey) over the period 1901-2015. The y-axis gives the magnitude of the recharge and precipitation ( $\mathrm{mm} / \mathrm{month}$ ). The violin plot (showing the probability density) illustrates differences in precipitation and recharge regimes. Negative recharge means that the monthly evapotranspiration is greater than the precipitation, which sometimes occurs in grid cells with shallow water tables. (b) Spatial distribution of hydrological drought duration (mean and 95\% quantile in months), 1901-2015. 

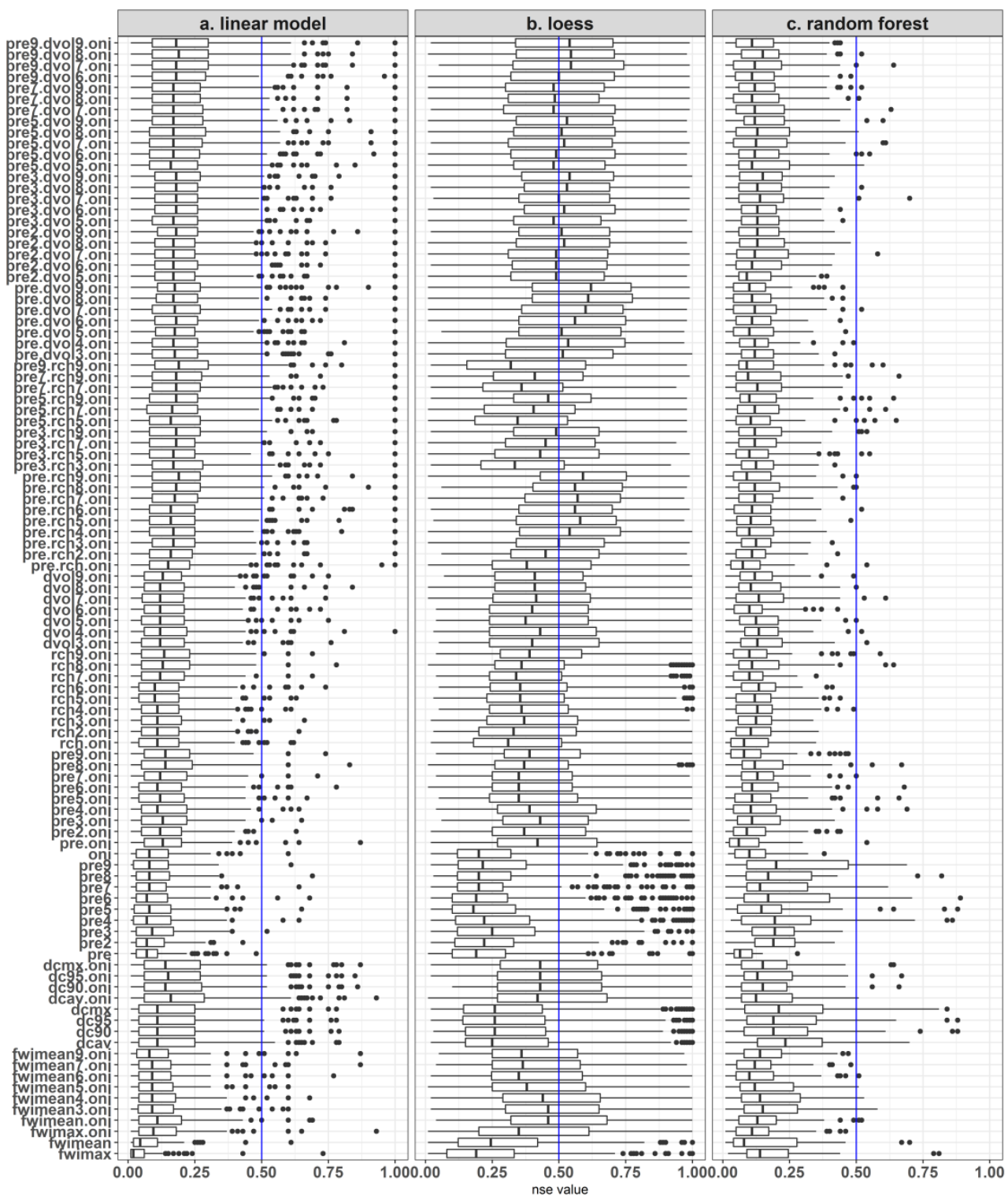

Figure C.3. Boxplot of statistical models that were fitted as possible predictors of area burnt: (a) Linear approaches, (b) non-linear approaches with loess models, and (c) non-linear approaches with Random Forest. Along the $y$-axis different combinations of predictors are listed (see Table C.2). The x-axis represents the Nash-Sutcliffe Efficiency (nse). The boxplot indicates the median, and the $25 \%$ and $75 \%$ quantiles. The dots indicate outliers. 


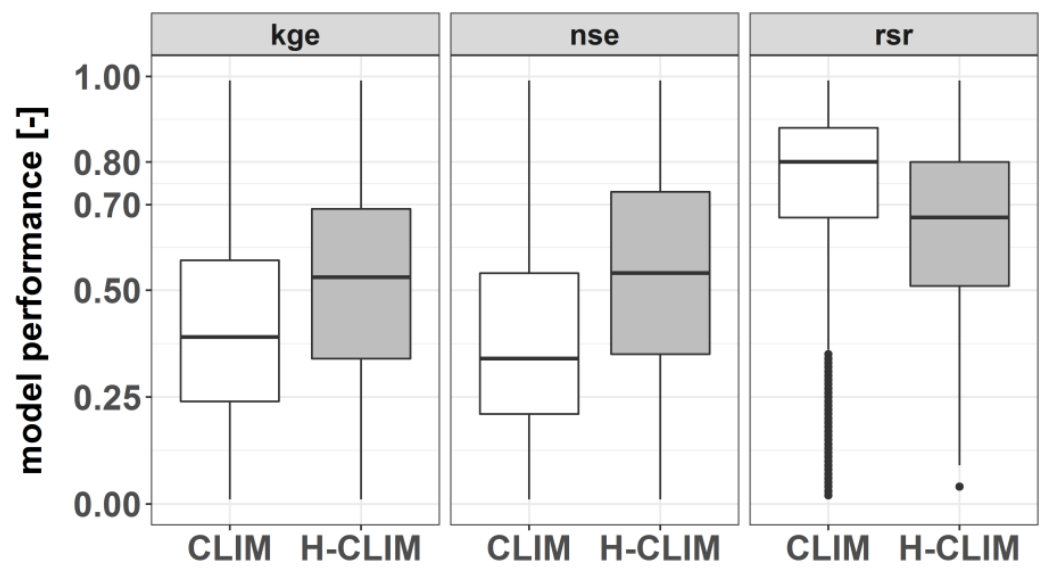

Figure C.4. Summary of goodness-of-fit criteria for the two model ensembles (Climate-oriented-CLIM and Hydroclimate-oriented - H-CLIM) using monthly model output for1996-2015. The criteria include: Kling-Gupta Efficiency (kge), Nash-Sutcliffe Efficiency (nse), and RMSE-observation standard deviation ratio (rsr). For kge and nse, the higher the value, the better model performance is, whereas the lower the rsr, the better the model ensemble performs. The boxplot explains the median, and the $25 \%$ and 75 $\%$ quantiles. The dots indicate outliers. The criteria suggest that H-CLIM better predicts area burnt than CLIM.

Table C.1. Annual area burnt (source: GFED4) for the whole of Borneo during drought and non-drought years for 1996-2015.

\begin{tabular}{|c|c|c|c|c|c|c|c|}
\hline \multirow[b]{2}{*}{ Year } & \multirow[b]{2}{*}{ Category } & \multicolumn{2}{|c|}{ Area Burnt (ha) } & \multirow[b]{2}{*}{ Year } & \multirow[b]{2}{*}{ Category } & \multicolumn{2}{|c|}{ Area Burnt (ha) } \\
\hline & & $\begin{array}{l}\text { Monthly } \\
\text { max }\end{array}$ & Total & & & $\begin{array}{l}\text { Monthly } \\
\text { max }\end{array}$ & Total \\
\hline 1996 & non drought & 46,908 & 169,405 & 2006 & drought & 504,196 & $1,215,872$ \\
\hline 1997 & drought & 990,400 & $2,443,364$ & 2007 & non drought & 46,666 & 74,490 \\
\hline 1998 & drought & $1,405,928$ & $3,232,449$ & 2008 & non drought & 6,109 & 21,308 \\
\hline 1999 & non drought & 126,831 & 252,258 & 2009 & drought & 653,327 & 949,294 \\
\hline 2000 & non drought & 28,470 & 54,159 & 2010 & non drought & 19,142 & 39,721 \\
\hline 2001 & non drought & 73,654 & 145,015 & 2011 & non drought & 80,299 & 227,672 \\
\hline 2002 & drought & 590,219 & 956,775 & 2012 & non drought & 148,401 & 244,071 \\
\hline 2003 & non drought & 99,592 & 227,865 & 2013 & non drought & 28,274 & 52,368 \\
\hline 2004 & drought & 308,657 & 796,284 & 2014 & drought & 356,888 & 688,975 \\
\hline 2005 & non drought & 144,886 & 227,308 & 2015 & drought & 640,829 & 972,659 \\
\hline
\end{tabular}



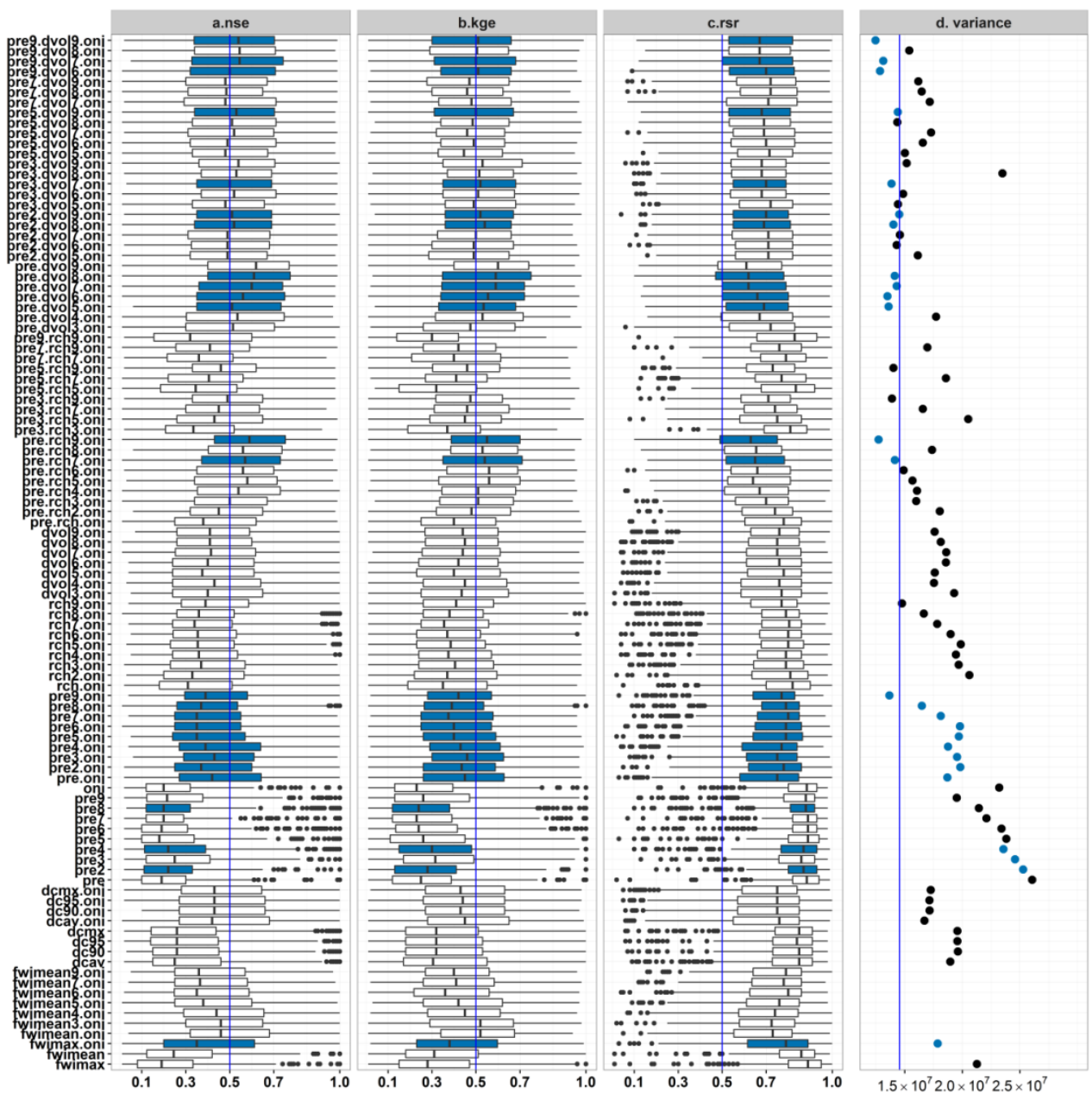

Figure C.5. Goodness of fit (i.e. three left panels) and variance of residuals (right panel) of the prediction model using loess: (a) Nash-Sutcliffe efficiency nse; (b) Kling-Gupta efficiency kge;(c) RMSE-observation standard deviation ratio rsr, and (d) variance of residuals. The goodness of fit is presented as boxplots: for nse and kge the closer to 1 the better the performance of the model, for the rsr the opposite. The boxplot indicates the median, and the $25 \%$ and $75 \%$ quantiles. The dots indicate outliers. As a complement for the goodness of fit, the variance of the residuals is shown: the lower the value, the better the model performance. The blue boxplots were chosen as ensemble members for H-CLIM (the 13 top boxplots) and CLIM (the 13 bottom boxplots). Along the $y$-axis different combinations of predictors are listed (see Extended Data Table 2).Vertical lines in Goodness of Fit (GOF) are used as guidance for which models statistically perform better. For variance, the vertical line represents the 20\% percentile as a threshold for model selection. In several models, the dot showing the variance is missing as the value is greater than $3 \times 10^{7}$. 
Table C.2. List of predictors used in this study. With these predictors, more than 90 combination models were tested for each approach (see Annex C. Figure C.3).

\begin{tabular}{|c|c|c|}
\hline No & Predictors & Description \\
\hline & CLIM & \\
\hline 1 & pre & monthly precipitation; \\
\hline 2 & pre2 & total precipitation for 2-consecutive months \\
\hline 3 & pre3 & total precipitation for 3-consecutive months \\
\hline 4 & pre4 & total precipitation for 4-consecutive months \\
\hline 5 & pre5 & total precipitation for 5-consecutive months \\
\hline 6 & pre6 & total precipitation for 6 -consecutive months \\
\hline 7 & pre7 & total precipitation for 7 -consecutive months \\
\hline 8 & pre8 & total precipitation for 8-consecutive months \\
\hline 9 & pre9 & total precipitation for 9-consecutive months \\
\hline 10 & oni & Oceanic Nino Index (ONI) \\
\hline 11 & fwimax & max daily fire weather index in respective month \\
\hline 12 & fwimean & average daily fire weather index in respective month \\
\hline 13 & fwimean3 & average daily fire weather index in 3-consecutive months \\
\hline 14 & fwimean4 & average daily fire weather index in 4-consecutive months \\
\hline 15 & fwimean5 & average daily fire weather index in 5-consecutive months \\
\hline 16 & fwimean6 & average daily fire weather index in 6-consecutive months \\
\hline 17 & fwimean7 & average daily fire weather index in 7-consecutive months \\
\hline 18 & fwimean9 & average daily fire weather index in 9-consecutive months \\
\hline 19 & dcav & average daily drought code (DC) in same month \\
\hline 20 & dc90 & $90^{\text {th }}$ percentile daily drought code (DC) in same month \\
\hline 21 & dc95 & $95^{\text {th }}$ percentile daily drought code (DC) in same month \\
\hline 22 & $\mathrm{dcm} x$ & maximum daily drought code (DC) in same month \\
\hline 23 & spi1 & monthly standardized precipitation index in respective month \\
\hline 24 & spi6 & total standardized precipitation index for 6-consecutive months \\
\hline \multirow[t]{2}{*}{25} & spi12 & total standardized precipitation index for 12 -consecutive months \\
\hline & H-CLIM & \\
\hline 26 & rch & monthly groundwater recharge \\
\hline 27 & rch2 & total recharge for 2-consecutive months \\
\hline 28 & rch3 & total recharge for 3-consecutive months \\
\hline 29 & rch4 & total recharge for 4-consecutive months \\
\hline 30 & rch5 & total recharge for 5 -consecutive months \\
\hline 31 & rch6 & total recharge for 6 -consecutive months \\
\hline 32 & rch7 & total recharge for 7 -consecutive months \\
\hline 33 & rch8 & total recharge for 8 -consecutive months \\
\hline 34 & rch9 & total recharge for 9-consecutive months \\
\hline 35 & dvol3 & total drought deficit volume for 3-consecutive months \\
\hline 36 & dvol4 & total drought deficit volume for 4-consecutive months \\
\hline 37 & dvol5 & total drought deficit volume for 5 -consecutive months \\
\hline 38 & dvol6 & total drought deficit volume for 6 -consecutive months \\
\hline 39 & dvol7 & total drought deficit volume for 7 -consecutive months \\
\hline 40 & dvol8 & total drought deficit volume for 8-consecutive months \\
\hline 41 & dvol9 & total drought deficit volume for 9-consecutive months \\
\hline
\end{tabular}




\section{Bibliography}

Adams, M. A., S. C. Cunningham, and M. T. Taranto. 2013. A critical review of the science underpinning fire management in the high altitude ecosystems of south-eastern Australia. Forest Ecology and Management 294. The Mega-Fire Reality: 225-237. doi:10.1016/j.foreco.2012.10.042.

Ager, A. A., M. A. Finney, B. K. Kerns, and H. Maffei. 2007. Modeling wildfire risk to northern spotted owl (Strix occidentalis caurina) habitat in Central Oregon, USA. Forest Ecology and Management 246: 45-56.

Ainuddin, N. A., and J. Ampun. 2008. Temporal Analysis of the Keetch-Byram Drought Index in Malaysia: Implications for Forest Fire Management. Journal of Applied Sciences 8: 3991-3994. doi:10.3923/jas.2008.3991.3994.

Alamgir, M., S. Shahid, M. K. Hazarika, S. Nashrrullah, S. B. Harun, and S. Shamsudin. 2015. Analysis of meteorological drought pattern during different climatic and cropping seasons in Bangladesh. JAWRA Journal of the American Water Resources Association 51: 794-806.

Aldrian, E., and R. . Susanto. 2003. Identification of three dominant rainfall regions within Indonesia and their relationship to sea surface temperature. International Journal of Climatology 23: 1435-1452. doi:10.1002/joc.950.

Alencar, A. A., P. M. Brando, G. P. Asner, and F. E. Putz. 2015. Landscape fragmentation, severe drought, and the new Amazon forest fire regime. Ecological Applications 25: 1493-1505. doi:10.1890/14-1528.1.

Allen, R. G., L. S. Pereira, D. Raes, and M. Smith. 1998. Crop Evapotranspiration-Guidelines for Computing Crop Water Requirements. No. 56. Rome, Italy: FAO.

Alley, W. M. 1984. The Palmer Drought Severity Index: Limitations and Assumptions. Journal of Climate and Applied Meteorology 23: 1100-1109. doi:http://dx.doi.org/10.1175/1520-0450(1984)023<1100:TPDSIL>2.0.CO;2.

Amatulli, G., A. Camia, and J. San-Miguel-Ayanz. 2013. Estimating future burned areas under changing climate in the EU-Mediterranean countries. Science of The Total Environment 450-451: 209-222.

Amiro, B. D., K. A. Logan, B. M. Wotton, M. D. Flannigan, J. B. Todd, B. J. Stocks, and D. L. Martell. 2005. Fire weather index system components for large fires in the Canadian boreal forest. International Journal of Wildland Fire 13: $391-400$.

Arpaci, A., C. S. Eastaugh, and H. Vacik. 2013. Selecting the best performing fire weather indices for Austrian ecoregions. Theoretical and Applied Climatology 114: 393-406. doi:10.1007/s00704-013-0839-7.

Asefi-Najafabady, S., and S. Saatchi. 2013. Response of African humid tropical forests to recent rainfall anomalies. Philosophical Transactions of the Royal Society B: Biological Sciences 368: 20120306-20120306.

Beaman, J. 2005. Mount Kinabalu: hotspot of plant diversity in Borneo. Biologiske Skrifter 55: 103-127.

Bedia, J., S. Herrera, J. M. Gutiérrez, A. Benali, S. Brands, B. Mota, and J. M. Moreno. 2015. Global patterns in the sensitivity of burned area to fire-weather: Implications for climate change. Agricultural and Forest Meteorology 214-215: 369-379. doi:10.1016/j.agrformet.2015.09.002.

Bennett, N. D., B. F. W. Croke, G. Guariso, J. H. A. Guillaume, S. H. Hamilton, A. J. Jakeman, S. Marsili-Libelli, L. T. H. Newham, J. P. Norton, C. Perrin, S. A. Pierce, B. Robson, R. Seppelt, A. A. Voinov, B. D. Fath, and V. Andreassian. 2013. Characterising performance of environmental models. Environmental Modelling \& Software 40: 1-20.

Boer, M. M., R. J. Sadler, R. S. Wittkuhn, L. McCaw, and P. F. Grierson. 2009. Long-term impacts of prescribed burning on regional extent and incidence of wildfires-Evidence from 50 years of active fire management in SW Australian forests. Forest Ecology and Management 259: 132-142. doi:10.1016/j.foreco.2009.10.005.

Bonal, D., B. Burban, C. Stahl, F. Wagner, and B. Hérault. 2016. The response of tropical rainforests to drought-lessons from recent research and future prospects. Annals of Forest Science 73: 27-44. doi:10.1007/s13595-0150522-5.

Bonan, G. B. 2008. Forests and climate change: forcings, feedbacks, and the climate benefits of forests. Science 320: 1444-1449. 


\section{Bibliography}

Bouma, J., and H. A. J. Van Lanen. 1987. Transfer functions and threshold values: from soil characteristics to land qualities. In Proceedings of the International Workshop on Quantified Land Evaluation Procedures, ed. K. J. Beek, P. A. Burrough, and D. E. McCormack. Vol. 106-110. Washington, DC, USA, 15-18 May 1986: ITC Publication 6, Enschede, The Netherlands.

Bowman, D. M. J. S., G. L. W. Perry, and J. B. Marston. 2015. Feedbacks and landscape-level vegetation dynamics. Trends in Ecology \& Evolution 30: 255-260. doi:10.1016/j.tree.2015.03.005.

Breiman, L. 2001. Random forests. Machine learning 45: 5-32. doi:10.1023/A:1010933404324.

Buchholz, G., and D. Weidemann. 2000. The use of simple fire danger rating system as a tool for early warming in forestry. International Forest Fire News 23: 32-36.

Caccamo, G., L. A. Chisholm, R. A. Bradstock, M. L. Puotinen, and B. G. Pippen. 2012. Monitoring live fuel moisture content of heathland, shrubland and sclerophyll forest in south-eastern Australia using MODIS data. International Journal of Wildland Fire 21: 257. doi:10.1071/WF11024.

Cai, W., S. Borlace, M. Lengaigne, P. van Rensch, M. Collins, G. Vecchi, A. Timmermann, A. Santoso, M. J. McPhaden, L. Wu, M. H. England, G. Wang, E. Guilyardi, and F.-F. Jin. 2014. Increasing frequency of extreme El Nino events due to greenhouse warming. Nature Climate Change 4: 111-116. doi:10.1038/nclimate2100.

Cai, W., A. Santoso, G. Wang, S. Yeh, S. An, K. M. Cobb, M. Collins, E. Guilyardi, F. Jin, J. Kug, M. Lengaigne, and M. J. McPhaden. 2015. ENSO and greenhouse warming. Nature Climate Change 5. Nature Publishing Group: 849-859. doi:10.1038/nclimate2743.

Carlson, K. M., L. M. Curran, G. P. Asner, A. M. Pittman, S. N. Trigg, and J. Marion Adeney. 2012. Carbon emissions from forest conversion by Kalimantan oil palm plantations. Nature Climate Change 3. Nature Publishing Group: $283-287$. doi:10.1038/nclimate1702.

Cattau, M. E., M. E. Harrison, I. Shinyo, S. Tungau, M. Uriarte, and R. DeFries. 2016. Sources of anthropogenic fire ignitions on the peat-swamp landscape in Kalimantan, Indonesia. Global Environmental Change 39: 205-219. doi:10.1016/j. gloenvcha.2016.05.005.

Chadwick, R., P. Good, G. Martin, and D. P. Rowell. 2015. Large rainfall changes consistently projected over substantial areas of tropical land. Nature Climate Change. doi:10.1038/nclimate2805.

Chan, D. W., J. T. Paul, and A. Dozier. 2004. Keetch-Byram Drought Index: can it help predict wildland fires. Fire Management Today 64: 39-42.

Chappel, N. A., A. R. Discenza, W. Tych, J. Whittaker, and K. Bidin. 2009. Simulating hourly rainfall occurrence within an equatorial rainforest, Borneo Island. Hydrological Sciences Journal 54: 571-581. doi:10.1623/hysj.54.3.571.

Choi, J., W. H. Cooke, and M. D. Stevens. 2009. Development of a Water Budget Management System for Fire Potential Mapping. GIScience \& Remote Sensing 46: 39-53. doi:10.2747/1548-1603.46.1.39.

Chokkalingam, U., I. Kurniawan, and Y. Ruchiat. 2005. Fire, livelihoods, and environmental change in the middle Mahakam peatlands, East Kalimantan. Ecology and Society 10 (1):26.

Cleary, D. F. R., A. Ø. Mooers, K. A. O. Eichhorn, J. Van Tol, R. De Jong, and S. B. J. Menken. 2004. Diversity and community composition of butterflies and odonates in an ENSO-induced fire affected habitat mosaic: a case study from East Kalimantan, Indonesia. Oikos 105: 426-448. doi:10.1111/j.0030-1299.2004.12219.x.

Cleveland, W. S., and S. J. Devlin. 1988. Locally Weighted Regression: An Approach to Regression Analysis by Local Fitting. Journal of the American Statistical Association 83: 596. doi:10.2307/2289282.

Cooke, W., V. Anantharaj, C. Wax, J. Choi, K. Grala, M. Jolly, G. P. Dixon, J. Dyer, D. L. Evans, and G. B. Goodrich. 2007. Integrating climatic and fuels information into national fire risk decision support tools. In Proceedings RMRS-P$46 C D$., ed. B. W. Butler and W. Cook. Fort Collins, CO: U.S. Department of Agriculture, Forest Service, Rocky Mountain Research Station.

Corlett, R. T. 2016. The Impacts of Droughts in Tropical Forests. Trends in Plant Science 21: 584-593. doi:10.1016/j. tplants.2016.02.003.

Crane, W. J. B. 1982. Computing grassland and forest fire behaviour, relative humidity and drought index by pocket calculator. Australian Forestry 45: 89-97. doi:10.1080/00049158.1982.10674339.

Crippa, P., S. Castruccio, S. Archer-Nicholls, G. B. Lebron, M. Kuwata, A. Thota, S. Sumin, E. Butt, C. Wiedinmyer, and D. V. Spracklen. 2016. Population exposure to hazardous air quality due to the 2015 fires in Equatorial Asia. Scientific Reports 6: 37074. doi:10.1038/srep37074.

Dai, A. 2013. Increasing drought under global warming in observations and models. Nature Climate Change 3: 52-58.

De Lange, W. J., G. F. Prinsen, J. C. Hoogewoud, A. A. Veldhuizen, J. Verkaik, G. H. P. Oude Essink, P. E. V. van Walsum, J. R. Delsman, J. C. Hunink, H. T. L. Massop, and T. Kroon. 2014. An operational, multi-scale, multi-model system for consensus-based, integrated water management and policy analysis: The Netherlands Hydrological Instrument. Environmental Modelling \& Software 59: 98-108. doi:10.1016/j.envsoft.2014.05.009.

Delinom, R. M., A. Assegaf, H. Z. Abidin, M. Taniguchi, D. Suherman, R. F. Lubis, and E. Yulianto. 2009. The contribution of human activities to subsurface environment degradation in Greater Jakarta Area, Indonesia. Science of The Total Environment 407: 3129-3141. doi:10.1016/j.scitotenv.2008.10.003.

Deni, S. M., and A. A. Jemain. 2009. Mixed log series geometric distribution for sequences of dry days. Atmospheric Research 92: 236-243. doi:10.1016/j.atmosres.2008.10.032. 
Dennekamp, M., and M. J. Abramson. 2011. The effects of bushfire smoke on respiratory health. Respirology 16: 198-209. doi:10.1111/j.1440-1843.2010.01868.x.

Dennis, R. A., J. Mayer, G. Applegate, U. Chokkalingam, C. J. P. Colfer, I. Kurniawan, H. Lachowski, P. Maus, R. P. Permana, Y. Ruchiat, F. Stolle, Suyanto, and T. P. Tomich. 2005. Fire, People and Pixels: Linking Social Science and Remote Sensing to Understand Underlying Causes and Impacts of Fires in Indonesia. Human Ecology 33: 465-504.

Di Giuseppe, F., F. Pappenberger, F. Wetterhall, B. Krzeminski, A. Camia, G. Libertá, and J. San Miguel. 2016. The Potential Predictability of Fire Danger Provided by Numerical Weather Prediction. Journal of Applied Meteorology and Climatology 55: 2469-2491. doi:10.1175/JAMC-D-15-0297.1.

Diffenbaugh, N. S., and A. Charland. 2016. Probability of emergence of novel temperature regimes at different levels of cumulative carbon emissions. Frontiers in Ecology and the Environment 14: 418-423. doi:10.1002/fee.1320.

Diffenbaugh, N. S., D. L. Swain, and D. Touma. 2015. Anthropogenic warming has increased drought risk in California. Proceedings of the National Academy of Sciences 112: 3931-3936. doi:10.1073/pnas.1422385112.

Dimitrakopoulos, A. P., and A. M. Bemmerzouk. 2002. Predicting live herbaceous moisture content from a seasonal drought index. International Journal of Biometeorology 47: 73-79. doi:10.1007/s00484-002-0151-1.

Dimitrakopoulos, A. P., A. M. Bemmerzouk, and I. D. Mitsopoulos. 2011. Evaluation of the Canadian fire weather index system in an eastern Mediterranean environment. Meteorological Applications 18: 83-93. doi:10.1002/met.214.

Dolling, K., P.-S. Chu, and F. Fujioka. 2005. A climatological study of the Keetch/Byram drought index and fire activity in the Hawaiian Islands. Agricultural and Forest Meteorology 133: 17-27. doi:10.1016/j.agrformet.2005.07.016.

EEA. 2010. Mapping the impacts of natural hazards and technological accidents in Europe. An overview of the last decade. Technical Report 13/2010. Copenhagen: European Environmental Agency (EEA).

Evers, S., C. M. Yule, R. Padfield, P. O'Reilly, and H. Varkkey. 2017. Keep wetlands wet: the myth of sustainable development of tropical peatlands - implications for policies and management. Global Change Biology 23: 534-549. doi:10.1111/gcb.13422.

Falk, D. A., C. Miller, D. McKenzie, and A. E. Black. 2007. Cross-Scale Analysis of Fire Regimes. Ecosystems 10: 809-823.

Fan, Y., and G. Miguez-Macho. 2011. A simple hydrologic framework for simulating wetlands in climate and earth system models. Climate Dynamics 37: 253-278. doi:10.1007/s00382-010-0829-8.

Fan, Y., G. Miguez-Macho, C. P. Weaver, R. Walko, and A. Robock. 2007. Incorporating water table dynamics in climate modeling: 1. Water table observations and equilibrium water table simulations. Journal of Geophysical Research: Atmospheres 112: D10125. doi:10.1029/2006JD008111.

Fernandes, K., L. Verchot, W. Baethgen, V. Gutierrez-Velez, M. Pinedo-Vasquez, and C. Martius. 2017. Heightened fire probability in Indonesia in non-drought conditions: the effect of increasing temperatures. Environmental Research Letters. doi:10.1088/1748-9326/aa6884.

Field, R. D., G. R. Van der Werf, and S. S. P. Shen. 2009. Human amplification of drought-induced biomass burning in Indonesia since 1960. Nature Geoscience 2: 185-188. doi:10.1038/ngeo443.

Field, R. D., A. C. Spessa, N. A. Aziz, A. Camia, A. Cantin, R. Carr, W. J. de Groot, A. J. Dowdy, M. D. Flannigan, K. Manomaiphiboon, F. Pappenberger, V. Tanpipat, and X. Wang. 2015. Development of a Global Fire Weather Database. Natural Hazards and Earth System Science 15: 1407-1423. doi:10.5194/nhess-15-1407-2015.

Finkele, K., G. A. Mills, G. Beard, and D. A. Jones. 2006. National gridded drought factors and comparison of two soil moisture deficit formulations used in prediction of Forest Fire Danger Index in Australia. Australian Meteorological Magazine 55: 183-197.

Fisher, B., D. P. Edwards, X. Giam, and D. S. Wilcove. 2011. The high costs of conserving Southeast Asia's lowland rainforests. Frontiers in Ecology and the Environment 9: 329-334. doi:10.1890/100079.

Flannigan, M. D., K. A. Logan, B. D. Amiro, W. R. Skinner, and B. J. Stocks. 2005. Future Area Burned in Canada. Climatic Change 72: 1-16. doi:10.1007/s10584-005-5935-y.

Forsyth, T. 2014. Public concerns about transboundary haze: A comparison of Indonesia, Singapore, and Malaysia. Global Environmental Change 25: 76-86. doi:10.1016/j.gloenvcha.2014.01.013.

Fu, R., L. Yin, W. Li, P. A. Arias, R. E. Dickinson, L. Huang, S. Chakraborty, K. Fernandes, B. Liebmann, R. Fisher, and R. B. Myneni. 2013. Increased dry-season length over southern Amazonia in recent decades and its implication for future climate projection. Proceedings of the National Academy of Sciences 110: 18110-18115.

Gallery, R. E. 2014. Ecology of Tropical Rain Forests. In Ecology and the Environment, ed. R. K. Monson, 1-22. New York, NY: Springer New York.

Galván, J. D., U. Büntgen, C. Ginzler, H. Grudd, E. Gutiérrez, I. Labuhn, and J. Julio Camarero. 2015. Drought-induced weakening of growth-temperature associations in high-elevation Iberian pines. Global and Planetary Change 124: 95-106. doi:10.1016/j.gloplacha.2014.11.011.

Garnier, E. 2017. Historic drought from archives: beyond the instrumental record. Chapter 3. In Drought: Science and Policy, ed. A. Iglesias, D. Assimacopoulos, and H. A. J. Van Lanen. Chichester: John Wiley \& Sons.

Gaveau, D. L. A., S. Sloan, E. Molidena, H. Yaen, D. Sheil, N. K. Abram, M. Ancrenaz, R. Nasi, M. Quinones, N. Wielaard, and E. Meijaard. 2014. Four Decades of Forest Persistence, Clearance and Logging on Borneo. Edited by Kamal Bawa. PLOS ONE 9: e101654. doi:10.1371/journal.pone.0101654. 


\section{Bibliography}

Giglio, L., J. T. Randerson, and G. R. Van Der Werf. 2013. Analysis of daily, monthly, and annual burned area using the fourth-generation global fire emissions database (GFED4). Journal of Geophysical Research: Biogeosciences 118: 317-328. doi:10.1002/jgrg.20042.

Gloor, M., R. J. W. Brienen, D. Galbraith, T. R. Feldpausch, J. Schöngart, J.-L. Guyot, J. C. Espinoza, J. Lloyd, and O. L. Phillips. 2013. Intensification of the Amazon hydrological cycle over the last two decades. Geophysical Research Letters 40: 1729-1733. doi:10.1002/grl.50377.

Glover, D., and T. Jessup, ed. 1999. Indonesia's fires and haze: the cost of catastrophe. Singapore : Ottawa, ON, Canada: Institute of Southeast Asian Studies; International Development Research Centre.

Goldammer, J. G. 2007. History of equatorial vegetation fires and fire research in Southeast Asia before the 1997-98 episode: A reconstruction of creeping environmental changes. Mitigation and Adaptation Strategies for Global Change 12: 13-32. doi:10.1007/s11027-006-9044-7.

Gray, C., and V. Mueller. 2012. Drought and Population Mobility in Rural Ethiopia. World Development 40: $134-145$. doi:10.1016/j.worlddev.2011.05.023.

Groisman, P. Y., B. G. Sherstyukov, V. N. Razuvaev, R. W. Knight, J. G. Enloe, N. S. Stroumentova, P. H. Whitfield, E. Førland, I. Hannsen-Bauer, H. Tuomenvirta, H. Aleksandersson, A. V. Mescherskaya, and T. R. Karl. 2007. Potential forest fire danger over Northern Eurasia: Changes during the 20th century. Global and Planetary Change 56. Northern Eurasia Regional Climate and Environmental Change: 371-386. doi:10.1016/j.gloplacha.2006.07.029.

Groot, W. J. de, R. D. Field, M. A. Brady, O. Roswintiarti, and M. Mohamad. 2006. Development of the Indonesian and Malaysian Fire Danger Rating Systems. Mitigation and Adaptation Strategies for Global Change 12: 165-180.

Gudmundsson, L., F. C. Rego, M. Rocha, and S. I. Seneviratne. 2014. Predicting above normal wildfire activity in southern Europe as a function of meteorological drought. Environmental Research Letters 9: 084008.

Gupta, A. K., P. Tyagi, and V. K. Sehgal. 2011. Drought disaster challenges and mitigation in India: strategic appraisal. Current science 100: 1795-1806.

Gupta, H. V., H. Kling, K. K. Yilmaz, and G. F. Martinez. 2009. Decomposition of the mean squared error and NSE performance criteria: Implications for improving hydrological modelling. Journal of Hydrology 377: 80-91.

Harris, I., P. D. Jones, T. J. Osborn, and D. H. Lister. 2014. Updated high-resolution grids of monthly climatic observations - the CRU TS3.10 Dataset. International Journal of Climatology 34: 623-642. doi:10.1002/joc.3711.

Harris, R. M. B., T. A. Remenyi, G. J. Williamson, N. L. Bindoff, and D. M. J. S. Bowman. 2016. Climate-vegetation-fire interactions and feedbacks: trivial detail or major barrier to projecting the future of the Earth system? Wiley Interdisciplinary Reviews: Climate Change: n/a-n/a. doi:10.1002/wcc.428.

Heim, R. R. 2002. A Review of Twentieth-Century Drought Indices Used in the United States. Bulletin of the American Meteorological Society 83: 1149-1165. doi:10.1175/1520-0477(2002)083<1149:AROTDI>2.3.CO;2.

Hendon, H. H. 2003. Indonesian rainfall variability: Impacts of ENSO and local air-sea interaction. Journal of Climate 16: 1775-1790.

Heudorfer, B., and K. Stahl. 2016. Comparison of different threshold level methods for drought propagation analysis in Germany. Hydrology Research. doi:10.2166/nh.2016.258.

Hidayat, H., A. J. Teuling, B. Vermeulen, M. Taufik, K. Kastner, T. J. Geertsema, D. C. C. Bol, D. H. Hoekman, G. S. Haryani, H. A. J. Van Lanen, R. M. Delinom, R. Dijksma, G. Z. Anshari, N. S. Ningsih, R. Uijlenhoet, and A. J. F. Hoitink. 2017. Hydrology of inland tropical lowlands: the Kapuas and Mahakam wetlands. Hydrology and Earth System Sciences 21: 2579-2594. doi:10.5194/hess-21-2579-2017.

Hirano, T., H. Segah, K. Kusin, S. Limin, H. Takahashi, and M. Osaki. 2012. Effects of disturbances on the carbon balance of tropical peat swamp forests. Global Change Biology 18: 3410-3422. doi:10.1111/j.1365-2486.2012.02793.x.

Hoekman, D. H., M. A. M. Vissers, and N. Wielaard. 2010. PALSAR wide-area mapping of Borneo: Methodology and map validation. IEEE Journal of Selected Topics in Applied Earth Observations and Remote Sensing 3: 605-617.

Hoffmann, W. A., W. Schroeder, and R. B. Jackson. 2003. Regional feedbacks among fire, climate, and tropical deforestae tion. Journal of Geophysical Research: Atmospheres 108: 4721. doi:10.1029/2003JD003494.

Hooijer, A., S. Page, J. G. Canadell, M. Silvius, J. Kwadijk, H. Wösten, and J. Jauhiainen. 2010. Current and future CO2 emissions from drained peatlands in Southeast Asia. Biogeosciences 7: 1505-1514. doi:10.5194/bg-7-1505-2010.

Hoscilo, A., S. E. Page, K. J. Tansey, and J. O. Rieley. 2011. Effect of repeated fires on land-cover change on peatland in southern Central Kalimantan, Indonesia, from 1973 to 2005. International Journal of Wildland Fire 20: 578.

Huijnen, V., M. J. Wooster, J. W. Kaiser, D. L. A. Gaveau, J. Flemming, M. Parrington, A. Inness, D. Murdiyarso, B. Main, and M. van Weele. 2016. Fire carbon emissions over maritime southeast Asia in 2015 largest since 1997. Scientific Reports 6: 26886. doi:10.1038/srep26886.

Ishii, Y., K. Koizumi, H. Fukami, K. Yamamoto, H. Takahashi, S. H. Limin, K. Kusin, A. Usup, and G. E. Susilo. 2016. Groundwater in Peatland. In Tropical Peatland Ecosystems, ed. M. Osaki and N. Tsuji, 15. Tokyo Heidelberg New York Dordrecht London: Springer Japan.

Jaber, F. H., S. Shukla, and S. Srivastava. 2006. Recharge, upflux and water table response for shallow water table conditions in southwest Florida. Hydrological Processes 20: 1895-1907. doi:10.1002/hyp.5951.

Jaenicke, J., H. Wösten, A. Budiman, and F. Siegert. 2010. Planning hydrological restoration of peatlands in Indonesia to 
mitigate carbon dioxide emissions. Mitigation and Adaptation Strategies for Global Change 15: 223-239.

Jauhiainen, J., S. Limin, H. Silvennoinen, and H. Vasander. 2008. Carbon dioxide and methane fluxes in drained tropical peat before and after hydrological restoration. Ecology 89: 3503-3514.

Jolly, W. M., M. A. Cochrane, P. H. Freeborn, Z. A. Holden, T. J. Brown, G. J. Williamson, and D. M. J. S. Bowman. 2015. Climate-induced variations in global wildfire danger from 1979 to 2013. Nature Communications 6: 7537.

Junk, W. J., S. An, C. M. Finlayson, B. Gopal, J. Květ, S. A. Mitchell, W. J. Mitsch, and R. D. Robarts. 2012. Current state of knowledge regarding the world's wetlands and their future under global climate change: a synthesis. Aquatic Sciences 75: 151-167. doi:10.1007/s00027-012-0278-z.

Keetch, J. J., and G. Byram. 1968. A drought index for forest fire control. Res. Paper SE-38. U.S. Department of Agriculture, Forest Service, Southeastern Forest Experiment Station, Asheville, NC.

Kelley, C. P., S. Mohtadi, M. A. Cane, R. Seager, and Y. Kushnir. 2015. Climate change in the Fertile Crescent and implications of the recent Syrian drought. Proceedings of the National Academy of Sciences 112: 3241-3246. doi:10.1073/ pnas. 1421533112.

Khanna, J., D. Medvigy, S. Fueglistaler, and R. Walko. 2017. Regional dry-season climate changes due to three decades of Amazonian deforestation. Nature Climate Change 7: 200-204. doi:10.1038/nclimate3226.

Kier, G., J. Mutke, E. Dinerstein, T. H. Ricketts, W. Küper, H. Kreft, and W. Barthlott. 2005. Global patterns of plant diversity and floristic knowledge. Journal of Biogeography 32: 1107-1116. doi:10.1111/j.1365-2699.2005.01272.x.

Koh, L. P., J. Miettinen, S. C. Liew, and J. Ghazoul. 2011. Remotely sensed evidence of tropical peatland conversion to oil palm. Proceedings of the National Academy of Sciences 108: 5127-5132. doi:10.1073/pnas.1018776108.

Konecny, K., U. Ballhorn, P. Navratil, J. Jubanski, S. E. Page, K. Tansey, A. Hooijer, R. Vernimmen, and F. Siegert. 2016. Variable carbon losses from recurrent fires in drained tropical peatlands. Global Change Biology 22: 1469-1480.

Kottek, M., J. Grieser, C. Beck, B. Rudolf, and F. Rubel. 2006. World Map of the Köppen-Geiger climate classification updated. Meteorologische Zeitschrift 15: 259-263. doi:10.1127/0941-2948/2006/0130.

Kozan, O. 2016. Rainfall and Groundwater Level Fluctuations in the Peat Swamps. In Catastrophe and Regeneration in Indonesia's Peatlands: Ecology, Economy and Society, ed. K. Mizuno, M. S. Fujita, and S. Kawai, 296-310. Kyoto CSEAS Series on Asian Studies 15. NUS Press and Kyoto University Press.

Krawchuk, M. A., M. A. Moritz, M.-A. Parisien, J. Van Dorn, and K. Hayhoe. 2009. Global Pyrogeography: the Current and Future Distribution of Wildfire. Edited by Jerome Chave. PLOS ONE 4: e5102. doi:10.1371/journal.pone.0005102.

Kroes, J. G., J. C. Van Dam, P. Groenendijk, R. F. A. Hendriks, and C. M. J. Jacobs. 2008. SWAP version 3.2. Theory description and user manual. 1649(02). Wageningen: Alterra.

Kumagai, T., T. M. Saitoh, Y. Sato, H. Takahashi, O. J. Manfroi, T. Morooka, K. Kuraji, M. Suzuki, T. Yasunari, and H. Komatsu. 2005. Annual water balance and seasonality of evapotranspiration in a Bornean tropical rainforest. Agricultural and Forest Meteorology 128: 81-92. doi:10.1016/j.agrformet.2004.08.006.

Kunii, O., S. Kanagawa, I. Yajima, Y. Hisamatsu, S. Yamamura, T. Amagai, and I. T. S. Ismail. 2002. The 1997 Haze Disaster in Indonesia: Its Air Quality and Health Effects. Archives of Environmental Health: An International Journal 57: 16-22. doi:10.1080/00039890209602912.

Lam, A., D. Karssenberg, B. J. J. M. van den Hurk, and M. F. P. Bierkens. 2011. Spatial and temporal connections in groundwater contribution to evaporation. Hydrol. Earth Syst. Sci. 15: 2621-2630. doi:10.5194/hess-15-2621-2011.

Langner, A., J. Miettinen, and F. Siegert. 2007. Land cover change 2002-2005 in Borneo and the role of fire derived from MODIS imagery. Global Change Biology 13: 2329-2340. doi:10.1111/j.1365-2486.2007.01442.x.

Lawrence, D., and K. Vandecar. 2014. Effects of tropical deforestation on climate and agriculture. Nature Climate Change 5: 27-36. doi:10.1038/nclimate2430.

Lee, J. S. H., Z. Jaafar, A. K. J. Tan, L. R. Carrasco, J. J. Ewing, D. P. Bickford, E. L. Webb, and L. P. Koh. 2016. Toward clearer skies: Challenges in regulating transboundary haze in Southeast Asia. Environmental Science \& Policy 55: 87-95.

Lee, J.-E., B. R. Lintner, C. K. Boyce, and P. J. Lawrence. 2011. Land use change exacerbates tropical South American drought by sea surface temperature variability: Drought over tropical South America. Geophysical Research Letters 38: doi:10.1029/2011GL049066.

Leung, L. R., M. Huang, Y. Qian, and X. Liang. 2011. Climate-soil-vegetation control on groundwater table dynamics and its feedbacks in a climate model. Climate Dynamics 36: 57-81. doi:10.1007/s00382-010-0746-x.

Lewis, S. L., P. M. Brando, O. L. Phillips, G. M. F. van der Heijden, and D. Nepstad. 2011. The 2010 Amazon Drought. Science 331: 554-554. doi:10.1126/science.1200807.

Lintner, B. R., M. Biasutti, N. S. Diffenbaugh, J.-E. Lee, M. J. Niznik, and K. L. Findell. 2012. Amplification of wet and dry month occurrence over tropical land regions in response to global warming. Journal of Geophysical Research: Atmospheres 117: D11106. doi:10.1029/2012JD017499.

Liu, Y., J. Stanturf, and S. Goodrick. 2010. Trends in global wildfire potential in a changing climate. Forest Ecology and Management 259. Adaptation of Forests and Forest Management to Changing ClimateSelected Papers from the Conference on "Adaptation of Forests and Forest Management to Changing Climate with Emphasis on Forest Health: A Review of Science, Policies and Practices", Umeå, Sweden, August 25-28, 2008.: 685-697.

Lobell, D. B., M. B. Burke, C. Tebaldi, M. D. Mastrandrea, W. P. Falcon, and R. L. Naylor. 2008. Prioritizing Climate Change 


\section{Bibliography}

Adaptation Needs for Food Security in 2030. Science 319: 607-610. doi:10.1126/science.1152339.

Loewenberg, S. 2014. Breaking the cycle: drought and hunger in Kenya. The Lancet 383: 1025-1028.

Lowry, C. S., and S. P. Loheide. 2010. Groundwater-dependent vegetation: Quantifying the groundwater subsidy. Water Resources Research 46: W06202. doi:10.1029/2009WR008874.

Malevsky-Malevich, S. P., E. K. Molkentin, E. D. Nadyozhina, and O. B. Shklyarevich. 2007. An assessment of potential change in wildfire activity in the Russian boreal forest zone induced by climate warming during the twenty-first century. Climatic Change 86: 463-474. doi:10.1007/s10584-007-9295-7.

Malingreau, J. P., G. Stephens, and L. Fellows. 1985. Remote Sensing of Forest Fires: Kalimantan and North Borneo in 1982-83. Ambio 14: 314-321.

Marengo, J. A., J. Tomasella, L. M. Alves, W. R. Soares, and D. A. Rodriguez. 2011. The drought of 2010 in the context of historical droughts in the Amazon region: DROUGHT AMAZON 2010. Geophysical Research Letters 38: n/a-n/a.

Margono, B. A., P. V. Potapov, S. Turubanova, F. Stolle, and M. C. Hansen. 2014. Primary forest cover loss in Indonesia over 2000-2012. Nature Climate Change 4: 730-735. doi:10.1038/nclimate2277.

Marlier, M. E., R. S. DeFries, A. Voulgarakis, P. L. Kinney, J. T. Randerson, D. T. Shindell, Y. Chen, and G. Faluvegi. 2013. El Nino and health risks from landscape fire emissions in southeast Asia. Nature Climate Change 3: 131-136.

McKee, T. B., N. J. Doesken, and J. Kleist. 1993. The relationship of drought frequency and duration to time scales. In , 179-184. California, 17-22 January 1993.

Meyn, A., P. S. White, C. Buhk, and A. Jentsch. 2007. Environmental drivers of large, infrequent wildfires: the emerging conceptual model. Progress in Physical Geography 31: 287-312. doi:10.1177/0309133307079365.

Miettinen, J., C. Shi, and S. C. Liew. 2012. Two decades of destruction in Southeast Asia's peat swamp forests. Frontiers in Ecology and the Environment 10: 124-128. doi:10.1890/100236.

Miettinen, J., E. Hyer, A. S. Chia, L. K. Kwoh, and S. C. Liew. 2013. Detection of vegetation fires and burnt areas by remote sensing in insular Southeast Asian conditions: current status of knowledge and future challenges. International Journal of Remote Sensing 34: 4344-4366. doi:10.1080/01431161.2013.777489.

Mishra, A. K., and V. P. Singh. 2010. A review of drought concepts. Journal of Hydrology 391: 202-216. doi:10.1016/j. jhydrol.2010.07.012.

Moriasi, D. N., J. G. Arnold, M. W. Van Liew, R. L. Binger, R. D. Harmel, and T. L. Veith. 2007. Model evaluation guidelines for systematic quantification of accuracy in watershed simulations. Transactions of the ASABE 50: 885-900.

Moritz, M. A., M. E. Morais, L. A. Summerell, J. M. Carlson, and J. Doyle. 2005. Wildfires, complexity, and highly optimized tolerance. Proceedings of the National Academy of Sciences 102: 17912-17917.

Murdiyarso, D., M. Widodo, and D. Suyamto. 2002. Fire risks in forest carbon projects in Indonesia. Science In China Series C Life Sciences 45: 65-74.

Narasimhan, B., and R. Srinivasan. 2005. Development and evaluation of Soil Moisture Deficit Index (SMDI) and Evapotranspiration Deficit Index (ETDI) for agricultural drought monitoring. Agricultural and Forest Meteorology 133: 69-88. doi:10.1016/j.agrformet.2005.07.012.

Nath, R., D. Nath, Q. Li, W. Chen, and X. Cui. 2017. Impact of drought on agriculture in the Indo-Gangetic Plain, India. Advances in Atmospheric Sciences 34: 335-346. doi:10.1007/s00376-016-6102-2.

Naylor, R. L., W. P. Falcon, D. Rochberg, and N. Wada. 2001. Using El Nino/Southern Oscillation climate data to predict rice production in Indonesia. Climatic Change 50: 255-265.

Neale, R., and J. Slingo. 2003. The maritime continent and its role in the global climate: A GCM study. Journal of Climate 16: 834-848.

Newbery, D. M., and M. Lingenfelder. 2004. Resistance of a lowland rain forest to increasing drought intensity in Sabah, Borneo. Journal of Tropical Ecology 20: 613-624. doi:10.1017/S0266467404001750.

Niemeyer, S. 2008. New drought indices. Option Mediterraneennes, Series A 80: 267-274.

Novelli, P. C., K. A. Masarie, P. M. Lang, B. D. Hall, R. C. Myers, and J. W. Elkins. 2003. Reanalysis of tropospheric CO trends: Effects of the 1997-1998 wildfires. Journal of Geophysical Research: Atmospheres 108: 4464.

Orlowsky, B., and S. I. Seneviratne. 2013. Elusive drought: uncertainty in observed trends and short- and long-term CMIP5 projections. Hydrology and Earth System Sciences 17: 1765-1781. doi:10.5194/hess-17-1765-2013.

Page, S. E., and A. Hooijer. 2016. In the line of fire: the peatlands of Southeast Asia. Philosophical Transactions of the Royal Society B: Biological Sciences 371: 20150176. doi:10.1098/rstb.2015.0176.

Page, S. E., F. Siegert, J. O. Rieley, H.-D. V. Boehm, A. Jaya, and S. Limin. 2002. The amount of carbon released from peat and forest fires in Indonesia during 1997. Nature 420: 61-65. doi:10.1038/nature01131.

Page, S. E., J. O. Rieley, and C. J. Banks. 2011. Global and regional importance of the tropical peatland carbon pool. Global Change Biology 17: 798-818. doi:10.1111/j.1365-2486.2010.02279.x.

Palmer, W. C. 1968. Keeping Track of Crop Moisture Conditions, Nationwide: The New Crop Moisture Index. Weatherwise 21: 156-161. doi:10.1080/00431672.1968.9932814.

Páscoa, P., C. M. Gouveia, A. Russo, and R. M. Trigo. 2017. The role of drought on wheat yield interannual variability in the Iberian Peninsula from 1929 to 2012. International Journal of Biometeorology 61: 439-451. 
Pellizzaro, G., C. Cesaraccio, P. Duce, A. Ventura, and P. Zara. 2007. Relationships between seasonal patterns of live fuel moisture and meteorological drought indices for Mediterranean shrubland species. International Journal of Wildland Fire 16: 232. doi:10.1071/WF06081.

Peters, E., P. J. J. F. Torfs, H. A. J. Van Lanen, and G. Bier. 2003. Propagation of drought through groundwater-a new approach using linear reservoir theory. Hydrological Processes 17: 3023-3040. doi:10.1002/hyp.1274.

Peters, E., H. A. J. Van Lanen, P. J. J. F. Torfs, and G. Bier. 2005. Drought in groundwater-drought distribution and performance indicators. Journal of Hydrology 306: 302-317. doi:10.1016/j.jhydrol.2004.09.014.

Petros, G., M. Antonis, and T. Marianthi. 2011. Development of an adapted empirical drought index to the Mediterranean conditions for use in forestry. Agricultural and Forest Meteorology 151: 241-250.

Pfister, C., R. Weingartner, and J. Luterbacher. 2006. Hydrological winter droughts over the last 450 years in the Upper Rhine basin: a methodological approach. Hydrological Sciences Journal 51: 966-985. doi:10.1623/hysj.51.5.966.

Phillips, O. L., L. E. O. C. Aragao, S. L. Lewis, J. B. Fisher, J. Lloyd, G. Lopez-Gonzalez, Y. Malhi, A. Monteagudo, J. Peacock, C. A. Quesada, G. van der Heijden, S. Almeida, I. Amaral, L. Arroyo, G. Aymard, T. R. Baker, O. Banki, L. Blanc, D. Bonal, P. Brando, J. Chave, A. C. A. de Oliveira, N. D. Cardozo, C. I. Czimczik, T. R. Feldpausch, M. A. Freitas, E. Gloor, N. Higuchi, E. Jimenez, G. Lloyd, P. Meir, C. Mendoza, A. Morel, D. A. Neill, D. Nepstad, S. Patino, M. C. Penuela, A. Prieto, F. Ramirez, M. Schwarz, J. Silva, M. Silveira, A. S. Thomas, H. t. Steege, J. Stropp, R. Vasquez, P. Zelazowski, E. A. Davila, S. Andelman, A. Andrade, K.-J. Chao, T. Erwin, A. Di Fiore, E. H. C., H. Keeling, T. J. Killeen, W. F. Laurance, A. P. Cruz, N. C. A. Pitman, P. N. Vargas, H. Ramirez-Angulo, A. Rudas, R. Salamao, N. Silva, J. Terborgh, and A. Torres-Lezama. 2009. Drought Sensitivity of the Amazon Rainforest. Science 323: 1344-1347.

Phillips, O. L., G. van der Heijden, S. L. Lewis, G. López-González, L. E. O. C. Aragão, J. Lloyd, Y. Malhi, A. Monteagudo, S. Almeida, E. A. Dávila, I. Amaral, S. Andelman, A. Andrade, L. Arroyo, G. Aymard, T. R. Baker, L. Blanc, D. Bonal, Á. C. A. de Oliveira, K.-J. Chao, N. D. Cardozo, L. da Costa, T. R. Feldpausch, J. B. Fisher, N. M. Fyllas, M. A. Freitas, D. Galbraith, E. Gloor, N. Higuchi, E. Honorio, E. Jiménez, H. Keeling, T. J. Killeen, J. C. Lovett, P. Meir, C. Mendoza, A. Morel, P. N. Vargas, S. Patiño, K. S.-H. Peh, A. P. Cruz, A. Prieto, C. A. Quesada, F. Ramírez, H. Ramírez, A. Rudas, R. Salamão, M. Schwarz, J. Silva, M. Silveira, J. W. Ferry Slik, B. Sonké, A. S. Thomas, J. Stropp, J. R. D. Taplin, R. Vásquez, and E. Vilanova. 2010. Drought-mortality relationships for tropical forests. New Phytologist 187: 631-646.

Pook, E. W., and A. M. Gill. 1993. Variation of live and dead fine fuel moisture in Pinus radiata plantations of the Australian-Capital-Territory. International Journal of Wildland Fire 3: 155-168.

Posa, M. R. C., L. S. Wijedasa, and R. T. Corlett. 2011. Biodiversity and Conservation of Tropical Peat Swamp Forests. BioScience 61: 49-57. doi:10.1525/bio.2011.61.1.10.

Prudhomme, C., I. Giuntoli, E. L. Robinson, D. B. Clark, N. W. Arnell, R. Dankers, B. M. Fekete, W. Franssen, D. Gerten, S. N. Gosling, S. Hagemann, D. M. Hannah, H. Kim, Y. Masaki, Y. Satoh, T. Stacke, Y. Wada, and D. Wisser. 2014. Hydrological droughts in the 21st century, hotspots and uncertainties from a global multimodel ensemble experiment. Proceedings of the National Academy of Sciences 111: 3262-3267. doi:10.1073/pnas.1222473110.

Qin, Z., H. Tang, W. Li, H. Zhang, S. Zhao, and Q. Wang. 2014. Modelling impact of agro-drought on grain production in China. International Journal of Disaster Risk Reduction 7: 109-121. doi:10.1016/j.ijdrr.2013.09.002.

R Development Core Team, R. 2011. R: A Language and Environment for Statistical Computing. R Foundation for Statistical Computing. Vol. 1. doi:10.1007/978-3-540-74686-7.

Reardon, J., G. Curcio, and R. Bartlette. 2009. Soil moisture dynamics and smoldering combustion limits of pocosin soils in North Carolina, USA. International Journal of Wildland Fire 18: 326. doi:10.1071/WF08085.

Reddington, C. L., M. Yoshioka, R. Balasubramanian, D. Ridley, Y. Y. Toh, S. R. Arnold, and D. V. Spracklen. 2014. Contribution of vegetation and peat fires to particulate air pollution in Southeast Asia. Environmental Research Letters 9 : 094006. doi:10.1088/1748-9326/9/9/094006.

Riley, K. L., J. T. Abatzoglou, I. C. Grenfell, A. E. Klene, and F. A. Heinsch. 2013. The relationship of large fire occurrence with drought and fire danger indices in the western USA, 1984-2008: the role of temporal scale. International Journal of Wildland Fire 22: 894. doi:10.1071/WF12149.

Ritzema, H., S. Limin, K. Kusin, J. Jauhiainen, and H. Wösten. 2014. Canal blocking strategies for hydrological restoration of degraded tropical peatlands in Central Kalimantan, Indonesia. Catena 114: 11-20..

Rowell, E. J. 1936. Drought refugee and labor migration to California in 1936. Monthly Lab. Rev. 43: 1355.

Russell, J. M., and T. C. Johnson. 2007. Little Ice Age drought in equatorial Africa: intertropical convergence zone migrations and El Niño-Southern Oscillation variability. Geology 35: 21-24.

Salafsky, N. 1994. Drought in the rain forest: Effects of the $1991 \mathrm{El}$ Niño-Southern Oscillation event on a rural economy in West Kalimantan, Indonesia. Climatic Change 27: 373-396. doi:10.1007/BF01096268.

Sánchez-Pérez, J. M., E. Lucot, T. Bariac, and M. Trémolières. 2008. Water uptake by trees in a riparian hardwood forest (Rhine floodplain, France). Hydrological Processes 22: 366-375. doi:10.1002/hyp.6604.

Scharlemann, J. P., E. V. Tanner, R. Hiederer, and V. Kapos. 2014. Global soil carbon: understanding and managing the largest terrestrial carbon pool. Carbon Management 5: 81-91. doi:10.4155/cmt.13.77.

Schwinning, S., B. I. Starr, and J. R. Ehleringer. 2005. Summer and winter drought in a cold desert ecosystem (Colorado Plateau) part I: effects on soil water and plant water uptake. Journal of Arid Environments 60: 547-566.

Seneviratne, S. I., N. Nicholls, D. Easterling, C. M. Goodess, S. Kanae, J. Kossin, Y. Luo, J. Marengo, K. Mcinnes, M. Rahimi, 


\section{Bibliography}

M. Reichstein, A. Sorteberg, C. Vera, and X. Zhang. 2012. Changes in climate extremes and their impacts on the natural physical environment. In Managing the Risks of Extreme Events and Disasters to Advance Climate Change Adaptation, ed. C. B. Field, V. Barros, T. F. Stocker, D. Qin, D. J. Dokken, K. L. Ebi, M. D. Mastrandrea, K. J. Mach, G. K. Plattner, S. K. Allen, M. Tignor, and P. M. Midgley, 190-230. A Special Report of Working Groups I and II of the Intergovernmental Panel on Climate Change. Cambridge, UK and New York, NY, USA: Cambridge University Press.

Setiawan, B. I., M. Taufik, S. Afianto, Soewarso, J. Ginting, and A. Harisman. 2009. Modification of Keetch-Byram model to forecast fire risk in South Sumatra, Indonesia. In . Bogor, 17-19 November 2009.

Setiawan, B. I., S. T. Siregar, Nawari, A. Nugroho, and M. Sharma. 2016. Towards More Productive and Sustainable Use of Peatland for Acacia Plantations in Riau, Indonesia. In Peatlands in Harmony -Agriculture, Industry, and Nature, 514-517. Kuching, Sarawak Malaysia: Malaysian Peat Society and International Peatland Society.

Shafer, B. A., and L. E. Dezman. 1982. Development of a surface water supply index (SWSI) to assess the severity of drought conditions in snowpack runoff areas. In Proceedings of the 50th Annual Western Snow Conference. Reno, Nevada: Western Snow Conference.

Shanahan, T. M., J. T. Overpeck, K. J. Anchukaitis, J. W. Beck, J. E. Cole, D. L. Dettman, J. A. Peck, C. A. Scholz, and J. W. King. 2009. Atlantic Forcing of Persistent Drought in West Africa. Science 324: 377-380.

Sheffield, J., E. F. Wood, and M. L. Roderick. 2012. Little change in global drought over the past 60 years. Nature 491: 435-438. doi:10.1038/nature11575.

Sivakumar, M. V. K., R. Stefanski, M. Bazza, S. Zelaya, D. Wilhite, and A. R. Magalhaes. 2014. High Level Meeting on National Drought Policy: Summary and Major Outcomes. Weather and Climate Extremes 3: 126-132.

Sleedoorn, R. 2017. Investigation of drought in a sub-catchment of the Kapuas river (Indonesia): using a spatially-distributed groundwater flow model. MSc Thesis, Wageningen: Wageningen University and Research.

Snyder, R. L., D. Spano, P. Duce, D. Baldocchi, L. Xu, and K. T. Paw U. 2006. A fuel dryness index for grassland fire-danger assessment. Agricultural and Forest Meteorology 139: 1-11. doi:10.1016/j.agrformet.2006.05.006.

Sodhi, N. S., M. R. C. Posa, T. M. Lee, D. Bickford, L. P. Koh, and B. W. Brook. 2010. The state and conservation of Southeast Asian biodiversity. Biodiversity and Conservation 19: 317-328. doi:10.1007/s10531-009-9607-5.

Spano, D., P. Duce, R. L. Snyder, P. Zara, and A. Ventura. 2005. Assessment of fuel dryness index on Mediterranean vege $\Theta$ tation. In Proceedings of the 6th Symposium on Fire and Forest Meteorology. Cammore, Canada, October 24-27.

Sparks, J. C., R. E. Masters, D. M. Engle, and G. A. Bukenhofer. 2002. Season of Burn Influences Fire Behavior and Fuel Consumption in Restored Shortleaf Pine-Grassland Communities. Restoration Ecology 10: 714-722.

Stager, J. C., D. B. Ryves, B. M. Chase, and F. S. R. Pausata. 2011. Catastrophic Drought in the Afro-Asian Monsoon Region During Heinrich Event 1. Science 331: 1299-1302. doi:10.1126/science.1198322.

Stahl, K., I. Kohn, V. Blauhut, J. Urquijo, L. De Stefano, V. Acácio, S. Dias, J. H. Stagge, L. M. Tallaksen, E. Kampragou, A. F. Van Loon, L. J. Barker, L. A. Melsen, C. Bifulco, D. Musolino, A. de Carli, A. Massarutto, D. Assimacopoulos, and H. A. J. Van Lanen. 2016. Impacts of European drought events: insights from an international database of text-based reports. Natural Hazards and Earth System Sciences 16: 801-819. doi:10.5194/nhess-16-801-2016.

Stephens, S. L., N. Burrows, A. Buyantuyev, R. W. Gray, R. E. Keane, R. Kubian, S. Liu, F. Seijo, L. Shu, K. G. Tolhurst, and J. W. van Wagtendonk. 2014. Temperate and boreal forest mega-fires: characteristics and challenges. Frontiers in Ecology and the Environment 12: 115-122. doi:10.1890/120332.

Sternberg, T. 2010. Unravelling Mongolia's Extreme Winter Disaster of 2010. Nomadic Peoples 14: 72-86.

Suhaila, J., and A. A. Jemain. 2011. Spatial analysis of daily rainfall intensity and concentration index in Peninsular Malaysia. Theoretical and Applied Climatology 108: 235-245. doi:10.1007/s00704-011-0529-2.

Sun, G., K. Alstad, J. Chen, S. Chen, C. R. Ford, G. Lin, C. Liu, N. Lu, S. G. McNulty, H. Miao, A. Noormets, J. M. Vose, B. Wilske, M. Zeppel, Y. Zhang, and Z. Zhang. 2011. A general predictive model for estimating monthly ecosystem evapotranspiration. Ecohydrology 4: 245-255. doi:10.1002/eco.194.

Surmaini, E., T. W. Hadi, K. Subagyono, and N. T. Puspito. 2015. Early detection of drought impact on rice paddies in Indonesia by means of Niño 3.4 index. Theoretical and Applied Climatology 121: 669-684. doi:10.1007/s00704-0141258-0.

Tacconi, L., P. F. Moore, and D. Kaimowitz. 2006. Fires in tropical forests - what is really the problem? lessons from Indonesia. Mitigation and Adaptation Strategies for Global Change 12: 55-66. doi:10.1007/s11027-006-9040-y.

Tacconi, L. 2016. Preventing fires and haze in Southeast Asia. Nature Climate Change 6: 640-643. doi:10.1038/nclimate3008.

Takeuchi, W., T. Hirano, and O. Roswintiarti. 2016. Estimation Model of GroundWater Table at Peatland in Central Kalimantan, Indonesia. In Tropical Peatland Ecosystems, ed. M. Osaki and N. Tsuji, 9. Tokyo Heidelberg New York Dordrecht London: Springer Japan.

Tallaksen, L. M., and H. A. J. Van Lanen, ed. 2004. Hydrological Drought: Processes and Estimation Methods for Streamflow and Groundwater. Elsevier.

Tallaksen, L. M., H. Hisdal, and H. A. J. Van Lanen. 2009. Space-time modelling of catchment scale drought characteristics. Journal of Hydrology 375: 363-372. doi:10.1016/j.jhydrol.2009.06.032.

Tani, M., A. R. Nik, Y. Yasuda, S. Noguchi, S. A. Shamsuddin, M. M. . Sahat, and S. Takanashi. 2003. Long-term estimation of 
evapotranspiration from a tropical rain forest in Peninsular Malaysia. In Water Resources Systems-water Availability and Global Change: Proceedings of an International Symposium (Symposium HSO2a) Held During IUGG 2003, the XXIII General Assembly of the International Union of Geodesy and Geophysics: at Sapporo, Japan, from 30 June to 11 July, 2003, 278:267. International Association $\mathrm{n}$ of Hydrological Sciences.

Taufik, M., B. I. Setiawan, and H. A. J. Van Lanen. 2015. Modification of a fire drought index for tropical wetland ecosystems by including water table depth. Agricultural and Forest Meteorology 203: 1-10.

Taufik, M., P. J. J. F. Torfs, R. Uijlenhoet, P. D. Jones, D. Murdiyarso, and H. A. J. Van Lanen. 2017. Amplification of wildfire area burnt by hydrological drought in the humid tropics. Nature Climate Change 7: 428-431.

Thompson, A. M., J. C. Witte, R. D. Hudson, H. Guo, J. R. Herman, and M. Fujiwara. 2001. Tropical Tropospheric Ozone and Biomass Burning. Science 291: 2128-2132. doi:10.1126/science.291.5511.2128.

Trenberth, K. E., A. Dai, G. van der Schrier, P. D. Jones, J. Barichivich, K. R. Briffa, and J. Sheffield. 2013. Global warming and changes in drought. Nature Climate Change 4: 17-22. doi:10.1038/nclimate2067.

Turetsky, M. R., B. Benscoter, S. Page, G. Rein, G. R. van der Werf, and A. Watts. 2015. Global vulnerability of peatlands to fire and carbon loss. Nature Geoscience 8: 11-14. doi:10.1038/ngeo2325.

Underwood, E. C., D. Olson, A. D. Hollander, and J. F. Quinn. 2014. Ever-wet tropical forests as biodiversity refuges. Nature Climate Change 4: 740-741. doi:10.1038/nclimate2351.

Urbieta, I. R., G. Zavala, J. Bedia, J. M. Gutiérrez, J. S. Miguel-Ayanz, A. Camia, J. E. Keeley, and J. M. Moreno. 2015. Fire activity as a function of fire-weather seasonal severity and antecedent climate across spatial scales in southern Europe and Pacific western USA. Environmental Research Letters 10: 114013. doi:10.1088/1748-9326/10/11/114013.

Van Dam, J. C., and R. A. Feddes. 2000. Numerical simulation of infiltration, evaporation and shallow groundwater levels with the Richards equation. Journal of Hydrology 233: 72-85. doi:10.1016/S0022-1694(00)00227-4.

Van Dam, J. C., P. Groenendijk, R. F. A. Hendriks, and J. G. Kroes. 2008. Advances of Modeling Water Flow in Variably Saturated Soils with SWAP. Vadose Zone Journal 7: 640. doi:10.2136/vzj2007.0060.

Van der Molen, M. K., A. J. Dolman, M. J. Waterloo, and L. A. Bruijnzeel. 2006. Climate is affected more by maritime than by continental land use change: A multiple scale analysis. Global and Planetary Change 54. Land-Use/Land-Cover Change and Its Impact on Climate: 128-149. doi:10.1016/j.gloplacha.2006.05.005.

Van der Werf, G. R., J. T. Randerson, L. Giglio, N. Gobron, and A. J. Dolman. 2008a. Climate controls on the variability of fires in the tropics and subtropics. Global Biogeochemical Cycles 22: GB3028. doi:10.1029/2007GB003122.

Van der Werf, G. R., J. Dempewolf, S. N. Trigg, J. T. Randerson, P. S. Kasibhatla, L. Giglio, D. Murdiyarso, W. Peters, D. C. Morton, G. J. Collatz, A. J. Dolman, and R. S. DeFries. 2008b. Climate regulation of fire emissions and deforestation in equatorial Asia. Proceedings of the National Academy of Sciences 105: 20350-20355.

Van Genuchten, M. T. 1980. A closed-form equation for predicting the hydraulic conductivity of unsaturated soils. Soil Science Society of America Journal 44(5): 892-898.

Van Huijgevoort, M. H. J., P. Hazenberg, H. A. J. Van Lanen, and R. Uijlenhoet. 2012. A generic method for hydrological drought identification across different climate regions. Hydrology and Earth System Sciences 16: 2437-2451.

Van Lanen, H. A. J., L. Kašpárek, O. Novický, E. P. Querner, M. Fendeková, and E. Kupczyk. 2004. Human Influences. In Hydrological Drought - Processes and Estimation Methods for Streamflow and Groundwater, ed. L. M. Tallaksen and H. A. J. Van Lanen, 347-410. Developments in Water Science 48. Amsterdam, the Netherlands: Elsevier.

Van Lanen, H. A. J., N. Wanders, L. M. Tallaksen, and A. F. Van Loon. 2013. Hydrological drought across the world: impact of climate and physical catchment structure. Hydrol. Earth Syst. Sci. 17: 1715-1732. doi:10.5194/hess-17-1715-2013.

Van Lanen, H. A. J., G. Laaha, D. G. Kingston, T. Gauster, M. Ionita, J.-P. Vidal, R. VInas, L. M. Tallaksen, K. Stahl, J. Hannaford, C. Delus, M. Fendekova, L. Mediero, C. Prudhomme, E. Rets, R. J. Romanowicz, S. Gailliez, W. K. Wong, M.-J. Adler, V. Blauhut, L. Caillouet, S. Chelcea, N. Frolova, L. Gudmundsson, M. Hanel, K. Haslinger, M. Kireeva, M. Osuch, E. Sauquet, J. H. Stagge, and A. F. Van Loon. 2016. Hydrology needed to manage droughts: the 2015 European case: Invited Commentary. Hydrological Processes 30: 3097-3104. doi:10.1002/hyp.10838.

Van Lanen, H. A. J., J. Vogt, J. Andreu, H. Carrao, L. De Stefano, E. Dutra, L. Feyen, G. Forzieri, M. Hayes, A. Iglesias, C. Lavaysse, G. Naumann, R. Pulwarty, J. Spinoni, K. Stahl, R. Stefanski, N. Stilianakis, M. Svoboda, and L. M. Tallaksen. 2017. Climatological risk: droughts. In Science for disaster risk management 2017: knowing better and losing less, ed. K. Poljanšek, M. Marin Ferrer, T. De Groeve, and I. Clark. Chapter 3.9. Luxembourg: EUR 28034 EN, Publications Office of the European Union.

Van Loon, A. ., H. A. J. van Lanen, H. Hisdal, L. M. Tallaksen, M. Fendekova, J. Oosterwijk, O. Horvat, and A. Machlica. 2010. Understanding hydrological winter drought in Europe. In Global Change: Facing Risks and Threats to Water Resources, 189-197. Centre for Ecology and Hydrology, Wallingford, Oxfordshire, OX10 8BB, UK: IAHS.

Van Loon, A. F., and H. A. J. Van Lanen. 2012. A process-based typology of hydrological drought. Hydrol. Earth Syst. Sci. 16: 1915-1946. doi:10.5194/hess-16-1915-2012.

Van Loon, A. F., K. Stahl, G. Di Baldassarre, J. Clark, S. Rangecroft, N. Wanders, T. Gleeson, A. I. J. M. Van Dijk, L. M. Tallaksen, J. Hannaford, R. Uijlenhoet, A. J. Teuling, D. M. Hannah, J. Sheffield, M. Svoboda, B. Verbeiren, T. Wagener, and H. A. J. Van Lanen. 2016. Drought in a human-modified world: reframing drought definitions, understanding, and analysis approaches. Hydrology and Earth System Sciences 20: 3631-3650. d

Van Noordwijk, M., R. Matthews, F. Agus, J. Farmer, L. Verchot, K. Hergoualc'h, S. Persch, H. L. Tata, B. Lusiana, A. Widayati, 


\section{Bibliography}

and S. Dewi. 2014. Mud, muddle and models in the knowledge value-chain to action on tropical peatland conservation. Mitigation and Adaptation Strategies for Global Change 19: 887-905. doi:10.1007/s11027-014-9576-1.

Varma, A. 2003. The economics of slash and burn: a case study of the 1997-1998 Indonesian forest fires. Ecological Economics 46: 159-171. doi:10.1016/S0921-8009(03)00139-3.

Verbesselt, J., P. Jonsson, S. Lhermitte, J. van Aardt, and P. Coppin. 2006. Evaluating satellite and climate data-derived indices as fire risk indicators in savanna ecosystems. IEEE Transactions on Geoscience and Remote Sensing 44: 1622-1632. doi:10.1109/TGRS.2005.862262.

Vicente-Serrano, S. M., S. Beguería, and J. I. López-Moreno. 2010. A Multiscalar Drought Index Sensitive to Global Warming: The Standardized Precipitation Evapotranspiration Index. Journal of Climate 23: 1696-1718. doi:10.1175/2009JCLI2909.1.

Villafuerte, M. Q., and J. Matsumoto. 2015. Significant Influences of Global Mean Temperature and ENSO on Extreme Rainfall in Southeast Asia. Journal of Climate 28: 1905-1919. doi:10.1175/JCLI-D-14-00531.1.

Waddington, J. M., D. K. Thompson, M. Wotton, W. L. Quinton, M. D. Flannigan, B. W. Benscoter, S. A. Baisley, and M. R. Turetsky. 2012. Examining the utility of the Canadian Forest Fire Weather Index System in boreal peatlands. Canadian Journal of Forest Research 42: 47-58. doi:10.1139/x11-162.

Wallenius, T. H., S. Lilja, and T. Kuuluvainen. 2007. Fire history and tree species composition in managed Picea abies stands in southern Finland: Implications for restoration. Forest Ecology and Management 250. Disturbances at Multiple Scales as the Basis of Forest Ecosystem Restoration and Management: 89-95. doi:10.1016/j.foreco.2007.03.016.

Walsh, R. P. D. 1996. Drought frequency changes in Sabah and adjacent parts of northern Borneo since the late nineteenth century and possible implications for tropical rain forest dynamics. Journal of Tropical Ecology 12: 385-407. doi:10.1017/S0266467400009585.

Walsh, R. P. D., and D. M. Newbery. 1999. The ecoclimatology of Danum, Sabah, in the context of the world's rainforest regions, with particular reference to dry periods and their impact. Philosophical Transactions of the Royal Society B. Biological Sciences 354: 1869-1883.

Wanders, N., and H. A. J. Van Lanen. 2015. Future discharge drought across climate regions around the world modelled with a synthetic hydrological modelling approach forced by three general circulation models. Natural Hazards and Earth System Science 15: 487-504. doi:10.5194/nhess-15-487-2015.

Wanders, N., H. A. J. Van Lanen, and A. F. Van Loon. 2010. Indicators for drought characterization on a global scale. WATCH Technical Report No. 24.

Wang, S.-Y., J.-H. Yoon, R. R. Gillies, and C. Cho. 2013. What Caused the Winter Drought in Western Nepal during Recent Years? Journal of Climate 26: 8241-8256.

Weiss, R., N. J. Shurpali, T. Sallantaus, R. Laiho, J. Laine, and J. Alm. 2006. Simulation of water table level and peat temperatures in boreal peatlands. Ecological Modelling 192: 441-456. doi:10.1016/j.ecolmodel.2005.07.016.

Wibowo, A., M. Suharti, A. P. S. Sagala, H. Hibani, and M. V. Noordwijk. 1997. Fire management on Imperata grasslands as part of agroforestry development in Indonesia. Agroforestry Systems 36: 203-217. doi:10.1007/BF00142874.

Wickham, H. 2009. ggplot2: Elegant Graphics for Data Analysis. Springer-Verlag New York.

Wilhite, D. A., M. D. Svoboda, and M. J. Hayes. 2007. Understanding the complex impacts of drought: A key to enhancing drought mitigation and preparedness. Water Resources Management 21: 763-774. doi:10.1007/s11269-006-9076-5.

Wilhite, D. A., M. V. K. Sivakumar, and R. Pulwarty. 2014. Managing drought risk in a changing climate: The role of national drought policy. Weather and Climate Extremes 3: 4-13. doi:10.1016/j.wace.2014.01.002.

Williams, A. P., and J. T. Abatzoglou. 2016. Recent Advances and Remaining Uncertainties in Resolving Past and Future Climate Effects on Global Fire Activity. Current Climate Change Reports 2: 1-14. doi:10.1007/s40641-016-0031-0.

Williams, A. P., R. Seager, A. K. Macalady, M. Berkelhammer, M. A. Crimmins, T. W. Swetnam, A. T. Trugman, N. Buenning, D. Noone, N. G. McDowell, N. Hryniw, C. I. Mora, and T. Rahn. 2015. Correlations between components of the water balance and burned area reveal new insights for predicting forest fire area in the southwest United States. International Journal of Wildland Fire 24: 14. doi:10.1071/WF14023.

Wooster, M. J., G. L. W. Perry, and A. Zoumas. 2012. Fire, drought and El Niño relationships on Borneo (Southeast Asia) in the pre-MODIS era (1980-2000). Biogeosciences 9: 317-340. doi:10.5194/bg-9-317-2012.

World Bank. 2016. The Cost of Fire: An Economic Analysis of Indonesia's 2015 Fire Crisis. Indonesia Sustainable Landscapes Knowledge Note: 1. The World Bank.

World Meteorological Organization. 2012. Standardized Precipitation Index User Guide. Edited by M. Svoboda, M. Hayes, and Wood. World Meteorological Organization Report WMO-No. 1090, Geneva, Switzerland.

World Meteorological Organization, and Global Water Partnership. 2016. Handbook of drought indicators and indices (M. Svoboda and B.A. Fuchs). Integrated Drought Management Programme (IDMP), Integrated Drought Management Tools and Guidelines Series 2. Geneva: World Meteorological Organization.

Wösten, H., A. Hooijer, C. Siderius, D. S. Rais, A. Idris, and J. Rieley. 2006. Tropical Peatland water management modelling of the Air Hitam Laut catchment in Indonesia. International Journal of River Basin Management 4: 233-244. doi:10. 1080/15715124.2006.9635293.

Wösten, J. H. M., P. A. Finke, and M. J. W. Jansen. 1995. Comparison of class and continuous pedotransfer functions to 
generate soil hydraulic characteristics. Geoderma 66: 227-237. doi:10.1016/0016-7061(94)00079-P.

Wösten, J. H. M., E. Clymans, S. E. Page, J. O. Rieley, and S. H. Limin. 2008. Peat-water interrelationships in a tropical peatland ecosystem in Southeast Asia. Catena 73. Hydropedology: Fundamental Issues and Practical Applications: 212-224. doi:10.1016/j.Catena.2007.07.010.

WWAP. 2016. Water and Jobs. United Nations World Water Development Report 2016. Paris: United Nations World Water Assessment Programme, UNESCO.

Xaud, H. A. M., F. da S. R. V. Martins, and J. R. dos Santos. 2013. Tropical forest degradation by mega-fires in the northern Brazilian Amazon. Forest Ecology and Management 294. The Mega-Fire Reality: 97-106. doi:10.1016/j.foreco.2012.11.036.

Yang, Y., M. Uddstrom, G. Pearce, and M. Revell. 2015. Reformulation of the Drought Code in the Canadian Fire Weather Index System Implemented in New Zealand. Journal of Applied Meteorology and Climatology 54: 1523-1537. doi:10.1175/JAMC-D-14-0090.1.

Yevjevich, V. 1967. An Objective Approach to Definitions and Investigations of Continental Hydrologic Droughts. Colorado State University, Fort Collins, USA.

Yule, C. M. 2008. Loss of biodiversity and ecosystem functioning in Indo-Malayan peat swamp forests. Biodiversity and Conservation 19: 393-409. doi:10.1007/s10531-008-9510-5.

Zargar, A., R. Sadiq, B. Naser, and F. I. Khan. 2011. A review of drought indices. Environmental Reviews 19: 333-349. doi:10.1139/a11-013.

Zeng, Y., Z. Xie, and J. Zou. 2017. Hydrologic and Climatic Responses to Global Anthropogenic Groundwater Extraction. Journal of Climate 30: 71-90. doi:10.1175/JCLI-D-16-0209.1.

Zhou, L., Y. Tian, R. B. Myneni, P. Ciais, S. Saatchi, Y. Y. Liu, S. Piao, H. Chen, E. F. Vermote, C. Song, and T. Hwang. 2014. Widespread decline of Congo rainforest greenness in the past decade. Nature 509: 86-90. doi:10.1038/nature13265. 


\section{Statement of authorship contribution}

The introduction (Chapter 1) and the synthesis (Chapter 6) were written by Muh Taufik. An overview of the contribution from co-authors to the other chapters is provided below.

\begin{tabular}{|c|c|c|c|c|c|}
\hline HVL & $=$ & Henny Van Lanen (WUR) & DM & $=$ & Daniel Murdiyarso (CIFOR and IPB) \\
\hline MT & $=$ & Muh Taufik (WUR and IPB) & BIS & $=$ & Budi Indra Setiawan (IPB) \\
\hline PT & $=$ & Paul Torfs (WUR) & JVM & $=$ & Jos Van Dam (WUR) \\
\hline $\mathrm{RU}$ & $=$ & Remko Uijlenhoet (WUR) & HW & $=$ & Henk Wösten (Alterra) \\
\hline PJ & $=$ & Philip Jones (UEA) & & & \\
\hline
\end{tabular}

\section{Chapter 2}

Conception or design of the work

: MT, HVL, JVD

Data collection

:MT, BIS, HW

Data analysis and interpretation

: MT, HVL, JVD

Drafting the article

: MT, HVL

Critical revision of the article

Approval of the version to be published

: HVL, HW, JVD, PJ

: MT, HVL, BIS, PJ, HW

\section{Chapter 3}

Conception or design of the work

: BIS, MT

: MT, BIS

Data collection

: MT, HVL

Data analysis and interpretation

Drafting the article

:MT

: HVL

Approval of the version to be published

: MT, HVL, BIS

\section{Chapter 4}

Conception or design of the work

Data collection

: MT, HVL

:MT

: MT, HVL

: MT

Drafting the article

: HVL, BIS

Critical revision of the article

: MT, HVL, BIS

\section{Chapter 5}

Conception or design of the work

Data collection

: MT, HVL

:MT

Data analysis and interpretation

Drafting the article

: MT, HVL, PT

Critical revision of the article

Approval of the version to be published

: MT, HVL

:RU, DM, PJ, PT

: MT, HVL, PT, RU, PJ, DM 


\section{Statement of code and data availability}

\section{Input and evaluation data:}

- Meteorological data for Pekanbaru, Jambi, Putussibau, and Palangkaraya (Chapter 2) are available online (http://dataonline.bmkg.go.id/home)

- CRU data (Chapter 5) are available online (https://crudata.uea.ac.uk/cru/data/hrg/)

- Fire area burnt data (Chapters 4 and 5) are available online (ftp://fuoco.geog.umd. edu/gfed4/monthly/, user password: fire/burnt)

- $\quad$ Fire weather system indices data (Chapter 5) are available online (ftp://ftp.nccs.nasa. gov/v2.0, user: GlobalFWI).

\section{Models:}

- $\quad$ SWAP model (Chapters 2 and 4) can be downloaded from: http://www.swap.alterra. $\underline{\mathrm{nl} /}$

- $\quad$ Code for water balance model (Chapter 5) is available upon request from Muh Taufik

- Code for the modified KBDI calculation (Chapter 3) is available upon request from Muh Taufik

\section{Output data:}

The output from the models that support the findings of this study are available from Muh Taufik upon request.

\section{Code:}

All code (R language), including the statistical models, used to perform analysis and to construct the figures is available upon request from Muh Taufik. 


\section{Summary}

Drought is a recurrent hazard, which has happened throughout human history, and it is anticipated to become more severe in multiple regions across the world. Drought occurs in all climate regimes from humid to dry and from hot to cold. Drought is often viewed through its impact on environment and society, including wildfire, which is the topic of this study. The nature of such impacts differs remarkably from region to region. Although drought does not directly cause wildfire, it provides favorable conditions for wildfire ignition and spread. When drought coincides with strong El Niño events in the humid tropics, e.g. Southeast Asia, the impacts worsen through uncontrolled forest fires affecting the global carbon cycle. These include reduction of the carbon stock, intensifying the haze hazard, and other severe socio-economic impacts in Southeast Asia, including areas far away from the burnt area, e.g. Singapore because of fires in Sumatra.

There still remains a serious lack of scientific understanding about the fundamental role of drought in fire-generating processes. Most research, so far, suggests that climate controls wildfire occurrence in the humid tropics. However, this climatecentered approach, which is reflected in contemporary drought-fire related indices, overlooks soil and hydrological processes beneath the surface across the humid tropics. There is also uncertainty about the relative roles of climate variability and human activities in influencing the nature and distribution of drought-related wildfires. Hence, the general objective of this $\mathrm{PhD}$ research is to examine how characterization of hydrological drought under natural and human-modified conditions can improve understanding of wildfires in general in the humid tropics.

Chapter 2 discusses the contribution of humans to an increase of hydrological drought severity in the tropical peatland of Southeast Asia. Climate variability induces drought in the region, however, human activities (human-modified drought) may increase its severity. Analyzing long time series of simulated historical groundwater levels from selected regions in Southeast Asia, which were validated against some years with observations, revealed that human interference (through canalization and land-use change) has amplified drought severity. The drought amplification due to human interference was at least double that of climate-induced drought. The amplification is even higher when peatland is converted into acacia plantation. Further, research findings suggest that even if the Paris Agreement target is met, drought risk of peatlands remains high unless sustainable water management receives top priority in the region. 
Chapter 3 deals with how an existing, well-known drought-fire related index, i.e. the Keetch-Byram Drought Index (KBDI), is modified to improve applicability in the humid climate environment of Southeast Asia. The improvement includes: (i) adjustment of the drought factor to the local climate, and (ii) addition of the water table depth as a dynamic factor to fine-tune the drought index. The results indicate that the modified KeetchByram Drought Index (mKBDI) performed well in predicting fire hazard. Furthermore, the research identified a critical water table depth, which represents maximum fire hazard ( $0.85 \mathrm{~m}$ for the wetland forest of South Sumatra). Below this value hazard does not increase anymore. The mKBDI could be more widely applied, if pedotransfer functions would be developed that link easily-obtainable soil properties to the parameters of the water table factor.

Chapter 4 shows that wetland transformation (i.e. through canalization and landuse change) not only affects hydrological drought (Chapter 2), but also influences fire behaviour. In Southeast Asia, expansion of agricultural cropland and forest plantations has changed the landscape of wetlands. The findings showed that the transformation into acacia plantation has amplified the fire hazard from $4 \%$ (under natural conditions) to $17 \%$. An even higher amplification ( $40 \%$ fire hazard) is expected under poor water management, that is, uncontrolled drainage. The findings derived from this observationbased modeling experiment suggest that improved water management (controlled drainage with higher dry season surface water levels) can minimize fire susceptibility.

Chapter 5 explains the importance of hydrology for fire hazard studies. Borneo is selected to investigate the added value of including hydrological variables in fire hazard prediction approaches. More than 300 statistical models were tested, and the results showed that models that include hydrological variables better predict area burnt than those solely based on climate indicators/indices. Further, modelling evidence shows amplifying wildfires and greater area burnt in response to El Niño Southern Oscillation (ENSO) strength, when hydrology is considered. These results highlight the importance of considering hydrological drought for wildfire prediction. I recommend that hydrology should be considered in future studies of the impact of projected ENSO strength, including effects on tropical ecosystems and biodiversity conservation.

The contributions of this thesis research to science are summarized and synthesized in Chapter 6. First, the research identified that fire hazard studies would benefit from adding hydrology, which is reflected in the improved model performance when hydrological variables are integrated. Next, the research revealed that humans play a substantial role in modifying groundwater drought characteristics, hence amplifying the fire hazard in Southeast Asia. Further, the chapter identified several relevant research findings, including the model choice, which should consider the simplicity and the applicability of the model. Another finding demonstrated that controlling canal water level through canal blocking is a practical water management tool to restore degraded wetland. This restored wetland would benefit some endemic species. However, the restored wetland still faces high drought severity. Hence they remain more fire-prone until the un-impacted hydrology condition is achieved. Finally, this research suggest that currently widely-used drought indices (such as FWI) require improvements in their model structure, which means integration of hydrological variables to increase their applicability for fire hazard studies in the humid tropics. 


\section{Acknowledgement}

When I mention your name here, please accept my sincere appreciation, gratitude and thanks. You have contributed to the completion of this thesis.

First, I thank my supervisors, each of them contributed in a different and complementary way to make the fulfilment of this thesis possible.

I am sincerely grateful to my daily supervisor, Dr. Henny Van Lanen, who was always there for me, and whose enthusiasm and patience played a major role on the completion of this journey. This PhD thesis is certainly the output of many shared hours of discussions here in Wageningen and in Indonesia. Henny, the discussion would have never been possible without your unlimited availability and support. I still remember when we had very long discussion about my first manuscript to highlight the 'novelty' of hydrological drought for fire studies. That was wracking the brain. Further, your impressive support when I prepared every manuscript is invaluable for my next journey to further develop as an independent researcher. Overall, I think your ability to communicate with different ethnics and cultures makes you a successful supervisor of every student you have (PhD and Master). I admit, you were the best supervisor I have ever had. I hope you admit, now, that not every paper should have a standalone conclusion.

Thanks to Prof. Remko Uijlenhoet for giving the opportunity, and for his support during my PhD journey. Remko, your critical comments from different angles on my manuscripts were highly appreciated. Also, your full support during the special 'revoke' moment is highly appreciated made me feel like at home in the Hydrology and Quantitative Water Management Group.

I highly appreciate the scholarship given by the Indonesian Directorate General of Higher Education (DIKTI) for the first 3 years of my PhD. The SPIN-JRP-29 project granted by the Royal Netherlands Academy of Arts and Sciences (KNAW) funded an important part of the work, especially the field activities in Indonesia, and the last PhD year. I wish to thank the project coordinator Prof. Ton Hoitink (Wageningen University), and his counterpart from Indonesia Prof. Robert Delinom (Indonesian Institute of Sciences, LIPI, Bandung), as well as all other project members for the valuable scientific and personal experience acquired through my participation in the project. I also would like to thank Prof. Gusti Anshari (Tanjungpura University Pontianak, Indonesia) for his kind assistance during my fieldworks in West Kalimantan. Special thanks to Dr. Hidayat (LIPI, Cibinong); we spent a lot of time together in the jungle and at remote places. Roel, we were together in a harsh environment (hot and very humid), I hope you enjoyed diving in the 'chocolate' water of Bika river. Karl, your support with the 'kokerjuffer' and stuff is highly appreciated. I am sorry for a limited cooperation, and I hope you will defend your PhD thesis soon (with your wife, of course). To my department at IPB (Bogor), special thanks to bu Rini, bu Tania and pak Rahmat, who gave permission and support to pursue my PhD at Wageningen University. 
I wish to thank my co-authors for their significant contribution to my $\mathrm{PhD}$ thesis. First to Paul Torfs, Paul you are 'Guru'. Your patience and encouragement in transferring knowledge on data analysis with R, makes everyone (including me) feels cosy. I have the feeling, without your significant contribution in analysing data, our Nature paper would have been further delayed. Next to Jos Van Dam. Thanks for your a valuable contribution and support to understand the SWAP model. Thanks also a lot to Henk Wösten for long-run discussion about the role of hydrology in peatland.

I would like to thank all my co-authors from abroad. First Prof. Budi Indra Setiawan (IPB, Bogor), who provided important data from remote peatland in Riau (Sumatra), and also for online discussions when I prepared my $3^{\text {rd }}$ manuscript. Prof. Daniel Murdiyarso (Center for International Forestry Research, CIFOR), I would like to thank you for providing me a place to do internships twice at CIFOR (Bogor). I think we still have to continue discussing the role of land use on fire, which we could not fully address in our Nature paper. I hope we can collaborate more in the future either at IPB or CIFOR. Prof. Phil Jones (University of East Anglia, UK), although we never met, your contribution to the finalization of my Nature paper is highly appreciated.

The research activities in the Upper Kapuas (Kalimantan) would have never been successful without the full assistance from my colleagues in the field, especially pak Syamsudin and pak Bujang in Puttusibau, and pak Unja in Labian. I hope I have an opportunity to visit you all in the future. Also my colleagues in the meteorological station at Putussibau airport namely mas Nurdeka and pak Trisilo, thanks for your kind help to obtain daily weather data.

To all my friends in K-PO (Indonesian community for Pimpong in Wageningen), thanks for accompanying me on this journey. Every smash during our practice was invaluable to release my stress obtained during work time. I can mention you here mbah Ery, pak Andy, pak Isa, kang Dede, kang Daud, Wied Belanda, and lately coach Audrey, thanks for your time. Thanks also to the Indonesian Student Association in Wageningen (PPI Wageningen) and to all its members for providing support and social events that made my stay in Wageningen more like home.

My DIKTI awardee colleagues: mbah Ery, teh Novi (\& kang Indra), pak Iman, pak Yohanes, mbak Nani, mbak Ita, and others, and to the 'senior'; mbak Sinta, teh Pini, pak Misbah, kang Dasep, and kang Dadan thanks for your sharing and support during this journey. Also to pak Dikky (the $1^{\text {st }}$ PhD Lurah in wageningen) and crew (pak Fajar, uni Eli, mbak Titis), and to all Indonesian PhD candidates and families in kelurahan Wageningen, thanks for your hospitality.

For my colleagues with whom I spent spare time in fund raising for the Moskee Wageningen, I miss you all. Special recognition to mbah Ery, pak Andy, pak Eko, mas Ilham, mas Deslak, mas Zulfikar, mas Gerald, Wied Belanda and others. I pray that our efforts are counted in the day of judgement. To the SIICW, especially Abdiazis, Hussein, Musthafa and Saleh, I appreciate your work for the mosque. I am sorry that I am not there when we have the new mosque.

Finally, any hard work is impossible without full support and encouragement of the family. To my dear wife Hermi, thanks for being my supporter all the time. For Hana, your cuteness is invaluable. I am sorry for insufficient time to enjoy the world together during this PhD journey. I love you all. To my brother (kang Kasir) and sisters (mbak Siti, Nur dan Isti) thanks for your support. For kang Din, I am very sorry that I missed your funeral, hope we meet again in paradise. Lastly, to my mom and dad, your prayers during night and day gave my strength to accomplish this $\mathrm{PhD}$. 


\section{About the author}

Muh Taufik

3 March 1981, Kudus, Indonesia

2007-now Lecturer, Bogor Agricultural University (IPB)

2013-2017 PhD Candidate, Wageningen University

2008-2010 MSc Civil and Environmental Engineering, Bogor Agricultural University

1998-2003 Undergraduate student, Bogor Agricultural University with specialization in Agrometeorology 


\section{List of publications}

\section{International peer review journals:}

- $\quad$ Taufik, M., P. J. J. F. Torfs, R. Uijlenhoet, P. D. Jones, D. Murdiyarso, and H. A. J. Van Lanen. 2017. Amplification of wildfire area burnt by hydrological drought in the humid tropics. Nature Climate Change 7: 428-431. doi:10.1038/nclimate3280.

- Hidayat, H., A. J. Teuling, B. Vermeulen, M. Taufik, K. Kastner, T. J. Geertsema, D. C. C. Bol, D. H. Hoekman, G.S. Haryani, H.A.J. Van Lanen, R.M. Delinom, R. Dijksma, G.Z. Anshari, N.S. Ningsih, R. Uijlenhoet, and A.J.F. Hoitink. 2017. Hydrology of inland tropical lowlands: the Kapuas and Mahakam wetlands. Hydrology and Earth System Sciences 21: 2579-2594. doi:10.5194/hess-21-2579-2017.

- Taufik, M., B. I. Setiawan, and H. A. J. Van Lanen. 2015. Modification of a fire drought index for tropical wetland ecosystems by including water table depth. Agricultural and Forest Meteorology 203: 1-10. doi:10.1016/j.agrformet.2014.12.006.

\section{In review:}

- $\quad$ Taufik, M., J. Van Dam, B.I. Setiawan, H. Wösten, P.D. Jones, and H.A.J. Van Lanen. 2017. Human contribution to increased drought severity in Southeast Asian peatland, Science of the Total Environment

- Taufik, M., B.I. Setiawan, and H.A.J. Van Lanen. 2017. Increased fire hazard in humanmodified wetlands in Southeast Asia, AMBIO

\section{Peer reviewed journals (national):}

- $\quad$ Taufik, M., B.I. Setiawan. 2012. Interpretation of soil water content into dryness index; implication for forest fire management. Jurnal Manajemen Hutan Tropika 18 (1): 31-38. DOI: $10.7226 / j t f m .18 .1 .31$ (in Indonesian)

\section{Proceedings:}

- Taufik, M., H. Van Lanen. 2015. Forest fire danger in tropical wetland Indonesia: an improved drought assessment. Proceedings on International Conference on Ecohydrology (ICE). Yogyakarta, 10 - 12 November 2014. Organized by Asia Pacific Centre for Ecohydrology - UNESCO and Research Center for Limnology

- $\quad$ Taufik M, D. Murdiyarso, H.A.J. Van Lanen. 2014. Climate variability in the Kapuas River basin (Kalimantan): impact on groundwater recharge. Proceedings of the $2^{\text {nd }}$ International Conference of Indonesian Forestry Researchers (INAFOR) 2013. Jakarta: 27-28 August 2013. Forestry Research and Development Agency. 


\section{I P L O M A}

For specialised PhD training

The Netherlands Research School for the Socio-Economic and Natural Sciences of the Environment (SENSE) declares that

\section{Muh Taufik}

born on 3 March 1981 in Kudus, Indonesia

has successfully fulfilled all requirements of the Educational Programme of SENSE.

Wageningen, 31 October 2017

the Chairman of the SENSE board

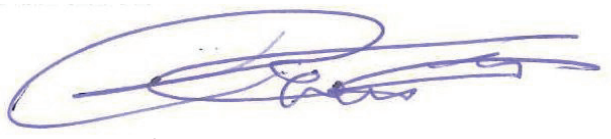

Prof. dr. Huub Rijnaarts the SENSE Director of Education

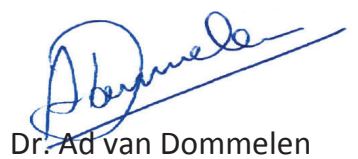

The SENSE Research School has been accredited by the Royal Netherlands Academy of Arts and Sciences (KNAW)

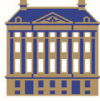

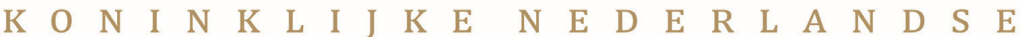

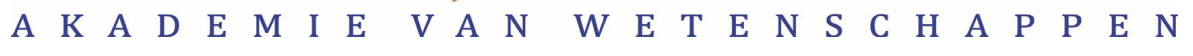




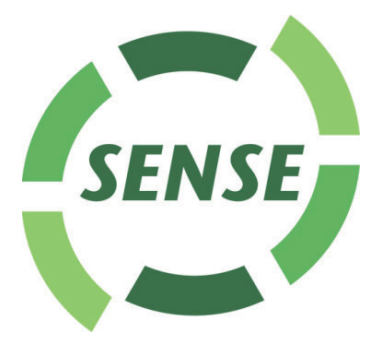

The SENSE Research School declares that Mr Muh Taufik has successfully fulfilled all requirements of the Educational PhD Programme of SENSE with a work load of 38.7 EC, including the following activities:

\section{SENSE PhD Courses}

- Environmental research in context (2016)

o Research in context activity: 'Co-organizing regional drought workshop for researchers and stakeholders in Bogor, Indonesia' (2015)

\section{Other PhD and Advanced MSc Courses}

- Meta-analysis, Wageningen University (2014)

- Ecohydrology: a tool for IWRM implementation at river basin level, training course UNESCO Office Jakarta and Indonesian Institute of Sciences (2014)

- Geostatistics, Wageningen University (2015)

- Monitoring climate from space, online course European Space Agency (2015-2016)

- Project and time management, Wageningen University (2016)

- Systematic approaches to reviewing literature, Wageningen University (2016)

- The essentials of scientific writing and presenting, Wageningen University (2016)

o Scientific Artwork with Photoshop and Illustrator, Wageningen University (2016)

\section{External training at a foreign research institute}

- Performing water balance modelling to study climate variability in the Kapuas river basin and the impact on groundwater recharge, CIFOR, Indonesia (2013)

- Using R for water balance modelling to explore drought conditions in tropical ecosystems of Borneo, CIFOR, Indonesia (2014)

\section{Management and Didactic Skills Training}

- Teaching MSc course Introductory R, Bogor Agricultural University (2015)

- Supervising MSc student with thesis entitled 'Investigation of drought in a subcatchment of the Kapuas river (Indonesia): using a spatially-distributed groundwater flow model' (2016-2017)

\section{Selection of Oral Presentations}

- Drought in a Humid Tropical Ecosystem, Indonesia. The ASEAN Conference on Science and Technology, 18-19 August 2014, Bogor, Indonesia

- Forest fire danger in tropical wetland forest Indonesia: an improved drought assessment. International Conference on Ecohydrology: 'Ecohydrology approaches facing the global water environment challenges', 10-12 November 2014, Yogyakarta, Indonesia

- Tropical forest fires and drought: is hydrology matters? PhD event at BOUSSINESQ LECTURE 2015, 22 October 2015, Amsterdam, The Netherlands

SENSE Coordinator PhD Education 
The research described in this thesis was financially supported by the Royal Netherlands Academy of Arts and Sciences KNAW (project SPIN-JRP-29) and the Directorate General of Higher Education (DIKTI, 4115/E4.4/K/2013).

Financial support from Wageningen University for printing this thesis is gratefully acknowledged.

Cover design by M Taufik

Printed by Digiforce - ProefschriftMaken, Wageningen, NL 